\title{
B Plant Complex Preclosure Work Plan
}

United States
Department of Energy
Richland, Washington

\section{RECORD COPY}

Approved for Public Release 


\section{B Plant Complex Preclosure Work Plan}

Date Published

February 1999

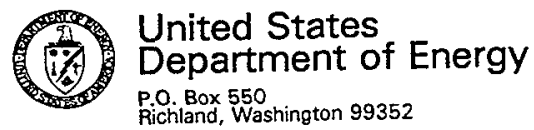

Approved for Public Release 


\section{RELEASE AUTHORIZATION}

Document DOE/RL-98-12, Rev. 0

Number:

Document B Plant Complex Preclosure Work Plan

Title:

This document, reviewed in accordance with DOE Order 241.1, "Scientific and Technical Information Management," and DOE 241.1-G "Guide to the Management of Scientific and Technical Information," does not contain classified or sensitive unclassified information and is:

\section{APPROVED FOR PUBLIC RELEASE}

\section{Y. L. Quetiand}

V. L. Birkland

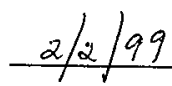

Lockheed Martin Services, Inc.

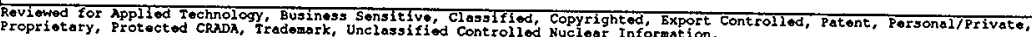
Propriotary, Protectod CRADA, Trademark, Unclassified Controllod Nuclear Information.

TRADEARK DISCLAIMRR. Roforoneo horein to any apocific comerctal product, proeess, or service by trado name, trademark, manufacturer, or otherwise, doos not necessarily constitute or inply lts endorsement, feccomendation, or fovoring by the

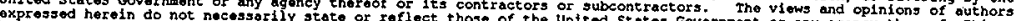
has been reproducod from the best ovatioble copy printe of the United States Governement or any agency thereof. This report

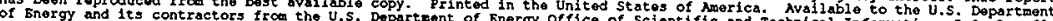
Oax Ridge, TH 37831; Telephono: 123/576-8401. Avaliable to the publis from the U.s. Dopartment of Comerce Nationel technical Information Service, 5285 port Rayal Roed,
Springfield, VA 22161; Telephone: j03/187-1650. 
CONTENTS

2

3

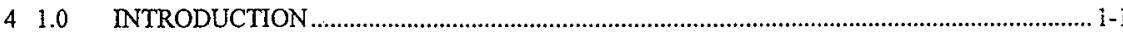

5 
DOE/RL-98-12, Rev. 1

02/99

1

2

3

4

5

This page intentionally left blank. 


\section{B PLANT COMPLEX PRECLOSURE WORK PLAN}

\subsection{INTRODUCTION}

This preclosure work plan describes the condition of the dangerous waste treatment, storage, and/or disposal (TSD) unit after completion of the B Plant Complex decommissioning Transition Phase preclosure activities. This description includes waste characteristics, waste types, locations, and associated hazards. The goal to be met by the Transition Phase preclosure activities is to place the TSD unit into a safe and environmentally secure condition for the long-term Surveillance and Maintenance (S\&M) Phase of the facility decommissioning process.

This preclosure work plan has been prepared in accordance with Section 8.0 of the Hanford Federal Facility Agreement and Consent Order (Tri-Party Agreement) (Ecology et al. 1996). The preclosure work plan is one of three critical Transition Phase documents, the other two being: B Plant End Points Document (WHC-SD-WM-TPP-054) and B Plant S\&M plan. These documents are prepared by the U.S. Department of Energy, Richland Operations Office (DOE-RL) and its contractors with the involvement of Washington State Department of Ecology (Ecology).

The tanks and vessels addressed by this preclosure work plan are limited to those tanks and vessels included on the B Plant Complex Part A, Form 3, Permit Application (DOE/RL-88-21). The criteria for determining which tanks or vessels are in the Part A, Form 3, are discussed in the following. The closure plan for the TSD unit will not be prepared until the Disposition Phase of the facility decommissioning process is initiated, which follows the long-term S\&M Phase. Final closure will occur during the Disposition Phase of the facility decommissioning process.

The Waste Encapsulation Storage Facility (WESF) is excluded from the scope of this preclosure work plan.

\subsection{CRITERIA FOR INCLUDING TANKS AND VESSELS IN THE PART A}

At the beginning of the B Plant deactivation, criteria for adding tanks or vessels to the Part A, Form 3 , permit application were developed by DOE-RL and Ecology as part of the negotiations for the B Plant Complex M-82 and M-20 Tri-Party Agreement milestone agreements (DOE-RL 97-EAP-032). Revision 5 of the B Plant Complex Part A, Form 3 was issued on October 1, 1996 to cover the expanded list of tanks and vessels (DOE/RL-88-21).

The criteria established by the Tri-Party Agreement negotiations for adding the tanks and vessels in the Part A were:

- Any canyon tanks or vessels that treated or stored dangerous or mixed waste [including listed mixed waste from the Double-Shell Tank System (DOE/RL-90-39)] on or after August 1987. The tank or vessel could contain a heel or could be dry and empty

- Canyon tanks or vessels that contained more than a minimum heel after August 1987. 
1 A 'minimum heel' is defined as the liquid remaining after the tank or vessel had been emptied to the

2 greatest extent possible using the existing liquid transfer equipment (generally steam jets).

3

4

\section{$5 \quad 1.2$ BACKGROUND}

6 The B Plant Complex is located in the northwest portion of the 200 East Area of the Hanford Site (refer 7 to Chapter 2.0, Figure 2-1). The 221-B Building, also known as B Plant, was designed and constructed 8 between 1943 and 1945 to recover plutonium using a bismuth phosphate chemical separation process.

9 B Plant operated as a plutonium recovery facility from 1945 to 1952 . With newer and more efficient

In the late 1950 's, there was a growing concern regarding the heat generated by high-activity radioactive waste stored in the Hanford Site single-shell tanks. Some of the waste generated enough heat to cause the liquid waste to boil. A program to partition the high-activity waste to remove some of the high-heat isotopes was developed. After a period of experimentation and process development, B Plant was selected to house the large-scale partitioning mission. Modifications to B Plant started in 1962 and were completed in 1967. Between 1968 and 1983, B Plant separated various isotopes from the waste. Over 100 million curies of strontium-90 and cesium-137 were recovered. Since 1974, B Plant supported storage of the strontium and cesium capsules at WESF.

From 1984 through 1985, B Plant was prepared for a demonstration test in the pre-treatment, or preliminary separation, of Hanford Site tank waste. Pre-treatment was to be the first step in processing the onsite waste into a form compatible with long-term storage. In 1990, a determination was made that B Plant could not meet modern safety, seismic, and secondary containment criteria. B Plant was eliminated from consideration as the pre-treatment facility.

Between 1990 and 1995, B Plant continued to support WESF, and commenced limited facility stabilization, cleanup, and cleanout activities. 'On October 5, 1995, the U.S. Department of Energy issued a shutdown order. This order included separating WESF from the B Plant Complex so that WESF would function independently. The first phase of the decommissioning process, the Transition Phase, has been successful with deactivation of B Plant Complex completed September 29, 1998. 


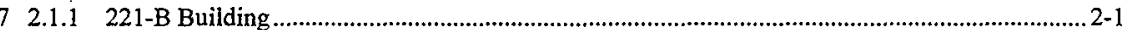

8 2.1.2 221-BB Process and Steam Condensate Building......................................................................... 2-2

9 2.1.3 221-BF Process Condensate Effluent Discharge Facility ........................................................... 2-2

$10 \quad 2.1 .4 \quad 276-B A$ Interim Organic Storage Facility ....................................................................................... 2-2

2.2 B PLANT COMPLEX WASTE MANAGEMENT UNITS ........................................................2-3

132.2 .1 Waste Treatment and/or Storage in Vessels................................................................................ 2-3

2.2.2 Secondary Containment for the Vessel Systems.

2.2.3 Areas of Concern in the Secondary Containment.

2.2.4 Cell 4 Containerized Waste Storage ........................................................................................... 2-7

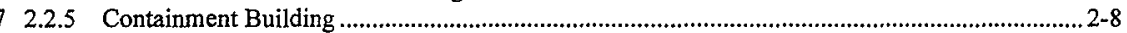

221-B Building Longitudinal Section through Cell Drain Header Looking South.........2-10 
1

2

3

4

5

This page intentionally left blank. 


\subsection{FACILITY DESCRIPTION}

This chapter briefly describes the B Plant Complex and the three waste management systems within the B Plant Complex, and provides information on Hanford Facility security.

\subsection{B PLANT COMPLEX PHYSICAL DESCRIPTION}

The B Plant Complex, Figure 2-1, is located in the northwest quadrant of the 200 East Area. The B Plant Complex includes a large canyon building (221-B Building) and several supporting buildings and office trailers. The TSD boundary (Figure 2-2) within the B Plant Complex includes the 221-B Building, the 221-BB Process and Steam Condensate Building (221-BB Building), the 221-BF Process Condensate Effluent Discharge Facility (221-BF Facility), and the 276-BA Interim Organic Storage Facility (276-BA Facility). Specific details of the three waste management systems housed in these structures are presented in Section 2.2 .

\subsubsection{1-B Building}

The 221-B Building (referred to as B Plant) is a canyon-type building constructed between 1943 and 1945 (Figures 2-3 and 2-4). Process information is presented in Chapter 3.0.

B Plant is a steel-reinforced concrete structure 247.04 meters long, with a maximum cross-sectional width of 20.18 meters and a height of 23.53 meters, supported on a 1.83-meter-thick concrete foundation. The foundation is 4.88 meters below grade as measured from the north side of the building. The structure is divided into 20 segments separated by interlocking expansion joints. Most segments are 12.2 meters long with three segments ranging between 13.1 meters to 13.4 meters long (Figure 2.10). The roof is of concrete construction. The roof varies in thickness from 0.91 meter at the midspan to 1.22 meters at the edges where the roof is supported by the exterior walls.

Cutaway and cross-section views of the B Plant canyon are shown in Figures 2-3 and 2-4, respectively. The crane way, the operating gallery, the pipe gallery, and the electrical gallery are located on the north side. The hot pipe trench and wind tunnel are located along the south side. The lower portion of the canyon, between the two interior walls, is divided into a series of individual process cells. On top of both the process cells and the hot pipe trench are removable concrete cover blocks. The canyon deck is the area on top of the cover blocks.

A typical process cell is 5.5 meters long by 3.9 meters wide by 8.5 meters deep. A few of the cells are longer, deeper, or both. Each cell is covered with 1.88-meter-thick concrete cover blocks. The process equipment in a cell was designed for remote handling and maintenance. Jumpers were used to make connections between the process equipment and the rest of $\mathrm{B}$ Plant. The jumpers provided piping, electrical, and/or air connections.

The operating gallery, pipe gallery, and electrical gallery parallel, but are isolated from, the canyon. The operating gallery contains the process instrument racks and controls and other process support equipment (valves, pumps, chemical addition tanks, etc.) for the in-cell process equipment. The pipe gallery contains the piping and valves that supplied various utilities (air, water, steam) and nonradioactive solutions to the in-cell process equipment. The electrical gallery contains the main electrical conduits and electrical distribution centers, and some process control equipment. The hot pipe trench contains pipes connecting the various process cells. These pipes were used for the transfer of radioactive liquids 
among the cells. The wind tunnel exhausted the ventilation air drawn from the canyon and the process cells to the main ventilation filters. The filtered air was discharged to the atmosphere via a 60.96 meter stack.

An overhead bridge crane spans the width of the canyon. The crane cab rode within the crane way for protection from radiation. The bridge crane was used to remove and install the 1.83-meter-thick cover blocks to obtain access to the cells, remove and install process equipment, and to perform in-cell maintenance. The crane also was used for visual inspection of the canyon deck, process cells, and hot pipe trench after the appropriate cover blocks were removed.

\subsubsection{1-BB Process and Steam Condensate Building}

The 221-BB Building is located on the south side of the 221-B Building between the R-13 and R-15 stairwells (Figure 2-2). The 221-BB Building consists of a belowgrade concrete vault (referred to as the condensate pit) and an abovegrade metal building (Figure 2-5).

The condensate pit is constructed of poured concrete and has a length of 5.28 meters, a maximum width of 1.83 meters, and a depth of 2.59 meters. On top of the pit is a steel-framed building with metal sides and roof. The building is approximately 2.15 meters from the south exterior wall of the 221-B Building. The metal building is approximately 7.0 meters long by 7.7 meters wide. The 7.7 meter wall is parallel to the south exterior wall of the 221-B Building.

The two vessels in the 221-BB Building condensate pit are part of the Miscellaneous Tank Storage System (Section 2.2.1.5).

\subsubsection{1-BF Process Condensate Effuent Discharge Facility}

The 221-BF Facility is located in the southwest portion of the B Plant Complex (Figure 2-2). The 221-BF (Figures 2-6 and 2-7) is a belowgrade concrete vault. The vault is divided into a sample room, a monitor room, and a tank room.

The overall dimensions of the vault are 11.0 meters long by 11.0 meters wide by 8.2 meters deep. An abovegrade stair building is 4.5 meters long by 1.68 meters wide and 2.4 meters high. The stair building is of steel frame and sheet metal construction.

The two vessels in the 221-BF Facility tank room are part of the Miscellaneous Tank Storage System (Section 2.2.1.5).

\subsubsection{6-BA Interim Organic Storage Facility}

The 276-BA Facility is located in the northeast portion of the B Plant Complex (Figure 2-2). The 276-BA Facility consists of the secondary containment structure for two storage tanks (Figure 2-8). One of the two tanks has been closed and removed. Refer to Chapter 7.0, Section 7.1.4 for information on the removal. secondary containment structure is divided into two separate compartments, each holding one 
1 containerized storage tank. The secondary containment structure is lined for compatibility with the

2 organic mixed waste in the tanks.

The remaining tank in the 276-BA Facility is part of the Organic Mixed Waste Storage System (Section 2.2.1.4).

\subsection{B PLANT COMPLEX WASTE MANAGEMENT SYSTEMS}

There were three waste management systems at B Plant Complex: waste treatment and/or storage in vessels, containerized waste storage, and storage in a containment building. This section gives a brief description of the individual components of these waste management systems.

\subsubsection{Waste Treatment and/or Storage in Vessels}

The largest waste management system was waste treatment and/or storage in vessels. This waste management system was divided into the following five separate vessel systems. A vessel system included one or more treatment and/or storage vessel, its ancillary equipment, and its secondary containment.

- Neutralized Current Acid Waste (NCAW) Storage and Treatment System

- Low-Level Waste (LLW) Storage and Treatment System

- LLW Concentrator

- Organic Mixed Waste Storage System

- Miscellaneous Tank Storage System.

The five systems included a total of 55 vessels. Tables $2-1$ and 2-2 provide a summary of the vessel systems and individual vessels affected by this preclosure work plan. Figures 2-5, 2-6, 2-8, and 2-9 provide an overview of the vesseis located in the 221-BB Building, the 221-BF Facility, the 276-BA Facility, and the canyon process cells in the 221-B Building, respectively. Vessel nomenclature is discussed in Appendix A.

\subsubsection{NCAW Storage and Treatment System}

In the 221-B Building, the NCAW Storage and Treatment System was spread between six process cells and included 10 vessel systems (Figure 2-9). The specifics of each vessel, location, physical characteristics, and ancillary equipment are presented in Tables 2-2 and 2-3.

\subsubsection{LLW Storage and Treatment System}

The LLW Storage and Treatment System was spread between six process cells in the 221-B Building and included eight vessel systems (Figure 2-9). The specifics of each vessel, location, physical characteristics, and ancillary equipment are presented in Tables 2-2 and 2-3.

\subsubsection{LLW Concentrator}

The LLW Concentrator System was located in one process cell in the 221-B.Building and included six vessel systems (Figure 2-9). The specifics of each vessel, location, physical characteristics, and ancillary equipment are presented in Tables $2-2$ and 2-3.

\subsubsection{Organic Mixed Waste Storage System}

The Organic Mixed Waste Storage System was spread between the 276-BA Facility and five process cells in the $221-\mathrm{B}$ Building. This system included 10 vessel systems. Only 9 vessel systems remain in 
1 place. Eight are located in the canyon process cells (Figure 2-9) and one is located externally

2 (Figure 2-2) in the 276-BA Facility. One of the two tanks originally located in the 276-BA Facility has

3 been removed (refer to Chapter 7.0, Section 7.1.4 for more information). There are no physical connections between the external tank and the process cells. The specifics of each vessel, location, physical characteristics, and ancillary equipment are presented in Tables 2-2 and 2-3.

\subsubsection{Miscellaneous Tank Storage System}

The Miscellaneous Tank Storage System was spread between 14 process cells in the 221-B Building (Figure 2-9), the 221-B Building canyon deck, the 221-BB Building (Figure 2-2), and the 221-BF Building (Figure 2-2). A total of 21 vessel systems comprised the miscellaneous waste tanks. The specifics of each vessel, its location, physical characteristics, and ancillary equipment are presented in Tables 2-2 and 2-3.

\subsubsection{Secondary Containment for the Vessel Systems}

Secondary containment for the vessel systems is divided among four structures: the 221-B Building, the 221-BB Building, the 221-BF Facility, and the 276-BA Facility.

\subsubsection{221-B Building Secondary Containment Documents}

There have been several documents developed related to the 221-B Building secondary containment. Two documents (WHC-SD-HWV-TI-017 and WHC-SD-W024H-SA-001) were prepared in 1991 to support the planned pretreatment mission.

These studies defined and discussed the secondary containment system needed to support the pretreatment mission.

Additional documents (WHC-SD-WM-WP-254 and WHC-SD-WM-ER-456) were prepared in 1994 and 1995 in support of the Tri-Party Agreement Milestone M-32-07 for interim status tank activities. The purpose of these documents was to meet the regulatory requirement in WAC 173-303-640(2) for an integrity assessment of the vessel systems actively managing dangerous or mixed waste. The report (WHC-SD-WM-ER-456) concluded that the 221-B Building secondary containment did not meet the requirements of WAC 173-303-640(4)(d).

\subsubsection{Secondary Containment in the 221-B Building}

In the 221-B Building, an interconnected system was used as secondary containment for the canyon process cells and the hot pipe trench. The process cells acted as the secondary containment for each vessel. The hot pipe trench acted as the secondary containment for the ancillary piping. Piping embedded in the canyon structure does not have any secondary containment:

The majority of the process cell floors are sloped toward the southeast corner of the cell. In that corner, a 152-milimeter vertical drain connects to the cell drain header. The cell drain header is a 610-millimeter earthenware pipe that drains into a collection tank (TK-10-1) in Cell 10. Additional details on the construction of the cell drain header are given in Section 2.2.2.3. For each building segment, the pipe trench floor also feeds into the cell drain header. The cell drain header runs the length of the 221-B Building.

\subsubsection{Cell Drain Header Construction Details}

The cell drain header construction is detailed as part of the seismic analysis (WHC-SD-W024H-SA-001). From Cell 10, the cell drain header nuns 54.9 meters to the east end of the 221-B Building and 182.9 meters to the west end of the building. Both parts of the cell drain header are sloped to drain by 
gravity into a collection tank (TK-10-1) in Cell 10. The cell drain header consists of a concrete encased earthenware pipe. The earthenware pipe was considered by the seismic analysis to be equivalent to today's vitrified clay pipe. Each pipe segment is about 1.22 meters long with an inside diameter of 4. 610 millimeters and an outside diameter of 711 millimeters. The segment is joined using the same bell5 and-spigot method used in modern vitrified clay pipe.

There are two different configurations for the cell drain header (Figure 2-10). Near Cell 10, the cell drain header is inside a 1.32 meter wide concrete encasement. The encasement is below and separate from the 221-B Building foundation. The building foundations were constructed after the encasement was constructed. The seismic analysis found that the encasement was continuous on each side of Cell 10 and that there were no joints in the encasement. Towards the ends of the 221-B Building, the cell drain header was embedded within the foundation segments. From east to west, the cell drain header is configured as follows.

- From the east end of the 221-B Building to the expansion joint between Cells 4 and 5, the cell drain header was embedded in the 221-B Building foundation.

- From the expansion joint between Cells 4 and 5 to Cell 10 and from Cell 10 to the expansion joint between Cells 18 and 19, the cell drain header was inside the encasement.

- From the expansion joint between Cells 18 and 19 to the west end of the 221-B Building, the cell drain header was embedded in the 221-B Building foundation.

The bell-and-spigot joints within the foundation and the encasement were sealed with a mastic or gum. The surrounding concrete provided additional sealing for the cell drain header in these areas. A special joint was used when the cell drain header crossed between building foundation segments. The type of joint between Cell 10 and the cell drain header/encasement was not known. The type of joint between the cell drain header/encasement was not known but might have been the same special joint used for spanning the building foundation joints.

The special cell drain header joint (Figure 2-11) between foundation segments consists of a 11.4 centimeter length of cell drain header pipe extending beyond the foundation segment. A collar of earthenware pipe was fitted over the projecting end of the cell drain header. The collar, 22.6 centimeters long with an inside diameter of 71.1 centimeters, has an outside diameter of 76.2 centimeters. The resulting 2.5 centimeter annulus was filled with a gum or mastic as the sealant. The end of the projecting cell drain header was covered with 1.3 centimeters of gum or mastic. The next length of cell drain header was inserted into the collar. The open annulus between the new cell drain header pipe segment and the collar was filled with grout. The concerns on the long-term integrity of this joint are discussed in Section 2.2.3.1.

\subsubsection{Results of the Low-Level Waste System Integrity Assessment}

As identified in Section 2.2.2.1, an integrity assessment (WHC-SD-WM-ER-456) of various components of the secondary containment was conducted from 1994 to 1995 . This assessment was limited to the tanks, vessels, and ancillary equipment (e.g., secondary containment) associated with the LLW System. The assessment included visual examination of the hot pipe trench at the Cell 23/Cell 24 sections, the Cell 31/Cell 32 sections, Cell 24, and Cell 25. The assessment also reviewed the video tapes of the Cell drain header made during 1989 and 1990.

In the hot pipe trench at the Cell $23 /$ Cell 24 sections, the assessment found sediments about 25 millimeters thick in a localized area. The coating on the hot pipe trench floor in this area had degraded but the degradation was not considered to be serious. The condition of the floor was not discussed specifically. The report implies that the concrete in the hot pipe trench was intact and undamaged. 
In the hot pipe trench at the Cell $31 /$ Cell 32 sections, the assessment found the floor coating and wall coating had degraded, but the floor appeared to be in good condition. The floor coating was rated as being up to $90 \%$ degraded. The wall coating was rated as being up to $10 \%$ degraded. The report implies that the concrete floor in this section was intact and undamaged.

In Cell 24, the assessment found that most of the floor coating was gone but that no cracks were noticed. Erosion of the cement between the aggregate was seen in some areas of the cell floor. The depth of the erosion was described as being up to 25 millimeters deep. While not stated clearly, it appears that there was some erosion of the concrete on the lower portions of the cell walls.

In Cell 25, the assessment.found the condition in this cell was similar to the condition of Cell 24 . There was an accumulation of precipitate in one area. In a couple of other areas, the assessment noted that erosion of the concrete had occurred. Cracks were noted in the walls, but the extent of the cracking could not be determined.

The assessment reviewed and evaluated a video tape from the $1989 / 1990$ inspection of the cell drain header. The assessment found that the sections of vitrified clay pipe were in good condition. The focus and resolution of the camera robot used in the inspection was not good enough to determine the condition of the joints. This inspection did not find any evidence of leakage from the cell drain header.

\subsubsection{Secondary Containment in the 221-BB Building}

In the 221-BB Building, the condensate pit acted as the secondary containment for two tanks from the Miscellaneous Tank Storage System. The overall condition of the secondary containment was not well defined. It is known that the secondary containment did not meet the regulatory requirements. No studies of the secondary containment have been conducted.

\subsubsection{Secondary Containment in the 221-BF Facility}

The same arrangement was used in the 221-BF Facility where the tank room acted as the secondary containment for two tanks from the Miscellaneous Tank Storage System. The overall condition of the secondary containment was not well defined. It is known that the secondary containment did not meet the regulatory requirements. No studies of the secondary containment have been conducted.

\subsubsection{Secondary Containment in the 276-BA Facility} In the 276-BA Facility, the secondary containment is the structure. Individual containment areas were provided for each tank. The secondary containment was lined with a compatible coating. Up to the time of removal of the organic mixed waste from the ISO East tank, the coating was in good shape. By mid1998 , bubbles had formed in the coating. There are no known spills with in the secondary containment.

\subsubsection{Areas of Concern in the Secondary Containment}

The secondary containment within the 221-B Building is known to contain several areas where the integrity of the secondary containment has been or could have been compromised. These include the cell drain header, the canyon (221-B) building expansion joints, and Cell 10.

\subsubsection{Cell Drain Header}

As detailed in Section 2.2.2.3, the cell drain header joints between the 221-B Building segments were sealed with a mastic or gum. Historically, the mastic in pipe joints did not maintain integrity over a long period. With the 221-B Building having been constructed between 1943 and 1945, the integrity of the 
mastic or gum joints is suspect. It is possible that liquid from the cell drain header could have leaked out of the pipe joints and entered the environment via the expansion joints. The joints embedded within the 221-B Building foundation and in the encasement should retain integrity. The type of joint between Cell 10 and the encasement is not known. The areas with the highest probability for releases to the environment are cell drain header joints/expansion joints at Cells 2 and 3, Cells 4 and 5, and the pipe joints/expansion joints from Cells 18 and 19 through to Cells 38 and 39 .

The condition and type of joint used between Cell 10 and the cell drain header/encasement are not known. The condition and type of joint between the cell drain header/encasement and the cell drain header embedded in the building foundation are not known.

\subsubsection{Expansion Joints}

The expansion joints for the canyon structure itself are known to be a potential pathway for dangerous waste to enter the environment. The expansion joints, located about every 12.2 meters through out the canyon building structure, with 12.2 meter section contain two process cells. The expansion joints were keyed to ensure building integrity and to help seal the interior from the outside environment. Each joint was filled with about 12 millimeters of transite filler. The cells were isolated from the expansion joints so there was no direct cell-expansion joint pathways.

There are no known releases of dangerous or mixed waste from the canyon secondary containment to the environment via the expansion joints. There is one known release of radioactive water via the expansion joints. Between 1989 and mid-1990, there was a leak of an estimated 322,000 to 871,000 liters of steam condensate into the hot pipe trench. This leak of radioactive water overflowed into the expansion joint located between Cell 38 and Cell 39. The overflow was caused by capping the drain from the hot pipe trench to the cell drain header as part of earlier operations.

\subsubsection{Cell 10}

Cell 10 is known to have managed mixed waste within the secondary containment over a long period. Cell 10 is the lowest point within the 221-B Building and the cell drain header feed into a tank (TK-10-1) in the cell. At low flow rates; liquid flowing from the east cell drain header could have dribbled into the cell itself. At high flow rates, there was enough liquid velocity for the stream to enter into the tank. There was a long operating history (at least since the 1980's) of liquid filling up the Cell 10 sump and being jetted into TK-10-1.

With secondary containment intended for short-term management of waste, there is a potential that the liquid mixed waste could have migrated into or through the secondary containment and into the environment. The substantial 1.83 -meter-thick concrete construction should be sufficient to contain any material. There are no known or documented releases of dangerous or mixed waste to the environment via the Cell 10 sump.

\subsubsection{Cell 4 Containerized Waste Storage}

The Cell 4 containerized waste storage unit was used for the storage of 208-liter containers of solid mixed waste, which did not contain free liquids. The design storage capacity of Cell 4 is 51.0 cubic meters. Cell 4 is 3.96 meters wide, 5.38 meters long, and 6.7 meters deep. 


\subsubsection{Containment Building}

Areas within the B Plant canyon are used to store solid (liquid-free) mixed waste in the form of discarded process equipment and lead shielding materials. These areas are considered to be a containment building' subject to the requirements of 40 CFR 265, Subpart DD. The containment building storage areas include the canyon deck and the process cells. The process design capacity of the containment building is 35,170 cubic meters. A qualified registered professional engineer certified that the 221-B Building meets the required design standards as specified in 40 CFR 265.1101(a) (ETS-W-96-524).

Use of the 'containment building' concept started in 1994 (refer to B Plant Complex Part A, Form 3, Revision 2, dated September 30, 1994). At this time, the storage of discarded process equipment within the B Plant canyon was considered to be 'miscellaneous storage' under the Part A, Form 3 process code S05. Revision 2 stated that the miscellaneous storage was conducted in a containment building. In 1996, the process code $\mathrm{S0} 5$ (miscellaneous storage) was changed by the U.S. Environmental Protection Agency to process code S06 (containment building). This change was made in Revision 4 of the Part A Permit Application, Form 3, issued on May 17, 1996.

The solid mixed waste consists of radioactively contaminated lead shielding materials. The failed canyon process equipment and jumpers (or isolated components thereof) contain lead used as weights, counterweights, or radiation shielding. The lead shielding materials are in the form of lead sheets, lead bricks, lead blankets, and lead shielding integral to various pieces of equipment. The solid mixed waste might be contaminated with waste residues (Chapter 4.0, Section 4.1.4).

\subsection{SECURITY INFORMATION}

The Hanford Facility is a controlled-access area. The Hanford Facility maintains around-the-clock surveillance for the protection of government property, classified information, and special nuclear materials. The Hanford Patrol maintains a continuous presence of protective force personnel to provide additional security. All personnel accessing Hanford Facility areas must have a DOE-issued security identification badge indicating the appropriate authorization. Personnel also could be subject to a random search of items carried into or out of the Hanford Facility.

Hanford Facility personnel receive training on security regulations in the form of required security education and on-the-job training. Methods for ensuring personnel compliance with security requirements and provisions for security training are maintained on the Hanford Facility. 


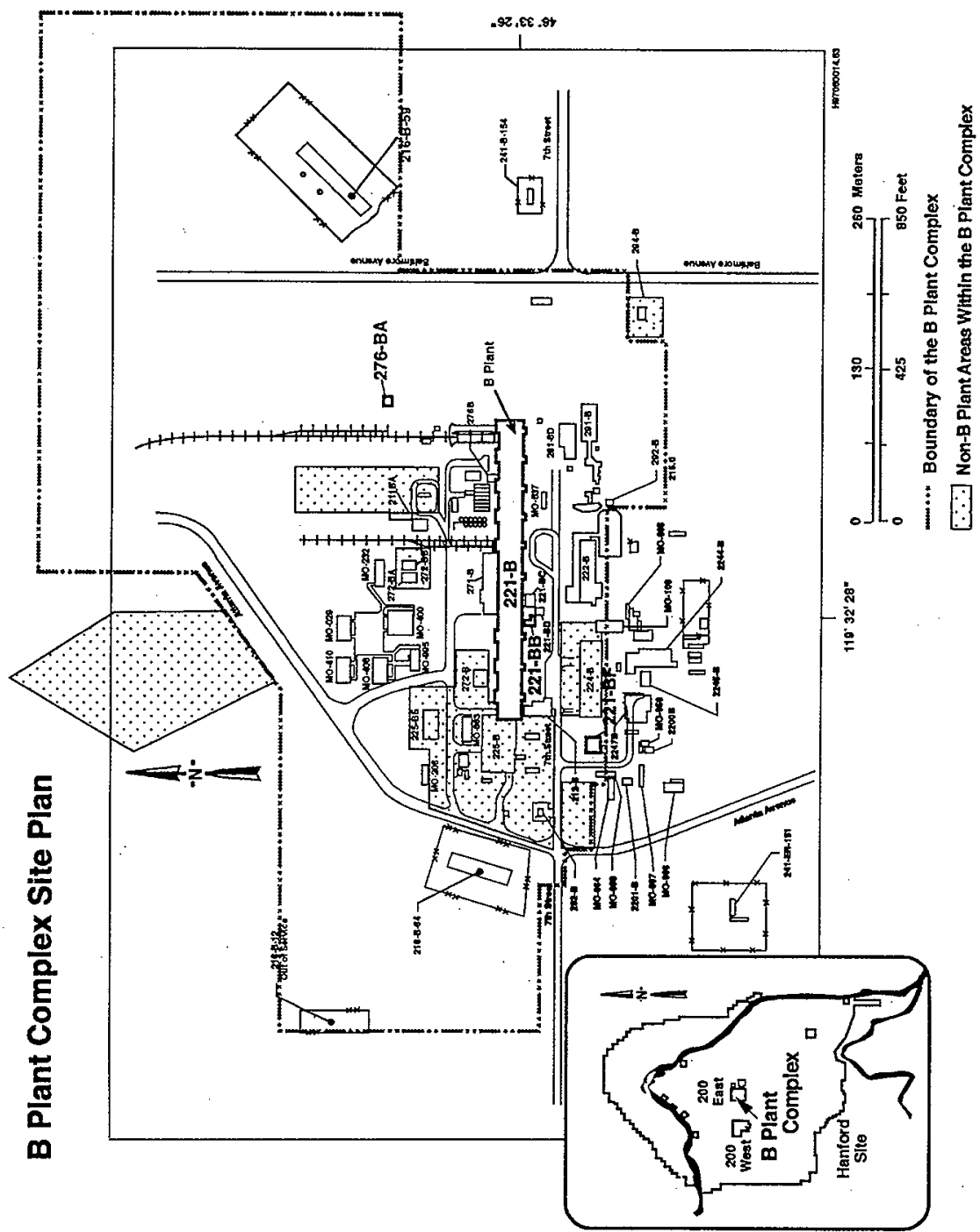

Figure 2-1. B Plant Complex. 
DOE/RL-98-12, Rev. 1

02/99
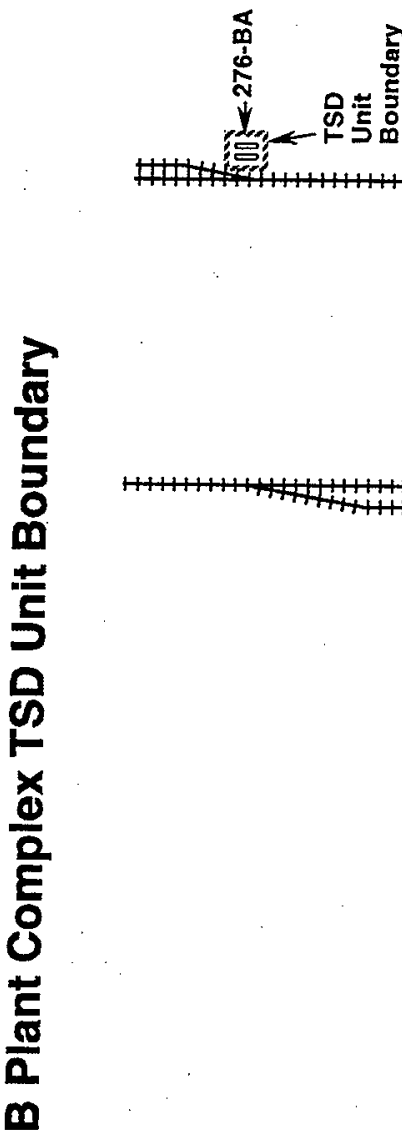

$$
\text { 롬 }
$$

\section{洒}
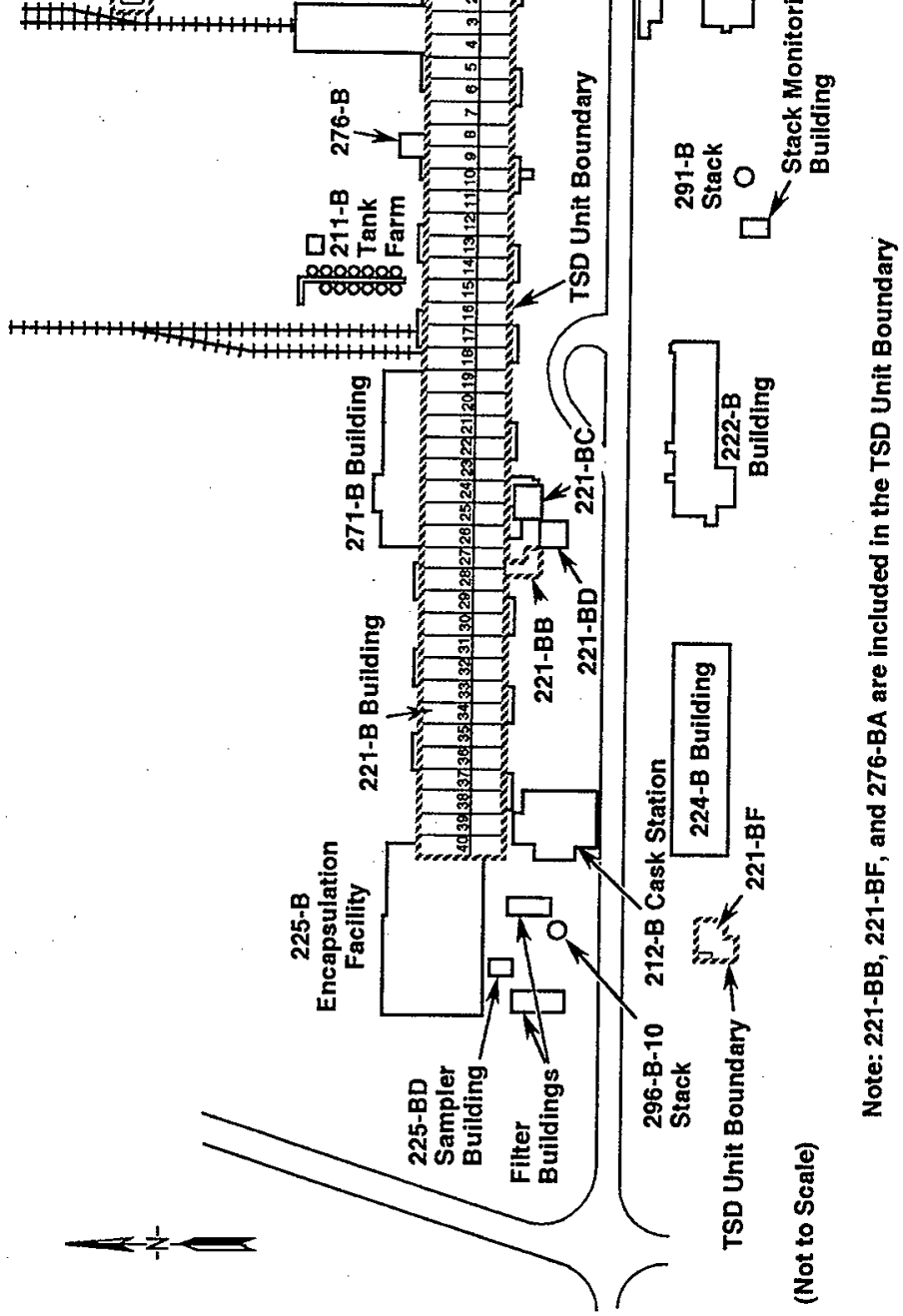

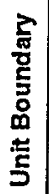

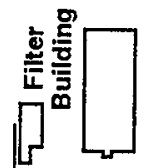

든



Figure 2-2. B Plant Complex Treatment, Storage, and/or Disposal Unit Boundary. 


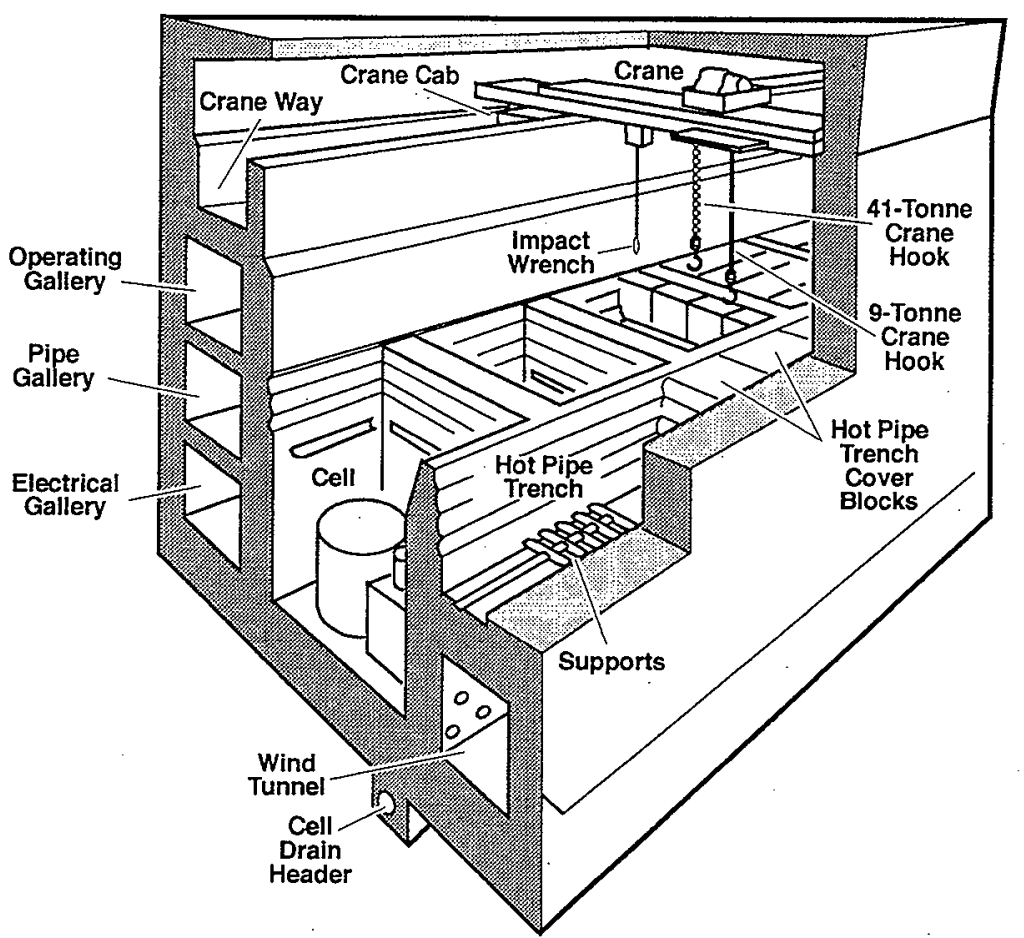

197050014.56R2

Figure 2-3. 221-B Building Cutaway (typical) 


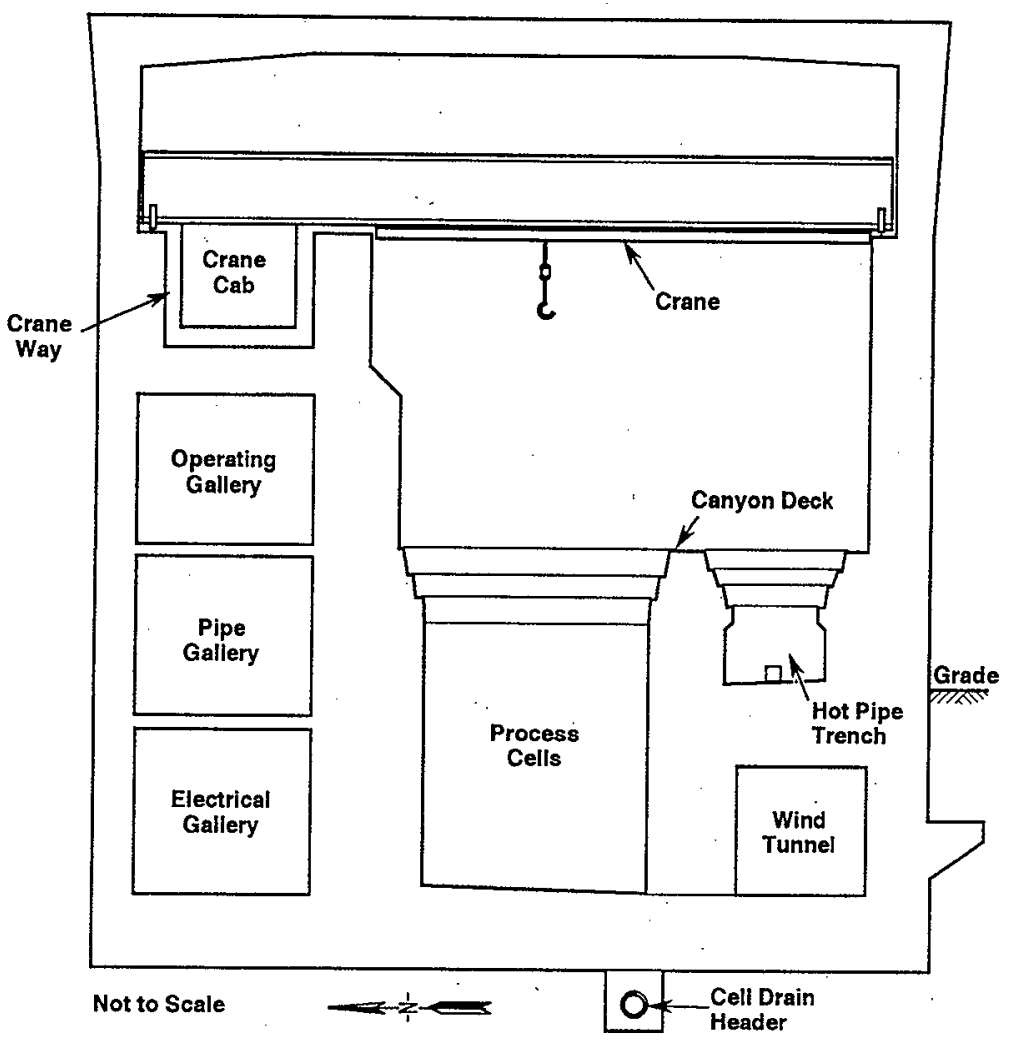

H97050014.51R2

Figure 2-4. 221-B Building Cross-Section (typical). 


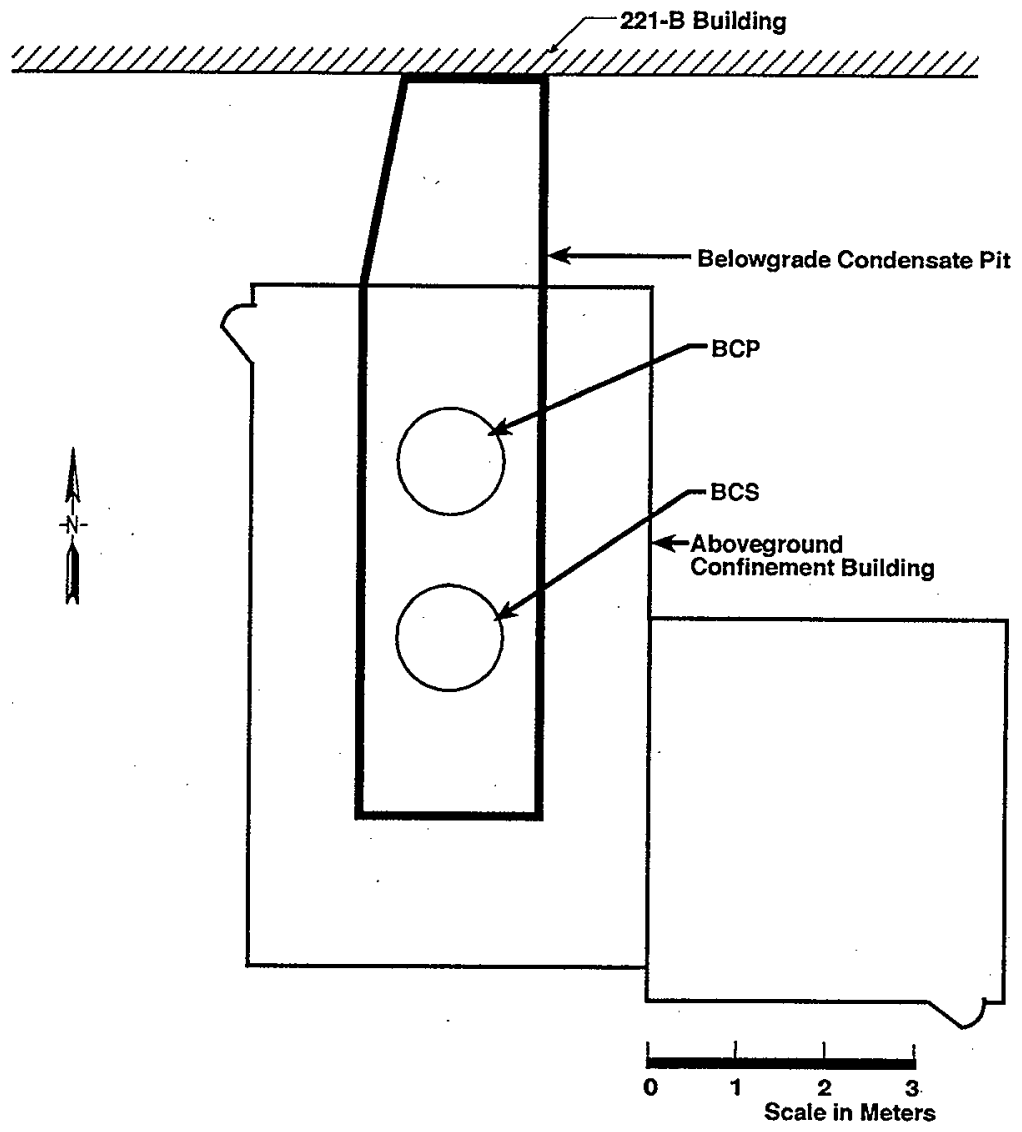

H97050014.58R1

Figure 2-5. 221-BB Process and Steam Condensate Building. 


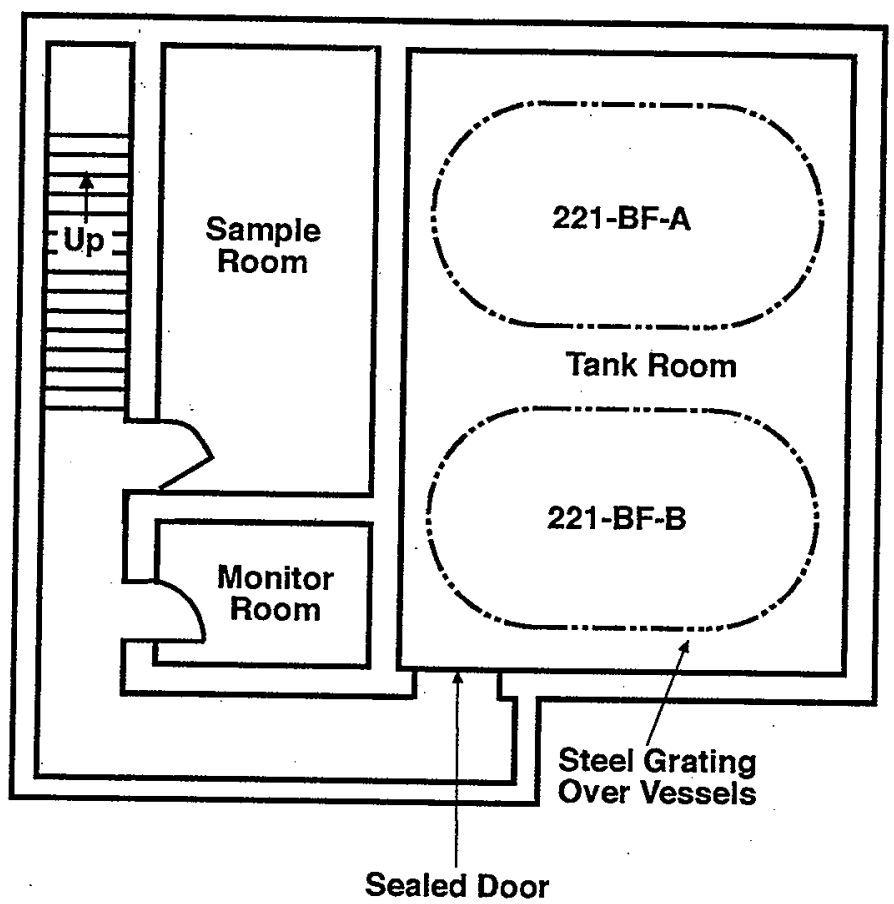

HG97050014.60R2

Figure 2-6. 221-BF Condensate Effluent Discharge Facility. 


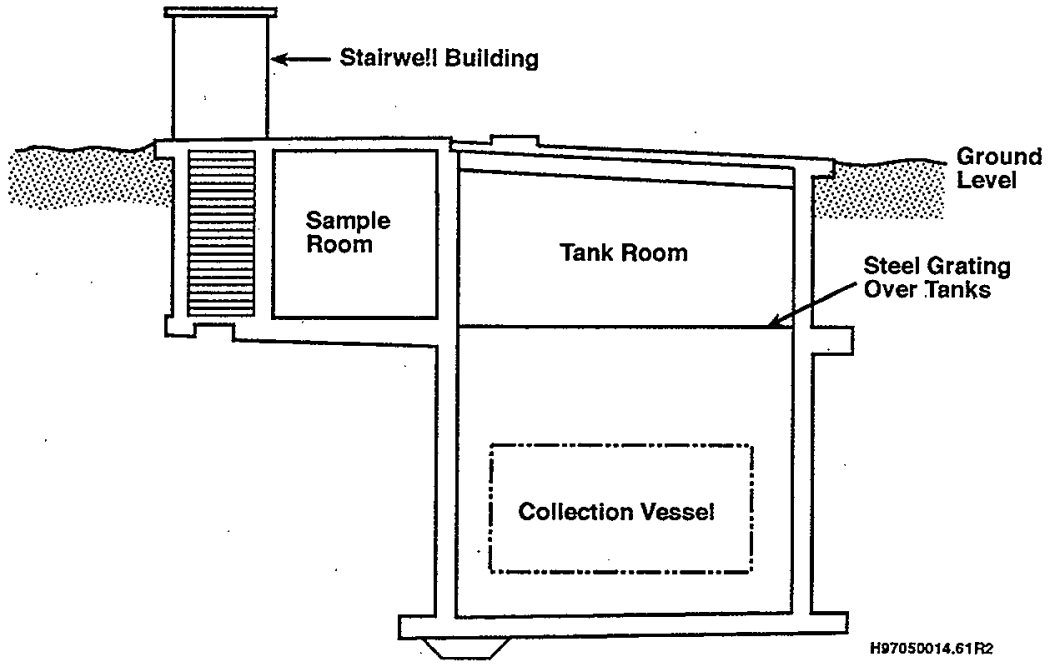

Figure 2-7. Cross-Section of the 221-BF Process Condensate Effluent Discharge Facility. 
DOE/RL-98-12, Rev. 1

02/99

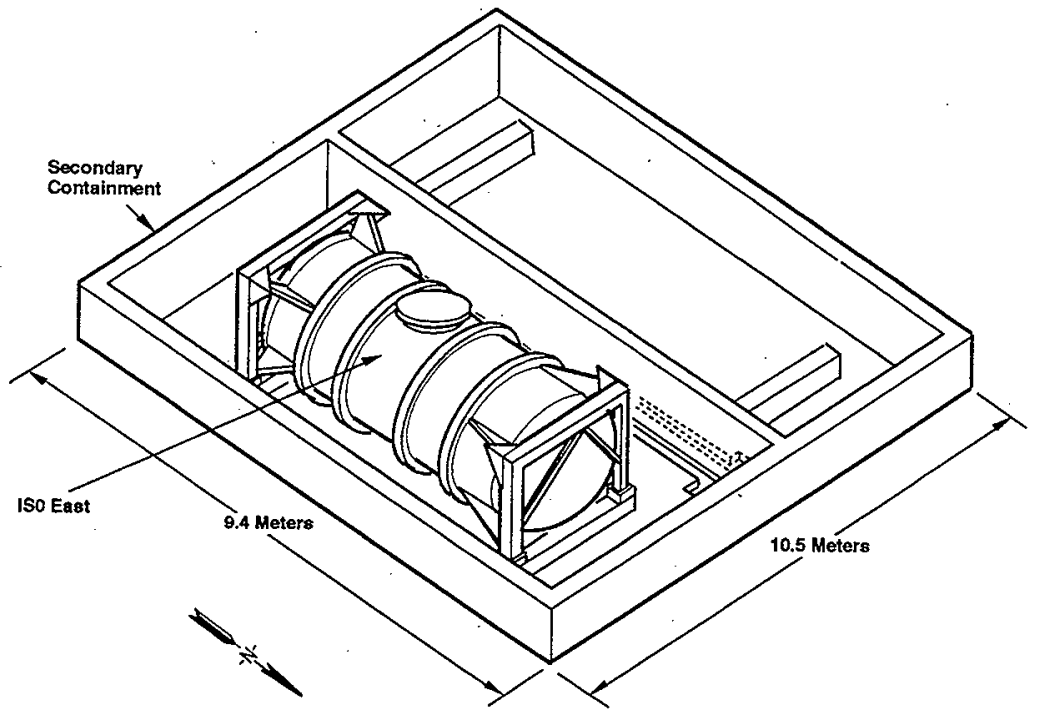

H98090083 IR1

Figure 2-8. 276-BA Interim Organic Storage Facility. 

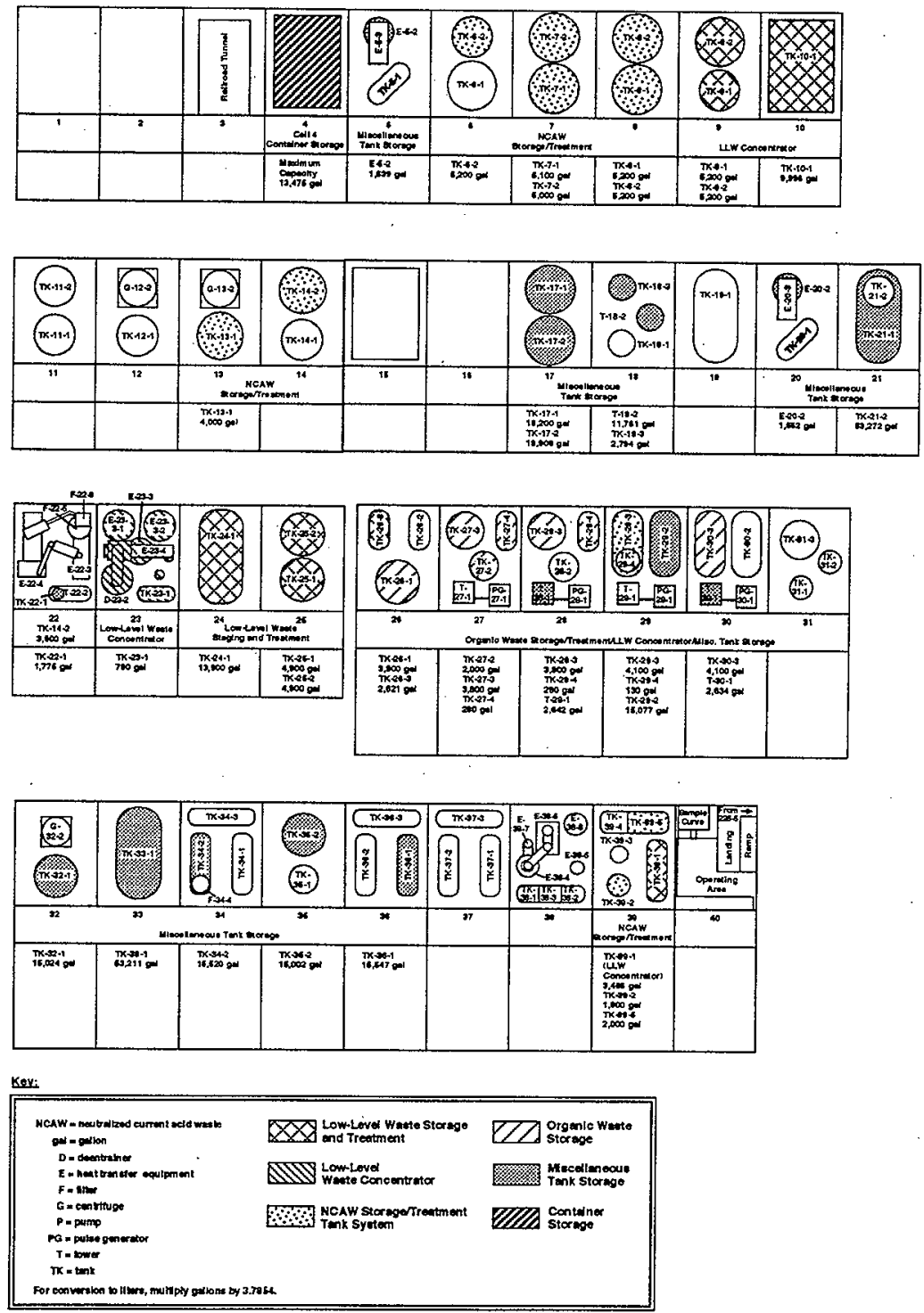

Figure 2-9. 221-B Building Process Cells. 


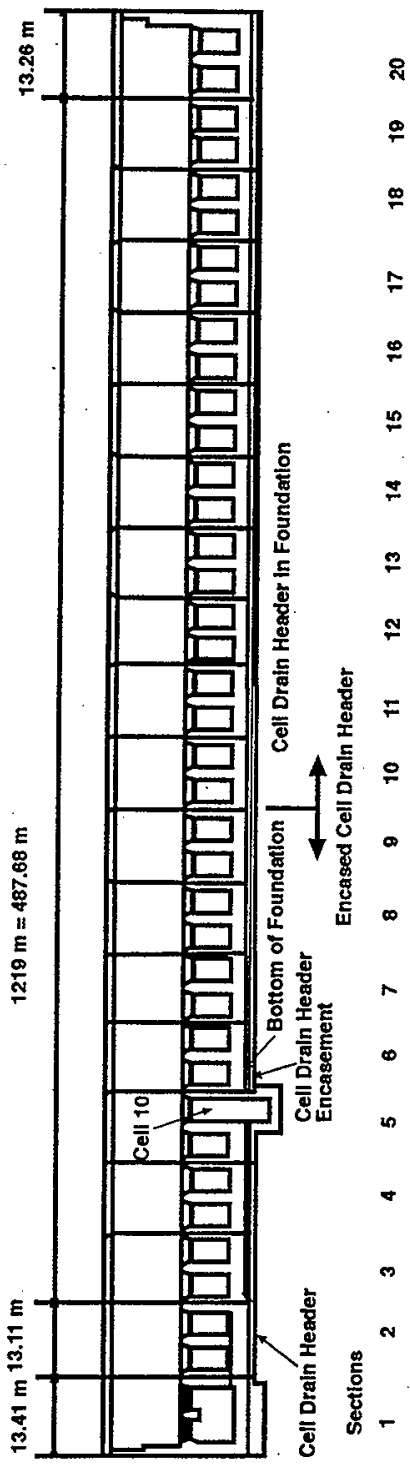

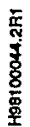

正

$\approx$

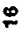

?

$\pm$

2

N

$F$

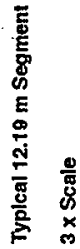

Figure 2-10. 221-B Building Longitudinal Section through Cell Drain Header Looking South (1:1000). 

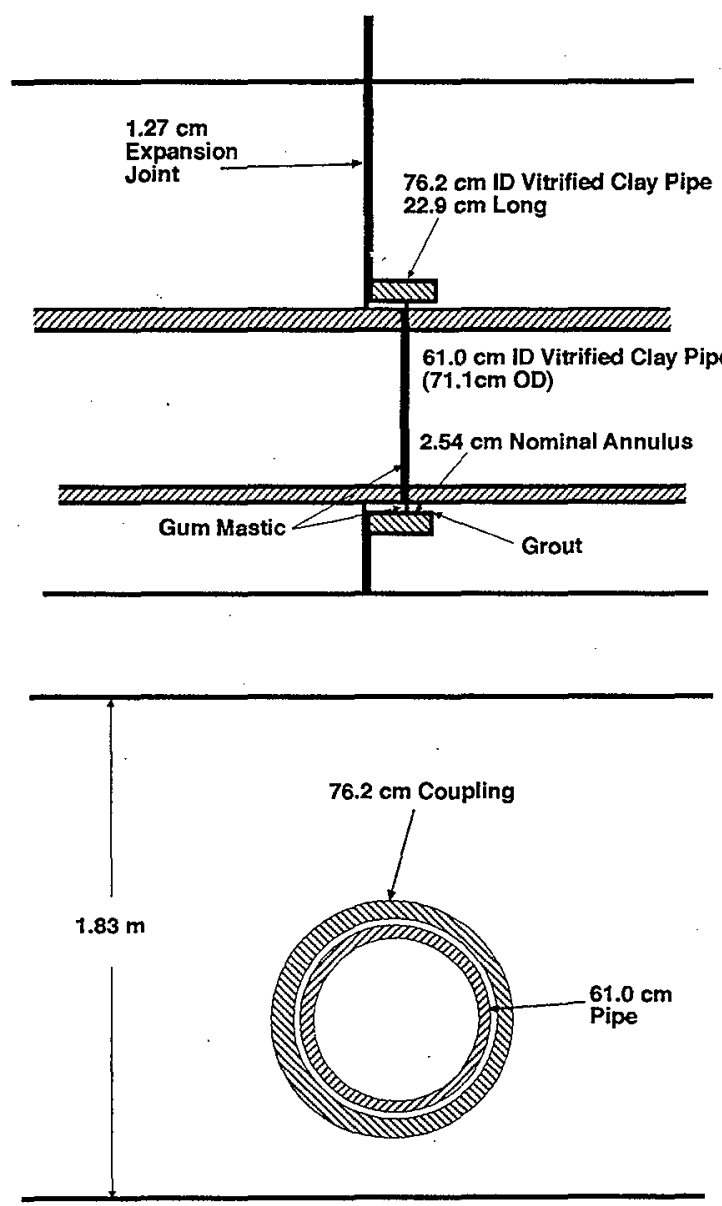

Not to scale.

$\mathrm{cm}=$ centimeter.

ID $=$ Inside diameter.

$O D=$ Outside diameter.

H88100044.1R2

Figure 2-11. Cell Drain Header Segment Joint. 
DOE/RL-98-12, Rev. 1

02/99

This page intentionally left blank. 
Table 2-1. Treatment and/or Storage Vessels

\begin{tabular}{|c|c|c|c|c|}
\hline Vessel & Vessel type & Location & TSD system & Process code \\
\hline$E-5-2$ & $\begin{array}{l}\text { Heat transfer } \\
\text { equipment }\end{array}$ & $\begin{array}{l}\text { 221-B Building, } \\
\text { Cell } 5\end{array}$ & MISC & 1,3 \\
\hline TK-6-2 & Storage tank & $\begin{array}{l}\text { 221-B Building, } \\
\text { Cell } 6\end{array}$ & NCAW & 2 \\
\hline TK-7-1 & Storage tank & $\begin{array}{c}\text { 221-B Building, } \\
\text { Cell } 7\end{array}$ & NCAW & 2 \\
\hline TK-7-2 & Storage tank & $\begin{array}{l}\text { 221-B Building, } \\
\text { Cell } 7\end{array}$ & NCAW & 2 \\
\hline TK-8-1 & Storage tank & $\begin{array}{c}\text { 221-B Building, } \\
\text { Cell } 8\end{array}$ & NCAW & 2 \\
\hline TK-8-2 & Storage tank & $\begin{array}{c}\text { 221-B Building, } \\
\text { Cell } 8\end{array}$ & NCAW & 2 \\
\hline TK-9-1 & Storage tank & $\begin{array}{c}\text { 221-B Building, } \\
\text { Cell } 9\end{array}$ & LLW & 7 \\
\hline TK-9-2 & Storage tank & $\begin{array}{c}\text { 221-B Building, } \\
\text { Cell } 9\end{array}$ & LLW & 7 \\
\hline TK-10-1 & Storage tank & $\begin{array}{c}\text { 221-B Building, } \\
\text { Cell } 10\end{array}$ & LLW & 7 \\
\hline TK-13-1 & Storage tank & $\begin{array}{l}\text { 221-B Building, } \\
\text { Cell } 13\end{array}$ & NCAW & 2 \\
\hline TK-14-2 & Storage tank & $\begin{array}{c}\text { 221-B Building, } \\
\text { Cell } 14\end{array}$ & NCAW & 2 \\
\hline TK-17-1 & Storage tank & $\begin{array}{l}\text { 221-B Building, } \\
\text { Cell } 17\end{array}$ & $\mathrm{MISC}$ & 3 \\
\hline $\mathrm{TK}-17-2$ & Storage tank & $\begin{array}{l}\text { 221-B Building, } \\
\text { Cell } 17\end{array}$ & MISC & 3 \\
\hline $\mathrm{T}-18-2$ & Tower & $\begin{array}{c}\text { 221-B Building, } \\
\text { Cell } 18\end{array}$ & MISC & 3 \\
\hline $\mathrm{TK}-18-3$ & Storage tank & $\begin{array}{l}\text { 221-B Building, } \\
\text { Cell } 18\end{array}$ & MISC & 3 \\
\hline E-20-2 & $\begin{array}{c}\text { Heat transfer } \\
\text { equipment }\end{array}$ & $\begin{array}{c}\text { 221-B Building, } \\
\text { Cell } 20\end{array}$ & MISC & 3 \\
\hline TK-21-1 & Storage tank & $\begin{array}{c}\text { 221-B Building, } \\
\text { Cell } 21\end{array}$ & MISC & 3 \\
\hline TK-22-1 & Storage tank & $\begin{array}{c}\text { 221-B Building, } \\
\text { Cell } 22\end{array}$ & MISC & 4 \\
\hline TK-23-1 & Storage tank & $\begin{array}{c}\text { 221-B Building, } \\
\text { Cell } 23\end{array}$ & LLW CONC & 6 \\
\hline E-23-3 & $\begin{array}{c}\text { Heat transfer } \\
\text { equipment } \\
\text { (concentrator) }\end{array}$ & $\begin{array}{c}\text { 221-B Building, } \\
\text { Cell } 23\end{array}$ & LLW CONC & 6 \\
\hline
\end{tabular}


Table 2-1. Treatment and/or Storage Vessels

\begin{tabular}{|c|c|c|c|c|}
\hline Vessel & Vessel type & Location & TSD system & Process code \\
\hline E-23-3-1 & $\begin{array}{l}\text { Heat transfer } \\
\text { equipment } \\
\text { (tube bundle) }\end{array}$ & $\begin{array}{l}\text { 221-B Building, } \\
\text { Cell } 23\end{array}$ & LLW CONC & 6 \\
\hline E-23-3-2 & $\begin{array}{l}\text { Heat transfer } \\
\text { equipment } \\
\text { (tube bundle) }\end{array}$ & $\begin{array}{c}\text { 221-B Building, } \\
\text { Cell } 23\end{array}$ & LLW CONC & 6 \\
\hline E-23-4 & $\begin{array}{l}\text { Heat transfer } \\
\text { equipment } \\
\text { (condenser) }\end{array}$ & $\begin{array}{l}\text { 221-B Building, } \\
\text { Cell } 23\end{array}$ & LLW CONC & 6 \\
\hline D-23-2 & De-entrainer & $\begin{array}{c}\text { 221-B Building, } \\
\text { Cell } 23\end{array}$ & LLW CONC & 6 \\
\hline TK-24-1 & Storage tank & $\begin{array}{c}\text { 221-B Building, } \\
\text { Cell } 24\end{array}$ & LLW & 7 \\
\hline TK-25-1 & Storage tank & $\begin{array}{l}\text { 221-B Building, } \\
\text { Cell } 25\end{array}$ & $\overline{L L W}$ & 7 \\
\hline TK-25-2 & Storage tank & $\begin{array}{l}\text { 221-B Building, } \\
\text { Cell } 25\end{array}$ & LLW & 7 \\
\hline TK-26-1 & Storage tank & $\begin{array}{l}\text { 221-B Building, } \\
\text { Cell } 26\end{array}$ & ORG & 5 \\
\hline TK-26-3 & Storage tank & $\begin{array}{l}\text { 221-B Building, } \\
\text { Cell } 26\end{array}$ & LLW & 7 \\
\hline TK-27-2 & Storage tank & $\begin{array}{c}\text { 221-B Building, } \\
\text { Cell } 27\end{array}$ & ORG & 5 \\
\hline TK-27-3 & Storage $\operatorname{tank}$ & $\begin{array}{c}\text { 221-B Building, } \\
\text { Cell } 27\end{array}$ & $\overline{O R G}$ & 5 \\
\hline TK-27-4 & Storage tank & $\begin{array}{c}\text { 221-B Building, } \\
\text { Cell } 27\end{array}$ & ORG & 5 \\
\hline T-28-1 & Tower & $\begin{array}{l}221-\mathrm{B} \\
\text { Cell } 28\end{array}$ & MISC & 5 \\
\hline TK-28-3 & Storage tank & $\begin{array}{l}\text { 221-B Building, } \\
\text { Cell } 28\end{array}$ & ORG & 5 \\
\hline TK-28-4 & Storage tank & $\begin{array}{c}\text { 221-B Building, } \\
\text { Cell } 28\end{array}$ & ORG & 5 \\
\hline TK-29-2 & Storage tank & $\begin{array}{c}\text { 221-B Building, } \\
\text { Cell } 29\end{array}$ & MISC & 5 \\
\hline TK-29-3 & Storage tank & $\begin{array}{c}\text { 221-B Building, } \\
\text { Cell } 29\end{array}$ & $\begin{array}{c}\mathrm{NCAW} \\
.\end{array}$ & 5 \\
\hline TK-29-4 & Storage tank & $\begin{array}{l}\text { 221-B Building, } \\
\text { Cell } 29\end{array}$ & ORG & 5 \\
\hline$T-30-1$ & Tower & $\begin{array}{c}\text { 221-B Building } \\
\text { Cell } 30\end{array}$ & MISC & 59 \\
\hline
\end{tabular}


Table 2-1. Treatment and/or Storage Vessels

\begin{tabular}{|c|c|c|c|c|}
\hline Vessel & Vessel type & Location & TSD system & Process code \\
\hline TK-30-3 & Storage tank & $\begin{array}{l}\text { 221-B Building, } \\
\text { Cell } 30\end{array}$ & ORG & 5 \\
\hline TK-32-1 & Storage tank & $\begin{array}{c}\text { 221-B Building, } \\
\text { Cell } 32\end{array}$ & MISC & 1 \\
\hline TK-33-1 & Storage tank & $\begin{array}{c}\text { 221-B Building, } \\
\text { Cell } 33\end{array}$ & MISC & 3 \\
\hline TK-34-2 & Storage tank & $\begin{array}{c}\text { 221-B Building, } \\
\text { Cell } 34\end{array}$ & MISC & 3 \\
\hline TK $-35-2$ & Storage tank & $\begin{array}{l}\text { 221-B Building, } \\
\text { Cell } 35\end{array}$ & MISC & 3 \\
\hline TK-36-1 & Storage tank & $\begin{array}{c}\text { 221-B Building } \\
\text { Cell } 36\end{array}$ & MISC & 3 \\
\hline TK-39-1 & Storage tank & $\begin{array}{l}\text { 221-B Building, } \\
\text { Cell } 39\end{array}$ & LLW & 3 \\
\hline TK-39-2 & Storage tank & $\begin{array}{l}\text { 221-B Building, } \\
\text { Cell } 39\end{array}$ & NCAW & 2 \\
\hline TK-39-5 & Storage tank & $\begin{array}{c}\text { 221-B Building, } \\
\text { Cell } 39\end{array}$ & NCAW & 2 \\
\hline TK -100 & Storage tank & $\begin{array}{c}\text { 221-B Building, } \\
\text { Canyon deck, trench side } \\
\text { of Cell } 34\end{array}$ & MISC & 7 \\
\hline $\mathrm{BCP}$ & Storage tank & $\begin{array}{l}\text { 221-BB Building, } \\
\text { Condensate Pit }\end{array}$ & MISC & 6 \\
\hline$\overline{\mathrm{BCS}}$ & Storage tank & $\begin{array}{l}\text { 221-BB Building, } \\
\text { Condensate Pit }\end{array}$ & MISC & 6 \\
\hline 221-BF-A & Storage tank & $\begin{array}{l}\text { 221-BF Facility } \\
\text { Effluent Control Pit }\end{array}$ & MISC & 6 \\
\hline $221-B F-B$ & Storage tank & $\begin{array}{l}\text { 221-BF Facility, } \\
\text { Effluent Control Pit }\end{array}$ & MISC & 6 \\
\hline ISO West & Storage tank & $\begin{array}{l}\text { 276-BA Facility } \\
\text { Note: This tank has been } \\
\text { closed and removed. }\end{array}$ & $\overrightarrow{\mathrm{ORG}}$ & 5 \\
\hline ISO East & Storage tank & 276-BA Facility & ORG & 5 \\
\hline
\end{tabular}


Process Codes/Legend:

Code

1 Strontium purification Sulfate precipitation

Caustic strike

Rare earth

2 NCAW

3

4
Process

Chemical Additions

$\mathrm{Na}_{2} \mathrm{SO}_{4}$ (sodium sulfate) $\mathrm{Na}_{2} \mathrm{CO} 3$ (sodium carbonate) $\mathrm{NaOH}$ (sodium hydroxide) $\mathrm{HNO}_{3}$ (nitric acid) HEDTA (hydroxyethylene diamine triacetic acid)

$\mathrm{NaOH}$

$\mathrm{HNO}_{3}$ HEDTA

$\mathrm{RE}\left(\mathrm{NO}_{3}\right)_{3}$ (rare earth nitrate) $\mathrm{Na}_{2} \mathrm{SO}_{4}$ HEDTA

$\mathrm{HNO}_{3}$ $\mathrm{Na}_{2} \mathrm{CO}_{3}$

DE (diatomaceous earth)
Batch process to separate strontium from metallic ions except for sodium, barium, and rare earths via precipitation, metathesis, and dissolution.

Precipitation process to remove metallic impurities such as iron, magnesium, nickel, chromium, rare earths, aluminum, cadmium, zinc, manganese, and lead.

Precipitation process with a rare earth carrier followed by metathesis then acid dissolution for strontium purification.

Separation and removal of transuranic bearing solids and high-heat radioisotopes by settling and filtration. This was a solid/liquid separation, no chemical additions were required.

Removal of cesium from solids by leaching and centrifugation in preparation for additional purification via ion exchange.

This is the second step in the cesium purification process. The process consists of the addition of a chelating agent to prevent precipitation of iron and aluminum impurities and subsequent cation removal of cesium, sodium, and potassium by ion exchange.

Final purification of cesium. Cesium carbonate was produced, which was suitable for the encapsulation process via ion exchange for cation removal.

Buildup of carbonate solids at discharge point of the vessel vent number 2 line required the addition of a scale inhibitor to prevent line pluggage. 
Process Codes/Legend:

Strontium recovery, (solvent extraction)

$6 \begin{aligned} & \text { Evaporator/ } \\ & \text { de-entrainer }\end{aligned}$

$6 \begin{aligned} & \text { Evaporator/ } \\ & \text { de-entrainer }\end{aligned}$

7
$\mathrm{NaOH}$

$\mathrm{Na}_{2} \mathrm{CO} 3$

$\mathrm{NaC}_{6} \mathrm{O}_{7} \mathrm{H}_{4}$ (Sodium

gluconate)

$\mathrm{HNO}_{3}$

HEDTA

EDTA (Ethylenediamine

tetraacetic acid)

Citric acid

ACOH (hydroxyacetic acetic

acid)

TBP (tributylphosphate)

HDEHP

(Di2ethylhexylphosphoic

acid)

NPH (normal paraffin

hydrocarbon)

$\mathrm{NaOH}$

$\mathrm{HNO}_{3}$

Citric acid

$\mathrm{NaOH}$

$\mathrm{NaNO}_{2}$ (sodium nitrite)

Strontium is purified through a series of solvent extraction columns, scrubbed, and concentrated for encapsulation as strontium fluoride at WESF. The rare earth elements and calcium impurities are stripped from the organic stream and routed to DST System.
The purpose of the waste concentration process is to collect, blend, and neutralize process waste for volume reduction, and ammonia separation for waste transmittal to DST System.

All waste sent to DSTs is required to meet $\mathrm{pH}$ and $\mathrm{NO}_{2}$ limits for DST System corrosion and compatibility.

TK-xx-xx Tank

$T-x x-x x \quad$ Tower

$\mathrm{E}-\mathrm{xx}-\mathrm{xx} \quad$ Heat transfer equipment

D-xx-xx De-entrainer

DST System Double-Shell Tank System

MISC Miscellaneous Tank Storage

NCAW NCAW Storage and Treatment System

LLW Low-Level Waste Storage and Treatment System

LLW CONC Low-Level Waste Concentrator

ORG Organic Mixed Waste Storage System

WESF Waste Encapsulation and Storage Facility

*Dearborn 874 is a trademark of Dearborne Division of W.R. Grace \& Co., Lake Zurick; Ill. 
Table 2-2. Vessels by Treatment and/or Storage System.

\begin{tabular}{|c|c|c|c|}
\hline Vessel & Vessel Type & Location & Process Code \\
\hline \multicolumn{4}{|c|}{ NCAW Storage and Treatment System } \\
\hline TK-6-2 & Storage tank & $\begin{array}{l}\text { 221-B Building, } \\
\text { Cell } 6\end{array}$ & 2 \\
\hline TK-7-1 & Storage tank & $\begin{array}{c}\text { 221-B Building, } \\
\text { Cell } 7\end{array}$ & 2 \\
\hline TK $-7-2$ & Storage tank & $\begin{array}{l}\text { 221-B Building, } \\
\text { Cell } 7\end{array}$ & 2 \\
\hline TK-8-1 & Storage tank & $\begin{array}{c}\text { 221-B Building, } \\
\text { Cell } 8\end{array}$ & 2 \\
\hline TK-8-2 & Storage tank & $\begin{array}{c}\text { 221-B Building, } \\
\text { Cell } 8\end{array}$ & 2 \\
\hline TK-13-1 & Storage tank & $\begin{array}{l}\text { 221-B Building, } \\
\text { Cell } 13\end{array}$ & 2 \\
\hline TK-14-2 & Storage tank & $\begin{array}{l}\text { 221-B Building, } \\
\text { Cell } 14\end{array}$ & 2 \\
\hline TK-29-3 & Storage tank & $\begin{array}{l}\text { 221-B Building, } \\
\text { Cell } 29\end{array}$ & 5 \\
\hline TK-39-2 & Storage tank & $\begin{array}{c}\text { 221-B.Building, } \\
\text { Cell } 39\end{array}$ & 2 \\
\hline TK-39-5 & Storage tank & $\begin{array}{l}\text { 221-B Building, } \\
\text { Cell } 39\end{array}$ & 2 \\
\hline \multicolumn{4}{|c|}{ LLW Storage and Treatment System } \\
\hline TK-9-1 & Storage tank & $\begin{array}{c}\text { 221-B Building, } \\
\text { Cell } 9\end{array}$ & 7 \\
\hline $\mathrm{TK}-9-2$ & Storage tank & $\begin{array}{c}\text { 221-B Building, } \\
\text { Cell } 9\end{array}$ & 7 \\
\hline TK-10-1 & Storage tank & $\begin{array}{c}\text { 221-B Building, } \\
\text { Cell } 10\end{array}$ & 7 \\
\hline TK-24-1 & Storage tank & $\begin{array}{l}\text { 221-B Building, } \\
\text { Cell } 24\end{array}$ & 7 \\
\hline $\mathrm{TK}-25-1$ & Storage tank & $\begin{array}{l}\text { 221-B Building, } \\
\text { Cell } 25\end{array}$ & 7 \\
\hline TK-25-2 & Storage tank & $\begin{array}{l}\text { 221-B Building, } \\
\text { Cell } 25\end{array}$ & 7 \\
\hline TK-26-3 & Storage tank & $\begin{array}{l}\text { 221-B Building, } \\
\text { Cell } 26\end{array}$ & 7 \\
\hline TK-39-1 & Storage $\operatorname{tank}$ & $\begin{array}{c}\text { 221-B Building, } \\
\text { Cell } 39\end{array}$ & 3 \\
\hline \multicolumn{4}{|c|}{ LLW Concentrator } \\
\hline TK-23-1 & Storage tank & $\begin{array}{c}\text { 221-B Building, } \\
\text { Cell } 23\end{array}$ & 6 \\
\hline
\end{tabular}


Table 2-2. Vessels by Treatment and/or Storage System.

\begin{tabular}{|c|c|c|c|}
\hline Vessel & Vessel Type & Location & Process Code \\
\hline $\mathrm{E}-23-3$ & $\begin{array}{l}\text { Heat transfer } \\
\text { equipment } \\
\text { (concentrator) }\end{array}$ & $\begin{array}{c}\text { 221-B Building, } \\
\text { Cell } 23\end{array}$ & 6 \\
\hline $\bar{E}-23-3-1$ & $\begin{array}{l}\text { Heat transfer } \\
\text { equipment } \\
\text { (tube bundle) }\end{array}$ & $\begin{array}{l}\text { 221-B Building, } \\
\text { Cell } 23\end{array}$ & 6 \\
\hline E-23-3-2 & $\begin{array}{l}\text { Heat transfer } \\
\text { equipment } \\
\text { (tube bundle) }\end{array}$ & $\begin{array}{l}\text { 221-B Building, } \\
\text { Cell } 23\end{array}$ & 6 \\
\hline E-23-4. & $\begin{array}{l}\text { Heat transfer } \\
\text { equipment } \\
\text { (condenser) }\end{array}$ & $\begin{array}{c}\text { 221-B Building, } \\
\text { Cell } 23\end{array}$ & 6 \\
\hline D-23-2 & De-entrainer & $\begin{array}{c}\text { 221-B Building, } \\
\text { Cell } 23\end{array}$ & 6 \\
\hline \multicolumn{4}{|c|}{ Organic Mixed Waste Storage System } \\
\hline TK-26-1 & Storage tank & $\begin{array}{c}\text { 221-B Building, } \\
\text { Cell } 26\end{array}$ & 5 \\
\hline TK-27-2 & Storage tank & $\begin{array}{c}\text { 221-B Building, } \\
\text { Cell } 27\end{array}$ & 5 \\
\hline TK-27-3 & Storage tank & $\begin{array}{c}\text { 221-B Building, } \\
\text { Cell } 27\end{array}$ & 5 \\
\hline TK-27-4 & Storage tank & $\begin{array}{c}\text { 221-B Building, } \\
\text { Cell } 27\end{array}$ & 5 \\
\hline TK $-28-3$ & Storage tank & $\begin{array}{c}\text { 221-B Building, } \\
\text { Cell } 28\end{array}$ & 5 \\
\hline TK-28-4 & Storage tank & $\begin{array}{c}\text { 221-B Building, } \\
\text { Cell } 28\end{array}$ & 5 \\
\hline TK-29-4 & Storage tank & $\begin{array}{c}\text { 221-B Building, } \\
\text { Cell } 29\end{array}$ & 5 \\
\hline TK $-30-3$ & Storage tank & $\begin{array}{c}\text { 221-B Building, } \\
\text { Cell } 30\end{array}$ & 5 \\
\hline ISO West & Storage tank & $\begin{array}{c}\text { 276-BA Facility } \\
\text { Note: This tank has been closed and } \\
\text { removed. }\end{array}$ & 5 \\
\hline ISO East & Storage tank & 276-BA Facility & 5 \\
\hline \multicolumn{4}{|c|}{ Miscellaneous Tank Storage } \\
\hline $\bar{E}-5-2$ & $\begin{array}{c}\text { Heat transfer } \\
\text { equipment }\end{array}$ & $\begin{array}{c}\text { 221-B Building, } \\
\text { Cell } 5\end{array}$ & 1,3 \\
\hline TK-17-1 & Storage tank & $\begin{array}{l}\text { 221-B Building, } \\
\text { Cell } 17\end{array}$ & 3 \\
\hline TK-17-2 & Storage tank & 221-B Building, & 3 \\
\hline
\end{tabular}


Table 2-2. Vessels by Treatment and/or Storage System.

\begin{tabular}{|c|c|c|c|}
\hline Vessel & Vessel Type & Location & Process Code \\
\hline & & Cell 17 & \\
\hline$T-18-2$ & Tower & $\begin{array}{l}\text { 221-B Building, } \\
\text { Cell } 18 \\
\end{array}$ & 3 \\
\hline TK-18-3 & Storage tank & $\begin{array}{l}\text { 221-B Building, } \\
\text { Cell } 18 \\
\end{array}$ & 3 \\
\hline E-20-2 & $\begin{array}{c}\text { Heat transfer } \\
\text { equipment }\end{array}$ & $\begin{array}{l}\text { 221-B Building, } \\
\text { Cell } 20 \\
\end{array}$ & 3 \\
\hline TK-21-1 & Storage tank & $\begin{array}{l}\text { 221-B Building, } \\
\text { Cell } 21\end{array}$ & 3 \\
\hline TK-22-1 & Storage tank & $\begin{array}{l}221-B \text { Building, } \\
\text { Cell } 22\end{array}$ & 4 \\
\hline $\mathrm{T}-28-1$ & Tower & $\begin{array}{l}\text { 221-B Building, } \\
\text { Cell } 28\end{array}$ & 5 \\
\hline TK-29-2 & Storage tank & $\begin{array}{l}\text { 221-B Building, } \\
\text { Cell } 29\end{array}$ & 5 \\
\hline$T-30-1$ & Tower & $\begin{array}{l}\text { 221-B Building, } \\
\text { Cell } 30\end{array}$ & 5 \\
\hline TK-32-1 & Storage tank & $\begin{array}{l}\text { 221-B Building, } \\
\text { Cell } 32\end{array}$ & 1 \\
\hline TK-33-1 & Storage tank & $\begin{array}{l}\text { 221-B Building, } \\
\text { Cell } 33\end{array}$ & 3 \\
\hline TK-34-2 & Storage tank & $\begin{array}{l}\text { 221-B Building, } \\
\text { Cell } 34\end{array}$ & 3 \\
\hline TK-35-2 & Storage tank & $\begin{array}{l}\text { 221-B Building, } \\
\text { Cell } 35\end{array}$ & 3 \\
\hline TK-36-1 & Storage tank & $\begin{array}{c}\text { 221-B Building, } \\
\text { Cell } 36\end{array}$ & 3 \\
\hline TK-100 & Storage tank & $\begin{array}{c}\text { 221-B Building, } \\
\text { Canyon deck, trench side of Cell } 34\end{array}$ & 7 \\
\hline$\overline{B C P}$ & Storage tank & $\begin{array}{c}\text { 221-BB Building, } \\
\text { Condensate } P \text { it }\end{array}$ & 6 \\
\hline$\overline{B C S}$ & Storage tank & $\begin{array}{l}\text { 221-BB Building, } \\
\text { Condensate Pit }\end{array}$ & 6 \\
\hline $221-B F-A$ & Storage tank & $\begin{array}{l}\text { 221-BF Facility, } \\
\text { Effluent Control Pit }\end{array}$ & 6 \\
\hline $221-\mathrm{BF}-\mathrm{B}$ & Storage tank & $\begin{array}{l}\text { 221-BF Facility, } \\
\text { Effluent Control Pit }\end{array}$ & 6 \\
\hline
\end{tabular}




\section{Process Codes/Legend}

\begin{tabular}{|c|c|c|}
\hline $\begin{array}{l}\text { Code } \\
1\end{array}$ & $\begin{array}{l}\text { Process } \\
\text { Strontium } \\
\text { purification }\end{array}$ & Chemical Additions \\
\hline & $\begin{array}{l}\text { Sulfate } \\
\text { precipitation }\end{array}$ & $\begin{array}{l}\mathrm{Na}_{2} \mathrm{SO}_{4} \text { (sodium sulfate) } \\
\mathrm{Na}_{2} \mathrm{CO} 3 \text { (sodium carbonate) } \\
\mathrm{NaOH}_{\text {(sodium hydroxide) }} \\
\mathrm{HNO}_{3} \text { (nitric acid) } \\
\text { HEDTA (hydroxyethylene di } \\
\text { triacetic acid) }\end{array}$ \\
\hline & Caustic strike & $\begin{array}{l}\mathrm{NaOH} \\
\text { HNO }_{3} \\
\text { HEDTA }\end{array}$ \\
\hline & Rare earth & $\begin{array}{l}\mathrm{RE}\left(\mathrm{NO}_{3}\right)_{3} \text { (rare earth nitrate) } \\
\mathrm{Na}_{2} \mathrm{SO}_{4} \\
\mathrm{HEDTA} \\
\mathrm{HNO}_{3} \\
\mathrm{Na}_{2} \mathrm{CO}_{3}\end{array}$ \\
\hline & NCAW & $\mathrm{DE}$ (diatomaceous earth) \\
\hline
\end{tabular}

3 Cesium processing

$\begin{array}{ll}\text { Cesium } & \mathrm{NaOH} \\ \text { clarification } & \mathrm{HNO}_{3} \\ & \mathrm{HEDTA}\end{array}$

Primary ion $\mathrm{NaOH}$ exchange

HEDTA

$\mathrm{HNO}_{3}$

$\mathrm{NH}_{3}$

$\mathrm{CO}_{2}$

Duolite resin

$\begin{array}{ll}\text { Ion exchange } & \mathrm{NaOH} \\ \text { Purification } & \mathrm{NH}_{3} \\ & \mathrm{CO}_{2} \\ & \text { Zeolite resin }\end{array}$

Process Descriptions

Batch process to separate strontium from metallic ions except for sodium, barium, and rare earths via precipitation, metathesis, and dissolution.

Precipitation process to remove metallic impurities such as iron, magnesium, nickel, chromium, rare earths, aluminum, cadmium, zinc, manganese, and lead.

Precipitation process with a rare earth carrier followed by metathesis then acid dissolution for strontium purification.

Separation and removal of transuranic bearing solids and high-heat radioisotopes by settling and filtration. This was a solid/liquid separation, no chemical additions were required.

Removal of cesium from solids by leaching and centrifugation in preparation for additional purification via ion exchange.

This is the second step in the cesium purification process. The process consists of the addition of a chelating agent to prevent precipitation of iron and aluminum impurities and subsequent cation removal of cesium, sodium, and potassium by ion exchange.

Final purification of cesium. Cesium carbonate was produced, which was suitable for the encapsulation process via ion exchange for cation removal. 
Process Codes/Legend

4

Vessel vent Scale inhibitor Dearbom 874* system

5

$$
\begin{aligned}
& \text { Strontium } \\
& \text { recovery, } \\
& \text { (solvent } \\
& \text { extraction) }
\end{aligned}
$$

6

$\begin{array}{ll}\text { Evaporator/ } & \mathrm{NaOH} \\ \text { de-entrainer } & \mathrm{HNO}_{3} \\ & \text { Citric acid }\end{array}$

$\begin{array}{ll}\text { Waste handling } & \mathrm{NaOH} \\ & \mathrm{NaNO}_{2} \text { (sodium nitrite) }\end{array}$

Buildup of carbonate solids at discharge point of the vessel vent number 2 line required the addition of a scale inhibitor to prevent line pluggage.

Strontium is purified through a series of solvent extraction columns, scrubbed, and concentrated for encapsulation as strontium fluoride at WESF. The rare earth elements and calcium impurities are stripped from the organic stream and routed to DST System.

The purpose of the waste concentration process is to collect, blend, and neutralize process waste for volume reduction, and ammonia separation for waste transmittal to DST System.

All waste transferred to DSTs was required to meet $\mathrm{pH}$ and $\mathrm{NO}_{2}$ limits for DST System corrosion and compatibility.

\section{TK-xx-xx Tank \\ $T-x x-x x \quad$ Tower \\ E-xx-xx Heat transfer equipment \\ D-xx-xx De-entrainer \\ DST System Double-Shell Tank System \\ WESF Waste Encapsulation and Storage Facility}

*Dearborn 874 is a trademark of Dearborne Division of W.R. Grace \& Co., Lake Zurick, Ill. 


\begin{tabular}{|c|c|c|c|}
\hline $\begin{array}{l}\text { Location } \\
\text { of vessels }\end{array}$ & $\begin{array}{l}\text { Equipment } \\
\text { or location }\end{array}$ & System & $\begin{array}{l}\text { Vessel characteristics and } \\
\text { related ancillary equipment }\end{array}$ \\
\hline \multirow[t]{2}{*}{$\begin{array}{l}\text { Cell 5, } \\
\text { 221-B Building }\end{array}$} & E-5-2 & MISC & $\begin{array}{l}\text { Characteristics: Shape: cylindrical with pipe connections on one side, height } \\
6.40 \text { meters overall, maximum diameter } 1.37 \text { meters. } \\
\text { Material of construction: stainless steel. } \\
\text { Capacity: } 6,204 \text { liters. } \\
\text { Specific ancillary equipment: Various jumpers that lead from vessel to the connections } \\
\text { on the cell walls. }\end{array}$ \\
\hline & Cell 5 & MISC & $\begin{array}{l}\text { General ancillary equipment } \\
\text { Hot pipe trench piping between Cell } 5 \text { and the other cells. } \\
\text { - Transfer piping between Cell } 5 \text { and } 221-\mathrm{BB} \text { Building. } \\
\text { - Secondary containment for E-5-2. }\end{array}$ \\
\hline \multirow[t]{2}{*}{$\begin{array}{l}\text { Cell 6, } \\
\text { 221-B Building }\end{array}$} & TK-6-2 & NCAW & $\begin{array}{l}\text { Characteristics: Shape: cylindrical, height } 4.27 \text { meters; diameter } 2: 44 \text { meters. } \\
\text { Material of construction: stainless steel. } \\
\text { Capacity: } 19,684 \text { liters. } \\
\text { Specific ancillary equipment: Various jumpers that lead from vessel to the connections } \\
\text { on the cell walls. }\end{array}$ \\
\hline & Cell 6 & NCAW & $\begin{array}{l}\text { General ancillary equipment: } \\
\text { - Hot pipe trench piping between Cell } 6 \text { and the other cells. } \\
\text { - Secondary containment for TK-6-2. }\end{array}$ \\
\hline $\begin{array}{l}\text { Cell 7, } \\
\text { 221-B Building }\end{array}$ & TK-7-1 & NCAW & $\begin{array}{l}\text { Characteristics: Shape: cylindrical, height } 4.27 \text { meters; diameter } 2.44 \text { meters. } \\
\text { Material of construction: stainless steel. } \\
\text { Capacity: } 19,306 \text { liters. } \\
\text { Specific ancillary equipment: Various jumpers that lead from vessel to the connections } \\
\text { on the cell walls. }\end{array}$ \\
\hline
\end{tabular}


DOE/RL-98-12, Rev. 1

$02 / 99$

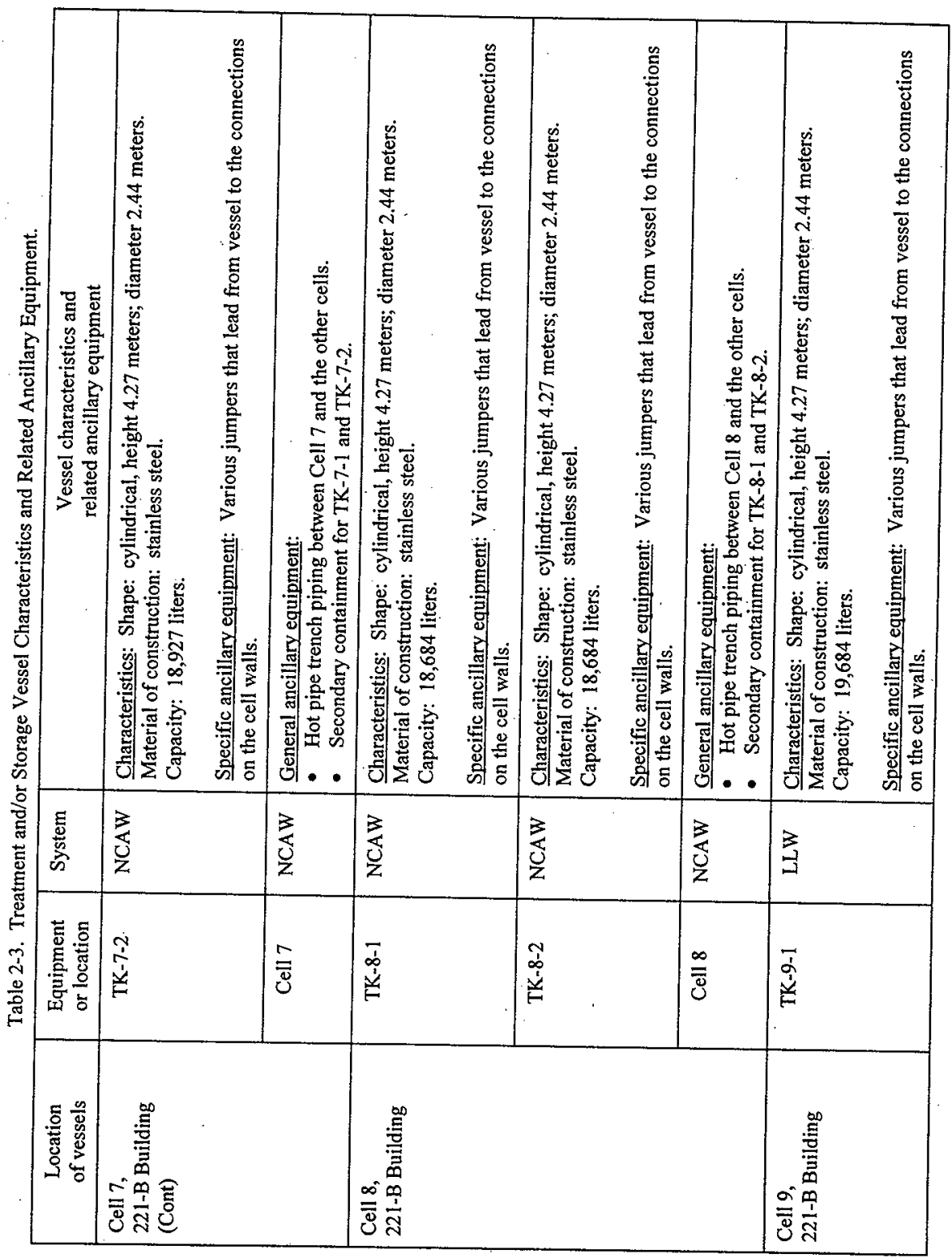




\begin{tabular}{|c|c|c|c|}
\hline $\begin{array}{l}\text { Location } \\
\text { of vessels }\end{array}$ & $\begin{array}{l}\text { Equipment } \\
\text { or location }\end{array}$ & System & $\begin{array}{l}\text { Vessel characteristics and } \\
\text { related ancillary equipment }\end{array}$ \\
\hline \multirow[t]{2}{*}{$\begin{array}{l}\text { Cell } 9 \text {, } \\
221-\mathrm{B} \text { Building } \\
\text { (Cont) }\end{array}$} & TK-9-2 & LLW & $\begin{array}{l}\text { Characteristics: Shape: cylindrical, height } 4.27 \text { meters; diameter } 2.44 \text { meters. } \\
\text { Material of construction: stainless steel. } \\
\text { Capacity: } 19,684 \text { liters. } \\
\text { Specific ancillary equipment: Various jumpers that lead from vessel to the connections } \\
\text { on the cell walls. }\end{array}$ \\
\hline & Cell 9 & LLW & $\begin{array}{l}\text { General ancillary equipment: } \\
\text { - Hot pipe trench piping between Cell } 9 \text { and the other cells. } \\
\text { - Transfer piping between Cell } 9 \text { and the } 154-B X-U 5 \text { diversion box. } \\
\text { - Secondary containment for TK-9-1- and TK-9-2. }\end{array}$ \\
\hline \multirow[t]{2}{*}{$\begin{array}{l}\text { Cell 10, } \\
221-\mathrm{B} \text { Building }\end{array}$} & TK-10-1 & LLW & $\begin{array}{l}\text { Characteristics: Shape: rectangular, height } 2.13 \text { meters, length } 5.49 \text { meters, width } \\
3.35 \text { meters. } \\
\text { Material of construction: stainless steel. } \\
\text { Capacity: } 37,839 \text { liters. } \\
\text { Specific ancillary equipment: Various jumpers that lead from vessel to the connections } \\
\text { on the cell walls. }\end{array}$ \\
\hline & Cell 10 & LLW & $\begin{array}{l}\text { General ancillary equipment: } \\
\text { Hot pipe trench piping between Cell } 10 \text { and the other cells. } \\
\text { - Transfer piping between Cell } 10 \text { and the 216-B-39 Trench and Retention Basin. } \\
\text { - Secondary containment for TK-10-1. }\end{array}$ \\
\hline \multirow[t]{2}{*}{$\begin{array}{l}\text { Cell 13, } \\
\text { 221-B Building }\end{array}$} & TK-13-1 & NCAW & $\begin{array}{l}\text { Characteristics: Shape: cylindrical, height } 2.74 \text { meters; diameter } 2.74 \text { meters. } \\
\text { Material of construction: stainless steel. } \\
\text { Capacity: } 14,812 \text { liters. } \\
\text { Specific ancillary equipment: Various jumpers that lead from vessel to the connections } \\
\text { on the cell walls. }\end{array}$ \\
\hline & Cell 13 & NCAW & $\begin{array}{l}\text { General ancillary equipment: } \\
\text { Hot pipe trench piping between Cell } 13 \text { and the other cells. } \\
\text { - Secondary containment for TK-10-1. }\end{array}$ \\
\hline
\end{tabular}


DOE/RL-98-12, Rev. I

02/99

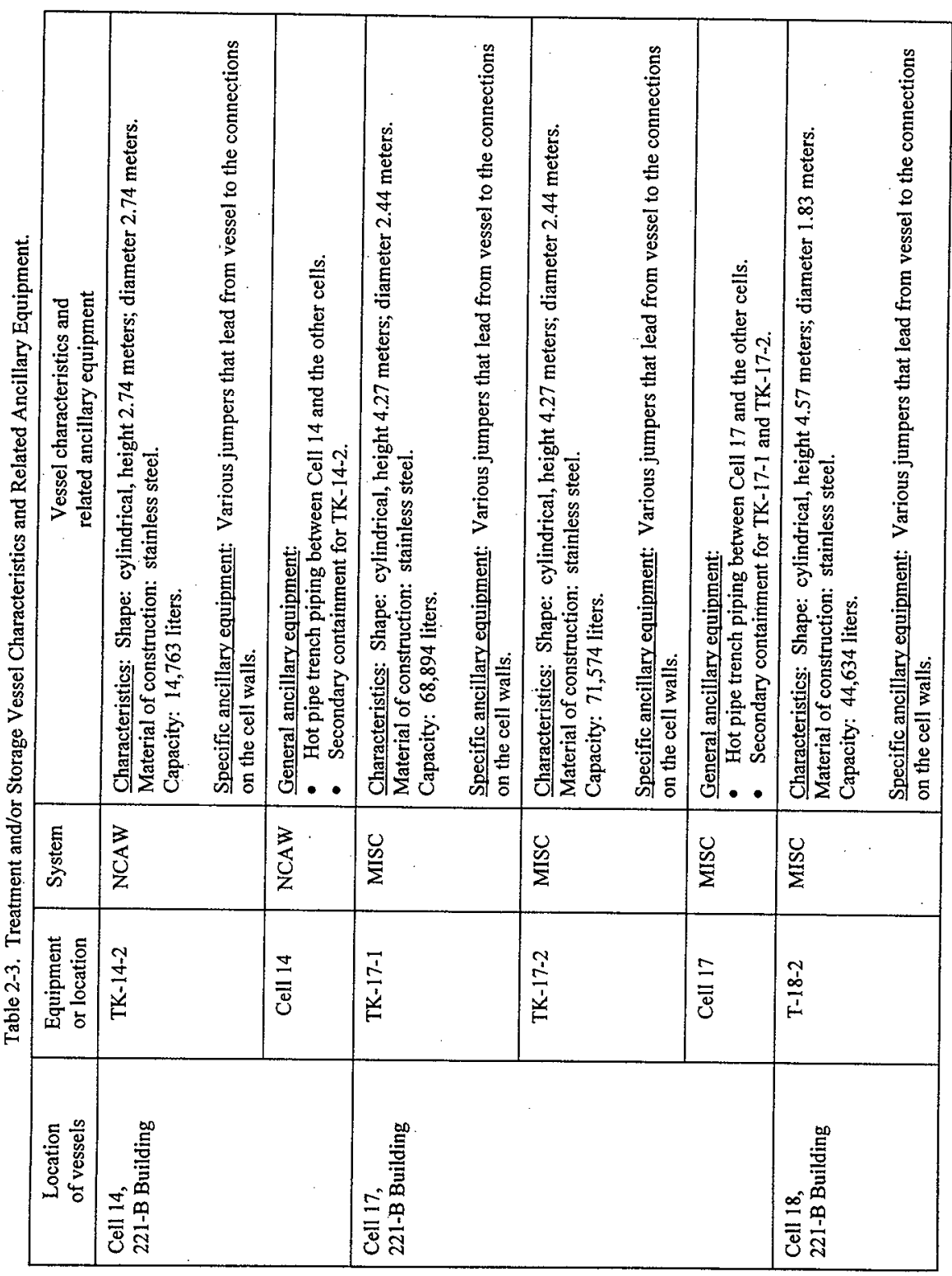


Table 2-3. Treatment and/or Storage Vessel Characteristics and Related Ancillary Equipment.

\begin{tabular}{|c|c|c|c|}
\hline $\begin{array}{l}\text { Location } \\
\text { of vessels }\end{array}$ & $\begin{array}{l}\text { Equipment } \\
\text { or location }\end{array}$ & System & $\begin{array}{l}\text { Vessel characteristics and } \\
\text { related ancillary equipment }\end{array}$ \\
\hline $\begin{array}{l}\text { Cell } 18 \text {, } \\
221-B \text { Building } \\
\text { (Cont) }\end{array}$ & TK-18-3 & MISC & $\begin{array}{l}\text { Characteristics: Shape: cylindrical, height } 2.13 \text { meters; diameter } 1.37 \text { meters. } \\
\text { Material of construction: stainless steel. } \\
\text { Capacity: } 10,576 \text { liters. } \\
\text { Specific ancillary equipment: Various jumpers that lead from vessel to the connections } \\
\text { on the cell walls. }\end{array}$ \\
\hline $\begin{array}{l}\text { Cell 20, } \\
\text { 221-B Building }\end{array}$ & Cell 20 & MISC & $\begin{array}{l}\text { General ancillary equipment: } \\
\text { - Hot pipe trench piping between Cell } 20 \text { and the other cells. } \\
\text { - Secondary containment for E-20-2. }\end{array}$ \\
\hline $\begin{array}{l}\text { Cell 21, } \\
\text { 221-B Building }\end{array}$ & TK-21-1 & MISC & $\begin{array}{l}\text { Characteristics: Shape: oval, height } 4.27 \text { meters, length } 4.88 \text { meters, width } 3.05 \text { meters. } \\
\text { Material of construction: stainless steel. } \\
\text { Capacity: } 201,656 \text { liters. } \\
\text { Specific ancillary equipment: Various jumpers that lead from vessel to the connections } \\
\text { on the cell walls. }\end{array}$ \\
\hline
\end{tabular}




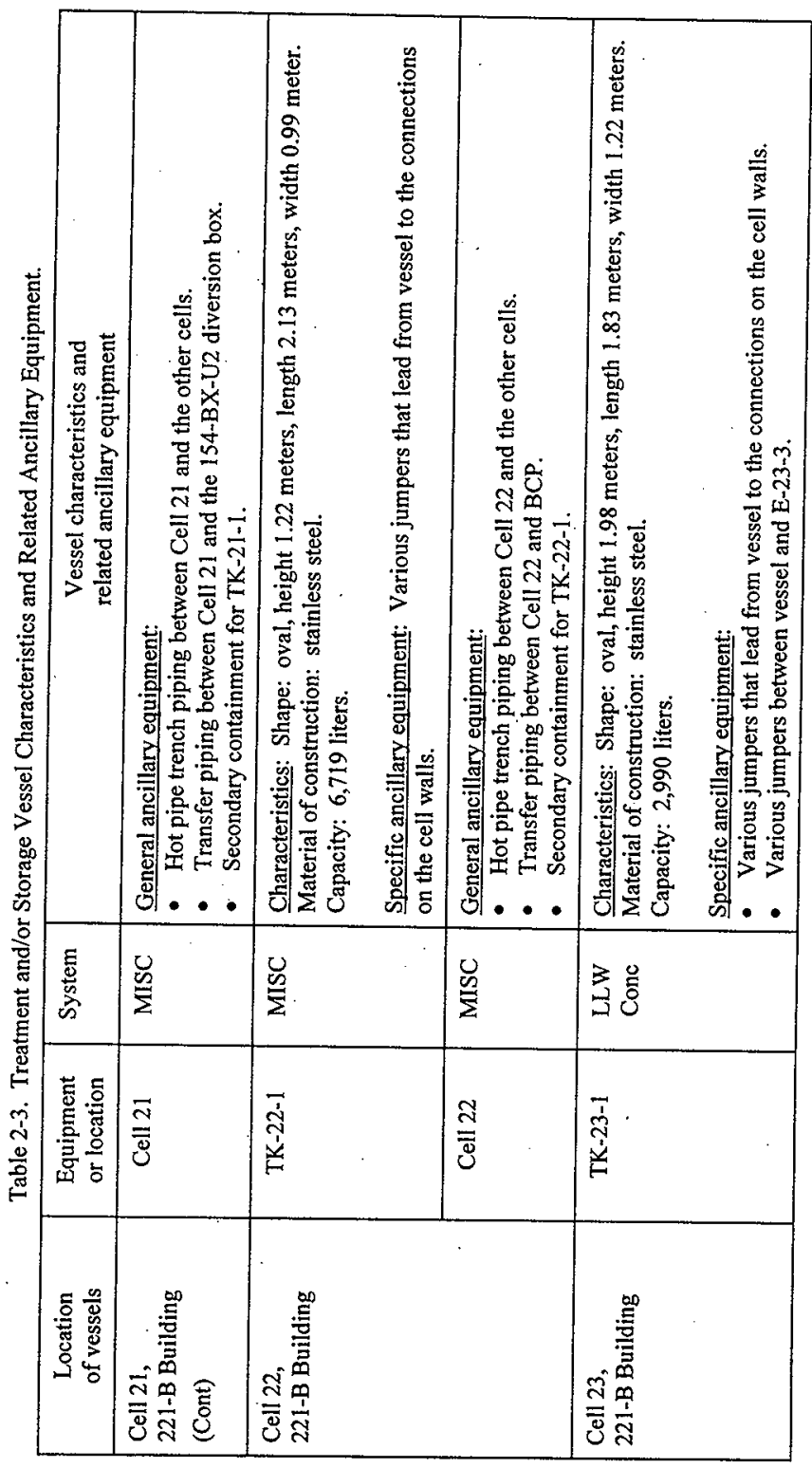




\begin{tabular}{|c|c|c|c|}
\hline $\begin{array}{l}\text { Location } \\
\text { of vessels }\end{array}$ & $\begin{array}{l}\text { Equipment } \\
\text { or location }\end{array}$ & System & $\begin{array}{l}\text { Vessel characteristics and } \\
\text { related ancillary equipment }\end{array}$ \\
\hline \multirow[t]{3}{*}{$\begin{array}{l}\text { Cell 23, } \\
\text { 221-B Building } \\
\text { (Cont) }\end{array}$} & E-23-3 & $\begin{array}{l}\text { LLW } \\
\text { Conc }\end{array}$ & $\begin{array}{l}\text { Characteristics: Shape: basically cylindrical, overall height } 4.88 \text { meters, overall } \\
\text { diameter } 1.52 \text { meters. } \\
\text { Material of construction: stainless steel. } \\
\text { Capacity: } 11,356 \text { liters. } \\
\text { Specific ancillary equipment } \\
\text { Various jumpers that lead from vessel to the connections on the cell walls. } \\
\text { - Various jumpers between vessel and: } \\
\text { - TK-23-1 } \\
\text { - D-23-2. } \\
\text { Process interconnection between vessel and: } \\
\text { - E-23-3-1 } \\
\text { - E-23-3-2 } \\
\text { - D-23-2. }\end{array}$ \\
\hline & E-23-3-1 & $\begin{array}{l}\text { LLW } \\
\text { Conc }\end{array}$ & $\begin{array}{l}\text { Characteristics: Shape: basically cylindrical, overall height } 4.66 \text { meters, overall } \\
\text { diameter } 1.40 \text { meters. } \\
\text { Material of construction: stainless steel. } \\
\text { Capacity: } 0 \text { liters. } \\
\text { Specific ancillary equipment: } \\
\text { Various jumpers that lead from vessel to the connections on the cell walls. } \\
\text { Process interconnection between vessel and E-23-3. }\end{array}$ \\
\hline & E-23-3-2 & $\begin{array}{l}\text { LLW } \\
\text { Conc }\end{array}$ & $\begin{array}{l}\text { CHARACTERISTICS: Shape: basically cylindrical, overall height } 4.66 \text { meters, overall } \\
\text { diameter } 1.40 \text { meters. } \\
\text { Material of construction: stainless steel. } \\
\text { Capacity: } 0 \text { liters. } \\
\text { Specific ancillary equipment: } \\
\text { Various jumpers that lead from vessel to the connections on the cell walls. } \\
\text { Process interconnection between vessel and E-23-3. }\end{array}$ \\
\hline
\end{tabular}




\begin{tabular}{|c|c|c|c|}
\hline $\begin{array}{l}\text { Location } \\
\text { of vessels }\end{array}$ & $\begin{array}{l}\text { Equipment } \\
\text { or location }\end{array}$ & System & $\begin{array}{l}\text { Vessel characteristics and } \\
\text { related ancillary equipment }\end{array}$ \\
\hline \multirow[t]{3}{*}{$\begin{array}{l}\text { Cell 23, } \\
\text { 221-B Building } \\
\text { (Cont) }\end{array}$} & E-23-4 & $\begin{array}{l}\text { LLW } \\
\text { Conc }\end{array}$ & $\begin{array}{l}\text { Characteristics: Shape: basically cylindrical with large number of additional pipes, } \\
\text { overall length } 3.66 \text { meters, overall height } 1.83 \text { meters. } \\
\text { Material of construction: stainless steel. } \\
\text { Capacity: } 0 \text { liters. } \\
\text { Specific ancillary equipment: } \\
\text { Various jumpers that lead from vessel to the connections on the cell walls. } \\
\text { Process interconnection between vessel and D-23-2. }\end{array}$ \\
\hline & D-23-2 & $\begin{array}{l}\text { LLW } \\
\text { Conc }\end{array}$ & $\begin{array}{l}\text { Characteristics: Shape: cylindrical, height } 2.13 \text { meters overall; diameter } 1.52 \text { meters. } \\
\text { Material of construction: stainless steel. } \\
\text { Capacity: } 0 \text { liters. } \\
\text { Specific ancillary equipment: } \\
\text { Various jumpers that lead from vessel to the connections on the cell walls. } \\
\text { Various jumpers between vessel and E-23-3. } \\
\text { Process interconnection between vessel and } \\
\text { - E-23-3 } \\
\text { - E-23-4. }\end{array}$ \\
\hline & Cell 23 & $\begin{array}{l}\text { LLW } \\
\text { Conc }\end{array}$ & $\begin{array}{l}\text { General ancillary equipment: } \\
\text { Hot pipe trench piping between Cell } 23 \text { and the other cells. } \\
\text { - Transfer piping between Cell } 23 \text { and the } 154-\mathrm{B}-\mathrm{U} 4 \text { diversion box BCS. } \\
\text { - Secondary containment for TK-23-1, E-23-3, E-23-4, and D-23-2. }\end{array}$ \\
\hline $\begin{array}{l}\text { Cell 24, } \\
\text { 221-B Building }\end{array}$ & TK-24-1 & LLW & $\begin{array}{l}\text { Characteristics: Shape: oval, height } 4.27 \text { meters, length } 4.88 \text { meters, width } 3.06 \text { meters. } \\
\text { Material of construction: stainless steel. } \\
\text { Capacity: } 52,614 \text { liters. } \\
\text { Specific ancillary equipment: Various jumpers that lead from vessel to the connections } \\
\text { on the cell walls. }\end{array}$ \\
\hline
\end{tabular}




\begin{tabular}{|c|c|c|c|}
\hline $\begin{array}{l}\text { Location } \\
\text { of vessels }\end{array}$ & $\begin{array}{l}\text { Equipment } \\
\text { or location }\end{array}$ & System & $\begin{array}{l}\text { Vessel characteristics and } \\
\text { related ancillary equipment }\end{array}$ \\
\hline $\begin{array}{l}\text { Cell } 24 \text {, } \\
221-B \text { Building } \\
\text { (Cont) }\end{array}$ & Cell 24 & LLW & $\begin{array}{l}\text { General ancillary equipment: } \\
\text { Hot pipe trench piping between Cell } 24 \text { and the other cells. } \\
\text { Transfer piping between Cell } 24 \text { and the Tank Farms BCS the } 221-B B \text { Building } \\
\text { Condensate Pit. } \\
\text { - Secondary containment for TK-24-1. }\end{array}$ \\
\hline \multirow[t]{3}{*}{$\begin{array}{l}\text { Cell 25, } \\
\text { 221-B Building }\end{array}$} & TK-25-1 & LLW & $\begin{array}{l}\text { Characteristics: Shape: cylindrical, height } 4.27 \text { meters; diameter } 2.44 \text { meters. } \\
\text { Material of construction: stainless steel. } \\
\text { Capacity: } 18,548 \text { liters. } \\
\text { Specific ancillary equipment: Various jumpers that lead from vessel to the connections } \\
\text { on the cell walls. }\end{array}$ \\
\hline & TK-25-2 & LLW & $\begin{array}{l}\text { Characteristics: Shape: cylindrical, height } 4.27 \text { meters; diameter } 2.44 \text { meters. } \\
\text { Material of construction: stainless steel. } \\
\text { Capacity: } 18,548 \text { liters. } \\
\text { Specific ancillary equipment: Various jumpers that lead from vessel to the connections } \\
\text { on the cell walls. }\end{array}$ \\
\hline & Cell 25 & LLW & $\begin{array}{l}\text { General ancillary equipment: } \\
\text { - Hot pipe trench piping between Cell } 25 \text { and the other cells. } \\
\text { Transfer piping between Cell } 25 \text { and the 244-AR Vault. } \\
\text { - Secondary containment for TK-25-1 and TK-25-2. }\end{array}$ \\
\hline $\begin{array}{l}\text { Cell 26, } \\
\text { 221-B Building }\end{array}$ & TK-26-1 & ORG & $\begin{array}{l}\text { Characteristics: Shape: cylindrical, height } 2.74 \text { meters; diameter } 2.74 \text { meters: } \\
\text { Material of construction: stainless steel. } \\
\text { Capacity: } 14,763 \text { liters. } \\
\text { Specific ancillary equipment: Various jumpers that lead from vessel to the connections } \\
\text { on the cell walls. }\end{array}$ \\
\hline
\end{tabular}




\begin{tabular}{|c|c|c|c|}
\hline $\begin{array}{l}\text { Location } \\
\text { of vessels }\end{array}$ & $\begin{array}{l}\text { Equipment } \\
\text { or location }\end{array}$ & System & $\begin{array}{l}\text { Vessel characteristics and } \\
\text { related ancillary equipment }\end{array}$ \\
\hline \multirow[t]{2}{*}{$\begin{array}{l}\text { Cell 26, } \\
\text { 221-B Building } \\
\text { (Cont) }\end{array}$} & TK-26-3 & LLW & $\begin{array}{l}\text { Characteristics: Shape: oval, height } 3.81 \text { meters, length } 2.13 \text { meters, width } 1.52 \text { meters. } \\
\text { Material of construction: stainless steel. } \\
\text { Capacity: } 9,922 \text { liters. } \\
\text { Specific ancillary equipment: Various jumpers that lead from vessel to the connections } \\
\text { on the cell walls. }\end{array}$ \\
\hline & Cell 26 & $\begin{array}{l}\text { ORG } \\
\text { and } \\
\text { LLW }\end{array}$ & $\begin{array}{l}\text { General ancillary equipment: } \\
\text { Hot pipe trench piping between Cell } 26 \text { and the other cells. } \\
\text { - Transfer piping between Cell } 26 \text { and the 154-B-U3 diversion box. } \\
\text { - Secondary containment for TK-26-1 and TK-26-3. }\end{array}$ \\
\hline \multirow[t]{3}{*}{$\begin{array}{l}\text { Cell 27, } \\
\text { 221-B Building }\end{array}$} & TK-27-2 & ORG & $\begin{array}{l}\text { Characteristics: Shape: cylindrical, height } 3.66 \text { meters; diameter width } 1.52 \text { meters. } \\
\text { Material of construction: stainless steel. } \\
\text { Capacity: } 7,571 \text { liters. } \\
\text { Specific ancillary equipment: Various jumpers that lead from vessel to the connections } \\
\text { on the cell walls. }\end{array}$ \\
\hline & TK-27-3 & ORG & $\begin{array}{l}\text { Characteristics: Shape: oval, height } 3.81 \text { meters, length } 2.13 \text { meters, width } 1.52 \text { meters. } \\
\text { Material of construction: stainless steel. } \\
\text { Capacity: } 14,385 \text { liters. } \\
\text { Specific ancillary equipment: Various jumpers that lead from vessel to the connections } \\
\text { on the cell walls. }\end{array}$ \\
\hline & TK-27-4 & ORG & $\begin{array}{l}\text { Characteristics: Shape: oval, height } 1.07 \text { meters, length } 1.52 \text { meters, } 2.75 \text { meters. } \\
\text { Material of construction: stainless steel. } \\
\text { Capacity: } 1,022 \text { liters. } \\
\text { Specific ancillary equipment: Various jumpers that lead from vessel to the connections } \\
\text { on the cell walls. }\end{array}$ \\
\hline $\begin{array}{l}\text { Cell 27, } \\
\text { 221-B Building } \\
\text { (Cont) }\end{array}$ & Cell 27 & ORG & $\begin{array}{l}\text { General ancillary equipment: } \\
\text { Hot pipe trench piping between Cell } 27 \text { and the other cells. } \\
\text { - Secondary containment for TK-27-2, TK-27-3, and TK-27-4. }\end{array}$ \\
\hline
\end{tabular}




\begin{tabular}{|c|c|c|c|}
\hline $\begin{array}{l}\text { Location } \\
\text { of vessels }\end{array}$ & $\begin{array}{l}\text { Equipment } \\
\text { or location }\end{array}$ & System & $\begin{array}{l}\text { Vessel characteristics and } \\
\text { related ancillary equipment }\end{array}$ \\
\hline \multirow[t]{4}{*}{$\begin{array}{l}\text { Cell 28, } \\
\text { 221-B Building }\end{array}$} & T-28-1 & MISC & $\begin{array}{l}\text { Characteristics: Shape: roughly cylindrical, height overall } 5.94 \text { meters; rectangular } \\
\text { footprint } 1.22 \text { meters wide and } 1.52 \text { meters long; tower also consists of a cylinder with a } \\
\text { diameter of about } 0.30 \text { meter and a height of about } 4.88 \text { meters. } \\
\text { Material of construction: stainless steel. } \\
\text { Capacity: } 10,001 \text { liters. } \\
\text { Specific ancillary equipment: } \\
\text { - Various jumpers that lead from vessel to the connections on the cell walls. } \\
\text { PG-28-1 (pulse generator for T-28-1). }\end{array}$ \\
\hline & TK-28-3 & ORG & $\begin{array}{l}\text { Characteristics: Shape: cylindrical, height } 4.27 \text { meters; diameter } 2.13 \text { meters. } \\
\text { Material of construction: stainless steel. } \\
\text { Capacity: } 14,385 \text { liters. } \\
\text { Specific ancillary equipment: Various jumpers that lead from vessel to the connections } \\
\text { on the cell walls. }\end{array}$ \\
\hline & TK-28-4 & ORG & $\begin{array}{l}\text { Characteristics: Shape: oval, height } 1.07 \text { meters, length } 1.52 \text { meters, width } 2.75 \text { meters. } \\
\text { Material of construction: stainless steel. } \\
\text { Capacity: } 1,060 \text { liters. } \\
\text { Specific ancillary equipment: Various jumpers that lead from vessel to the connections } \\
\text { on the cell walls. }\end{array}$ \\
\hline & Cell 28 & $\begin{array}{l}\text { MISC } \\
\text { and } \\
\text { ORG }\end{array}$ & $\begin{array}{l}\text { General ancillary equipment: } \\
\text { Hot pipe trench piping between Cell } 28 \text { and the other cells. } \\
\text { Transfer piping between Cell } 28 \text { and the 154-BX-U3 diversion box. } \\
\text { - Secondary containment for T-28-1, TK-28-3, and TK-28-4. }\end{array}$ \\
\hline $\begin{array}{l}\text { Cell 29, } \\
\text { 221-B Building }\end{array}$ & TK-29-2 & MISC & $\begin{array}{l}\text { Characteristics: Shape: oval, height } 4.27 \text { meters, length } 2.90 \text { meters, width } 1.52 \text { meters. } \\
\text { Material of construction: stainless steel. } \\
\text { Capacity: } 57,072 \text { liters. } \\
\text { Specific ancillary equipment: Various jumpers that lead from vessel to the connections } \\
\text { on the cell walls. }\end{array}$ \\
\hline
\end{tabular}




\begin{tabular}{|c|c|c|c|}
\hline $\begin{array}{l}\text { Location } \\
\text { of vessels }\end{array}$ & $\begin{array}{l}\text { Equipment } \\
\text { or location }\end{array}$ & System & $\begin{array}{l}\text { Vessel characteristics and } \\
\text { related ancillary equipment }\end{array}$ \\
\hline \multirow[t]{3}{*}{$\begin{array}{l}\text { Cell 29, } \\
221-\mathrm{B} \text { Building } \\
\text { (Cont) }\end{array}$} & TK-29-3 & NCAW & $\begin{array}{l}\text { Characteristics: Shape: oval, height } 4.27 \text { meters, length } 2.90 \text { meters, width } 1.52 \text { meters. } \\
\text { Material of construction: stainless steel. } \\
\text { Capacity: } 15,520 \text { liters. } \\
\text { Specific ancillary equipment: Various jumpers that lead from vessel to the connections } \\
\text { on the cell walls. }\end{array}$ \\
\hline & TK-29-4 & ORG & $\begin{array}{l}\text { Characteristics: Shape: cylindrical, height } 2.64 \text { meters; diameter } 0.51 \text { meter. } \\
\text { Material of construction: stainless steel. } \\
\text { Capacity: } 492 \text { liters. } \\
\text { Specific ancillary equipment: Various jumpers that lead from vessel to the connections } \\
\text { on the cell walls. }\end{array}$ \\
\hline & Cell 29 & $\begin{array}{l}\text { MISC, } \\
\text { ORG, } \\
\text { and } \\
\text { NCAW }\end{array}$ & $\begin{array}{l}\text { General ancillary equipment: } \\
\text { - Hot pipe trench piping between Cell } 29 \text { and the other cells. } \\
\text { Transfer piping between Cell } 29 \text { and the 154-BX-U7 diversion box. } \\
\text { - Secondary containment for TK-29-2, TK-29-3, and TK-29-4. }\end{array}$ \\
\hline \multirow[t]{2}{*}{$\begin{array}{l}\text { Cell 30, } \\
\text { 221-B Building }\end{array}$} & T-30-1 & MISC & $\begin{array}{l}\text { Characteristics: Shape: roughly cylindrical, height overall } 5.94 \text { meters; rectangular } \\
\text { footprint } 1.22 \text { meters wide and } 1.52 \text { meters long; tower also consists of a cylinder with a } \\
\text { diameter of about } 0.30 \text { meter and a height of about } 4.88 \text { meters. } \\
\text { Material of construction: stainless steel. } \\
\text { Capacity: } 9,971 \text { liters. } \\
\text { Specific ancillary equipment: } \\
\text { - Various jumpers that lead from vessel to the connections on the cell walls. } \\
\text { PG-30-1 (pulse generator for T-30-1). }\end{array}$ \\
\hline & TK-30-3 & ORG & $\begin{array}{l}\text { Characteristics: Shape: oval, height } 4.27 \text { meters, length } 2.90 \text { meters, width } 1.52 \text { meters. } \\
\text { Material of construction: stainless steel. } \\
\text { Capacity: } 15,520 \text { liters. } \\
\text { Specific ancillary equipment: Various jumpers that lead from vessel to the connections } \\
\text { on the cell walls. }\end{array}$ \\
\hline
\end{tabular}




\begin{tabular}{|c|c|c|c|c|c|c|c|c|c|c|}
\hline 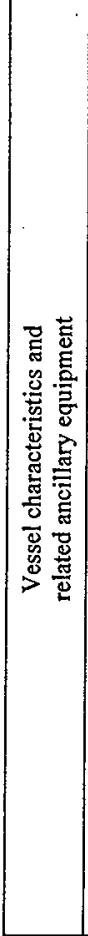 & 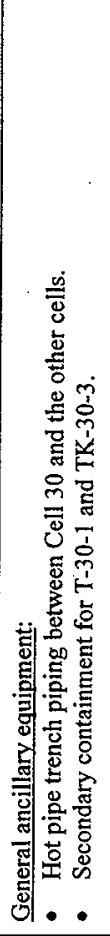 & 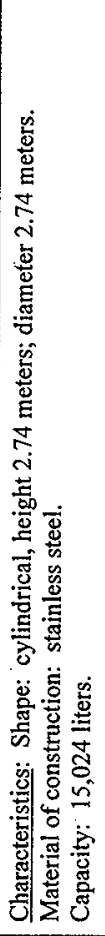 & 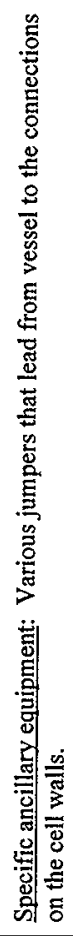 & 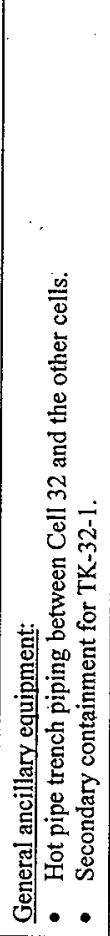 & 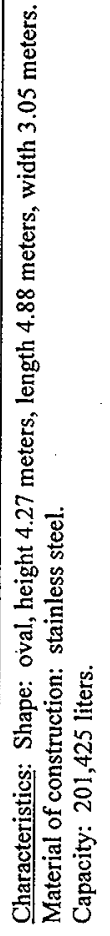 & 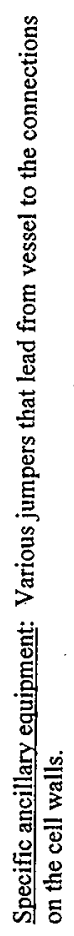 & 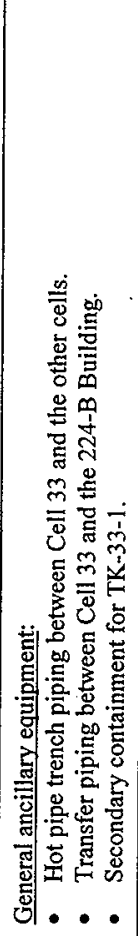 & 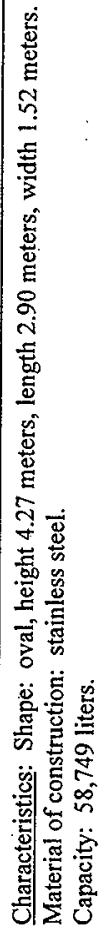 & 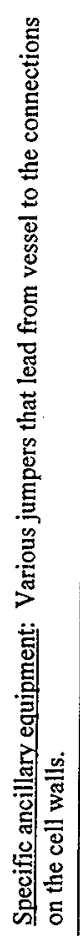 & 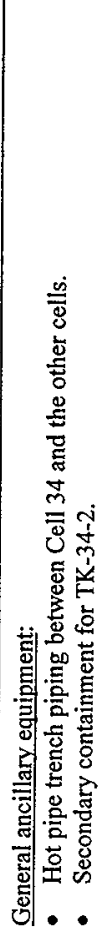 \\
\hline 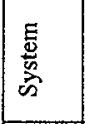 & 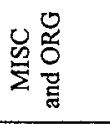 & $\stackrel{\circlearrowright}{ٍ}$ & & $\stackrel{U}{\Sigma}$ & $\underset{⿱ \varpi ు}{\Sigma}$ & & $\stackrel{\circlearrowright}{\mathscr{\Sigma}}$ & 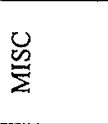 & & $\stackrel{\text { 怘 }}{\sum}$ \\
\hline 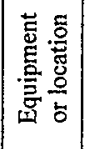 & $\frac{P}{\bar{v}}$ & 范 & & $\frac{\tilde{m}}{\bar{\Xi}}$ & 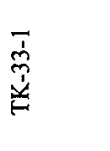 & & $\frac{m}{\bar{v}}$ & 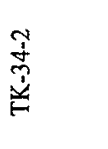 & & $\frac{\vec{m}}{\bar{\Xi}}$ \\
\hline 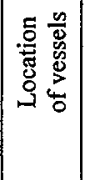 & 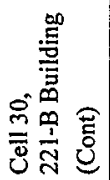 & 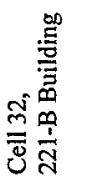 & & . & 毞 & & & 范 & & \\
\hline
\end{tabular}




\begin{tabular}{|c|c|c|c|}
\hline $\begin{array}{l}\text { Location } \\
\text { of vessels }\end{array}$ & $\begin{array}{l}\text { Equipment } \\
\text { or location }\end{array}$ & System & $\begin{array}{l}\text { Vessel characteristics and } \\
\text { related ancillary equipment }\end{array}$ \\
\hline \multirow[t]{2}{*}{$\begin{array}{l}\text { Cell 35, } \\
\text { 221-B Building }\end{array}$} & TK-35-2 & MISC & $\begin{array}{l}\text { Characteristics: Shape: cylindrical, height } 2.74 \text { meters; diameter } 2.74 \text { meters. } \\
\text { Material of construction: stainless steel. } \\
\text { Capacity: } 58,749 \text { liters. } \\
\text { Specific ancillary equipment: Various jumpers that lead from vessel to the connections } \\
\text { on the cell walls. }\end{array}$ \\
\hline & Cell 35 & MISC & $\begin{array}{l}\text { General ancillary equipment: } \\
\text { Hot pipe trench piping between Cell } 35 \text { and the other cells. } \\
\text { - Transfer piping between Cell } 35 \text { and the 224-B Building. } \\
\text { Secondary containment for TK-35-2. }\end{array}$ \\
\hline \multirow[t]{2}{*}{$\begin{array}{l}\text { Cell } 36 \text {, } \\
221-B \text { Building }\end{array}$} & TK-36-1 & MISC & $\begin{array}{l}\text { Characteristics: Shape: oval, height } 4.27 \text { meters, length } 2.90 \text { meters, width } 1.52 \text { meters. } \\
\text { Material of construction: stainless steel. } \\
\text { Capacity: } 58,749 \text { liters. } \\
\text { Specific ancillary equipment: Various jumpers that lead from vessel to the connections } \\
\text { on the cell walls. }\end{array}$ \\
\hline & Cell 36 & MISC & $\begin{array}{l}\text { General ancillary equipment: } \\
\text { - Hot pipe trench piping between Cell } 36 \text { and the other cells. } \\
\text { - Secondary containment for TK-36-1. }\end{array}$ \\
\hline \multirow[t]{2}{*}{$\begin{array}{l}\text { Cell 39, } \\
221-B \text { Building }\end{array}$} & TK-39-1 & LLW & $\begin{array}{l}\text { Characteristics: Shape: oval, height } 3.66 \text { meters, length } 2.90 \text { meters, width } 1.52 \text { meters. } \\
\text { Material of construction: stainless steel. } \\
\text { Capacity: } 13,120 \text { liters. } \\
\text { Specific ancillary equipment: Various jumpers that lead from vessel to the connections } \\
\text { on the cell walls. }\end{array}$ \\
\hline & TK-39-2 & NCAW & $\begin{array}{l}\text { Characteristics: Shape: cylindrical, height } 3.86 \text { meters; diameter } 1.52 \text { meters. } \\
\text { Material of construction: stainless steel. } \\
\text { Capacity: } 6,814 \text { liters. } \\
\text { Specific ancillary equipment: Various jumpers that lead from vessel to the connections } \\
\text { on the cell walls. }\end{array}$ \\
\hline
\end{tabular}




\begin{tabular}{|c|c|c|c|}
\hline $\begin{array}{l}\text { Location } \\
\text { of vessels }\end{array}$ & $\begin{array}{l}\text { Equipment } \\
\text { or location }\end{array}$ & System & $\begin{array}{l}\text { Vessel characteristics and } \\
\text { related ancillary equipment }\end{array}$ \\
\hline \multirow[t]{2}{*}{$\begin{array}{l}\text { Cell } 39 \text {, } \\
\text { 221-B Building } \\
\text { (Cont) }\end{array}$} & TK-39-5 & NCAW & $\begin{array}{l}\text { Characteristics: Shape: oval, height } 3.66 \text { meters, length } 2.90 \text { meters, width } 1.52 \text { meters. } \\
\text { Material of construction: stainless steel. } \\
\text { Capacity: } 7,571 \text { liters. } \\
\text { Specific ancillary equipment: Various jumpers that lead from vessel to the connections } \\
\text { on the cell walls. }\end{array}$ \\
\hline & Cell 39 & $\begin{array}{l}\text { LLW } \\
\text { and } \\
\text { NCAW }\end{array}$ & $\begin{array}{l}\text { General ancillary equipment: } \\
\text { - Hot.pipe trench piping between Cell } 39 \text { and the other cells. } \\
\text { Transfer piping between Cell } 39 \text { and the } 225-\mathrm{B} \text { Building. } \\
\text { - Secondary containment for TK-39-1, TK-39-2, and TK-39-5. } \\
\end{array}$ \\
\hline $\begin{array}{l}\text { Canyon Deck, } \\
\text { 221-B Building }\end{array}$ & TK-100 & MISC & $\begin{array}{l}\text { Characteristics: Shape: cylindrical, height } 3 \text { meters; diameter } 2.5 \text { meters } \\
\text { Material of construction: stainless steel } \\
\text { Capacity: } 15,142 \text { liters } \\
\text { Specific ancillary equipment: None, the tank is isolated and resting on the canyon deck. } \\
\text { General ancillary equipment: Secondary containment for TK-100 comprises the canyon } \\
\text { deck draining into the hot pipe trench and Cell } 34 \text {. }\end{array}$ \\
\hline 221-BB Building & BCP & MISC & $\begin{array}{l}\text { Characteristics: Shape: cylindrical, height } 1.98 \text { meters; diameter } 1.07 \text { meters. } \\
\text { Material of construction: stainless steel. } \\
\text { Capacity: } 8,597 \text {. litters. } \\
\text { Specific ancillary equipment: } \\
\text { Various jumpers that lead from the vessel to the pipe connections within the } \\
\text { 1-BB Building condensate pit. } \\
\text { Transfer piping between BCP and } \\
\text { - Cell } 22 \\
\text { - Cell } 23 \\
\text { - Cell } 24 \\
\text { - 221-BF-A and 221-BF-B } \\
\text { - 216-B-62 Crib and 216-B-64 Retention Basin via the BCS diverting pit. }\end{array}$ \\
\hline
\end{tabular}


DOE/RL-98-12, Rev. 1

$02 / 99$

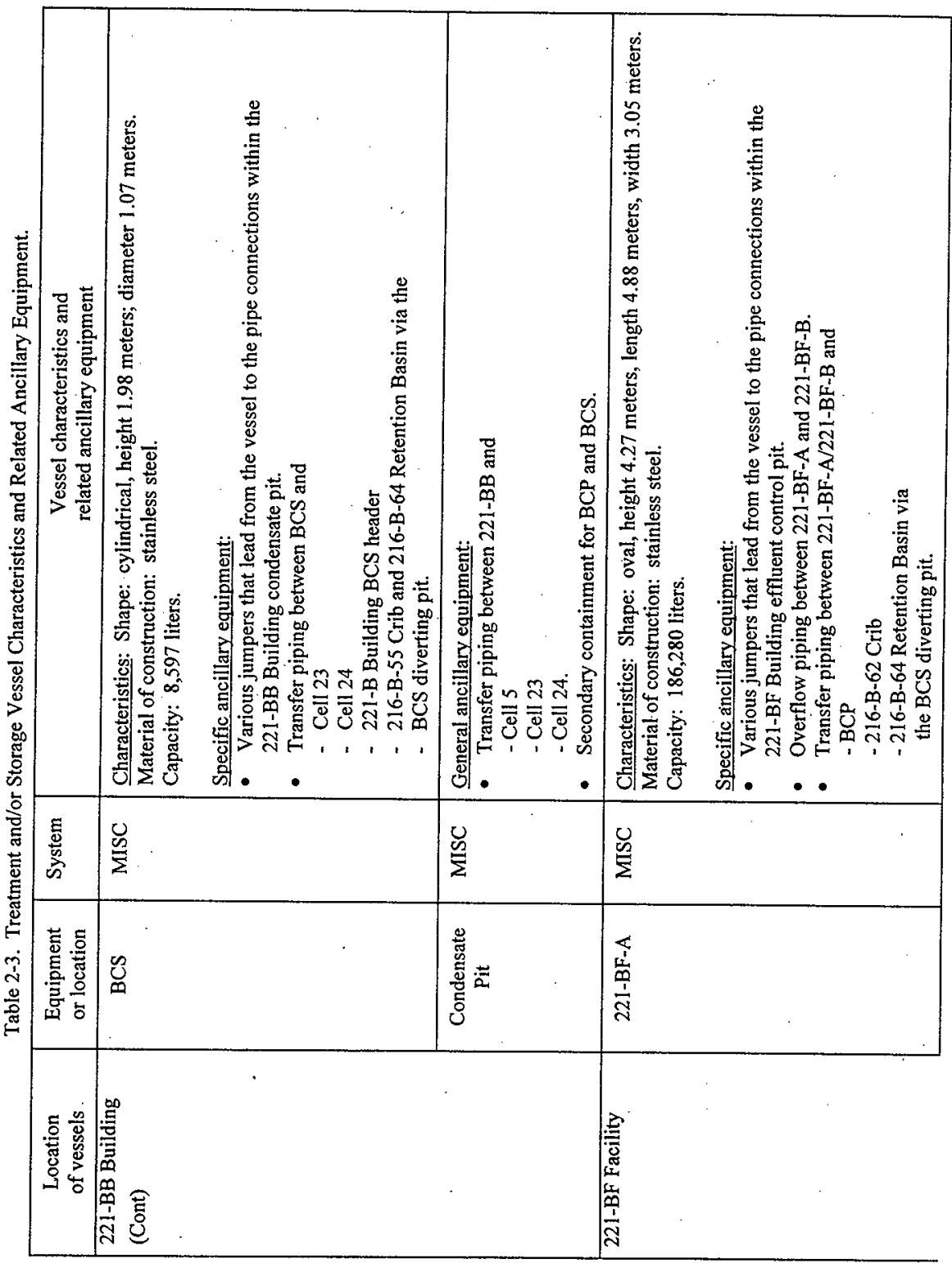


Table 2-3. Treatment and/or Storage Vessel Characteristics and Related Ancillary Equipment.

\begin{tabular}{|c|c|c|c|}
\hline $\begin{array}{l}\text { Location } \\
\text { of vessels }\end{array}$ & $\begin{array}{l}\text { Equipment } \\
\text { or location }\end{array}$ & System & $\begin{array}{l}\text { Vessel characteristics and } \\
\text { related ancillary equipment }\end{array}$ \\
\hline & 221-BF-B & MISC & $\begin{array}{l}\text { Characteristics: Shape: oval, height } 4.27 \text { meters, length } 4.88 \text { meters, width } 3.05 \text { meters. } \\
\text { Material of construction: stainless steel. } \\
\text { Capacity: } 186,280 \text { liters. } \\
\text { Specific ancillary equipment: } \\
\text { - Various jumpers that lead from the vessel to the pipe connections within the } \\
\text { 221-BF Building effluent control pit. } \\
\text { Overflow piping between } 221-\mathrm{BF}-\mathrm{A} \text { and } 221-\mathrm{BF}-\mathrm{B} \text {. } \\
\text { Transfer piping between } 221-\mathrm{BF}-\mathrm{A} / 221-\mathrm{BF}-\mathrm{B} \text { and } \\
\text { - BCP } \\
\text { - 216-B-62 Crib } \\
\text { - 216-B-64 Retention Basin via } \\
\text { the BCS diverting pit. }\end{array}$ \\
\hline 276-BA Facility & 276-BA & ORG & $\begin{array}{l}\text { General ancillary equipment: } \\
\text { - Secondary containment for ISO West. } \\
\text { - Secondary containment for ISO East. }\end{array}$ \\
\hline
\end{tabular}

$\begin{array}{ll}\text { MISC } & =\text { Miscellaneous Tank Storage } \\ \text { NCAW } & =\text { Neutralized Current Acid Waste Storage and Treatment System } \\ \text { LLW } & =\text { Low-Level Waste Storage and Treatment System } \\ \text { LLW Conc } & =\text { LLW Concentrator } \\ \text { ORG } & =\text { Organic Mixed Waste Storage System } \\ \text { TK-xx-xx } & =\text { tank } \\ \text { T-xx-xx } & =\text { tower } \\ \text { E-xx-xx } & =\text { heat transfer equipment } \\ \text { D-xx-xx } & =\text { de-entrainer } \\ 221-B B \text { Building } & =\text { Process Steam and Condensate Building. }\end{array}$


This page intentionally left blank. 


\section{CONTENTS}

43.0 PROCESS INFORMATION.

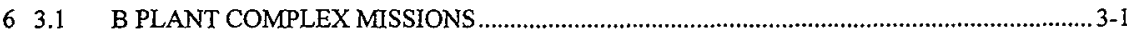

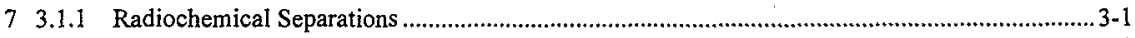

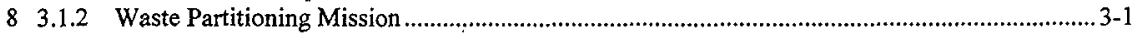

9 3.1.3 Support of Waste Encapsulation and Storage Facility Operations ..............................................3-1

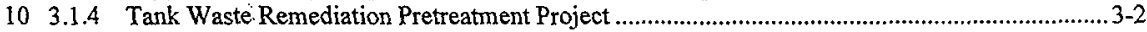

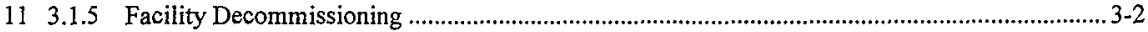

$13 \quad 3.2$ TREATMENT AND/OR STORAGE VESSEL PROCESS DESCRIPTIONS ..........................3-2

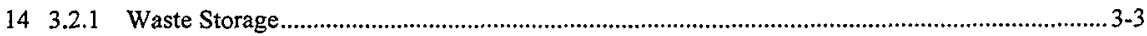

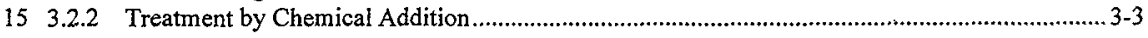

18 3.3.1 Neutralized Current Acid Waste Treatment and Storage System Process Summary .................... 3-3

19 3.3.2 Low-Level Waste Storage and Treatment System Process Summary .......................................... 3-4

$20 \quad 3.3 .3$ Low-Level Waste Concentrator Process Summary ....................................................................... 3-4

$21 \quad 3.3 .4$ Organic Mixed Waste Storage System Process Summary ........................................................ 3-4

22 3.3.5 Miscellaneous Tank Storage System Process Summary ........................................................... 3-4

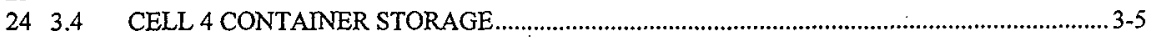

\section{FIGURE}


3

4

5

This page intentionally left blank. 
4 This chapter discusses the missions, the primary processes that occurred in the treatment and/or storage 5 vessel systems, a summary of the historical processes associated with the vessel systems, and the storage processes associated with Cell 4 and the containment building.

\section{3.1 B PLANT COMPLEX MISSIONS}

10 The first mission was radiochemical separations to recover plutonium using the bismuth-phosphate process (1945 to 1952). The second mission was waste partitioning to separate and recover strontium and cesium using a solvent extraction and ion exchange process (1963 to 1983). Associated with the second mission was support for WESF operations (1974 to 1998). The third mission was pretreatment of tank waste using ion exchange (1984 to 1990). The final mission is decommissioning (1995 onward). These activities are summarized in Figure 3-1.

\subsubsection{Radiochemical Separations}

19 The original mission was the recovery of plutonium from irradiated nuclear fuel using the bismuth-phosphate process. B Plant was the second full-scale radiochemical processing plant in the world. B Plant operated from 1945 to 1952 . With newer and more efficient plutonium recovery

facilities becoming operational, B Plant was shutdown in 1952. B Plant was inactive until re-roled for the waste partitioning mission (Section 3.1.2) in the early 1960's. The radiochemical separations mission did not contribute to the waste or waste residues in the B Plant treatment and/or storage systems. An extensive clean out of material from the radiochemical separations mission was conducted to prepare for the waste partitioning mission.

\subsubsection{Waste Partitioning Mission}

Modifications began in 1963 and were completed in 1968. Waste partitioning operations started in 1968 and were completed in 1983 . High-activity waste was partitioned using a combination solvent extraction and ion exchange process. A series of different process configurations were used during waste partitioning. The sources of the high-activity waste were the stored tank waste generated by reprocessing operations at both the Reduction-Oxidation (REDOX) and the Plutonium-Uranium Extraction (PUREX) Plants. After partitioning, the waste was returned to tank farms for continued storage.

The primary isotopes recovered during waste partitioning were strontium-90 via solvent extraction and cesium-137 via ion exchange. Other components partitioned out included promethium-147, technetium-99, rhodium, palladium, and a few other metals. Over 100 million curies of strontium-90 and capsules.

\subsubsection{Support of Waste Encapsulation and Storage Facility Operations}

45. An aspect of the waste partitioning mission was to support operations at WESF. WESF was constructed between 1970 and 1972 for storage of the strontium and cesium capsules produced during the waste partitioning mission. WESF became operational in 1974 and was considered an integral part of the 
1 B Plant Complex. WESF was separated from the B Plant Complex for independent operation during the

2 Transition Phase.

\section{3.1.4 Tank Waste Remediation Pretreatment Project}

6 The purpose of the pretreatment project was to separate the tank waste into high-and low-activity (i.e.,

7 radioactivity) waste streams. The high-activity waste would be sent to the Hanford Waste Vitrification

8 Plant (HWVP) and the low-activity waste would be sent to the Grout Treatment Facility. Pretreatment

used an ion exchange process to do the separation.

10

The B Plant Complex was selected to house the pretreatment process in the mid-1980's. Between 1987 and 1990, the necessary permits were sought to operate the B Plant Complex as the pretreatment facility. In 1990, it was determined that the B Plant Complex could not meet modern safety, seismic, and containment criteria. Because of these regulatory concerns, full-scale pretreatment did not occur.

\subsubsection{Facility Decommissioning}

The final mission, which commenced October 5, 1995, is facility decommissioning. The scope of facility decommissioning is defined in Chapter 8 of the Tri-Party Agreement. Facility decommissioning is divided into three phases: transition, $S \& M$, and disposition.

The Transition Phase involved stabilization, deactivation, and limited decontamination to bring the facility into a safe condition for entry into the long-term S\&M phase. The goal of the Transition Phase preclosure activities was to place the waste management systems into a safe and environmentally secure condition that would require minimum maintenance and care. The Transition Phase was completed in early 1998.

The objectives of the S\&M Phase are to ensure adequate containment of any contaminants left in place, to provide physical safety and security controls, and to maintain the B Plant Complex in a manner that presents no significant risk to human health or the environment. A S\&M Plan will address (1) surveillance, (2) maintenance, (3) quality assurance, (4) radiological controls, (5) hazardous materials protection, (6) health and safety including emergency preparedness, (7) safeguards and security, and (8) cost and schedule.

The Disposition Phase involves taking the B Plant Complex to a final end-state. Disposition Phase activities could include decontamination, dismantling, entombment, closure, and site restoration. For the B Plant Complex, this would include final closure or closure with postclosure care of the three waste management systems (treatment and/or storage in vessels, containerized waste storage, and storage in a containment building).

\subsection{TREATMENT AND/OR STORAGE VESSEL PROCESS DESCRIPTIONS}

Before being regulated, the processing operations conducted in the vessel systems included storage, separations using precipitation and centrifugation, solvent extraction and ion exchange, concentration by evaporation, de-entrainment (removing droplets of liquid traveling in a vapor stream), condensation of a vapor stream, and chemical additions. General process summaries for the individual vessel systems are presented in Section 3.3. Because these processes were not active when the B Plant Complex was regulated as a TSD unit, these processes are not addressed in detail. 
2 Only two processes occurred in the vessel system following regulation in 1987: waste storage

3 (Section 3.2.1) and waste treatment by chemical addition (Section 3.2.2). The decontamination of the

4 organic mixed waste was part of the Transition Phase activities and is discussed in greater detail in

5 Chapter 7.0, Section 7.1.3.

\section{3.2.1 Waste Storage}

9 Waste storage is simply storage of mixed waste in a vessel for more than 90 days. All treatment and/or storage vessel systems in the B Plant Complex were involved in waste storage.

\section{3.2.2 Treatment by Chemical Addition}

14 Treatment by chemical addition was done for waste being transferred to the DST System. The purpose of this treatment was to change some of the characteristics of the waste to meet the DST System waste acceptance criteria (DOE/RL-90-39). Part of the DST System waste acceptance criteria is a pH greater than 12.0 and a nitrite concentration greater than 0.011 molarity $(M)$. The purpose of the acceptance criteria is to obtain the necessary conditions to inhibit corrosion of the carbon steel tanks in the DST System. Generally, sodium hydroxide was added to raise the $\mathrm{pH}$ and sodium nitrite was added to raise the nitrite concentration. Only the treatment and/or storage vessels that routinely treated waste by chemical addition were part of the LLW Storage and Treatment System.

\subsection{TREATMENT AND/OR STORAGE VESSEL SYSTEM PROCESS SUMMARIES}

The process history for each of the treatment and/or storage vessel systems is summarized in the following sections.

\subsubsection{Neutralized Current Acid Waste Treatment and Storage System Process Summary}

The NCAW Treatment and Storage System was part of the Tank Waste Remediation Pretreatment Project. Following regulation as a treatment and/or storage vessel system, the primary process was waste storage. The system included a series of tanks, a sintered metal filter, and an ion exchange column. The vessels involved are identified in Chapter 2.0, Tables 2-2 and 2-3 and in Figure 2-9.

No waste processing operations using the NCAW Storage and Treatment System took place. Some limited, demonstration scale-testing using demineralized waste occurred during 1986 and 1987 . In 1990, the use of the B Plant Complex for pretreatment of tank waste was abandoned. All remaining.NCAW solutions were transferred back to the DST System in May of 1993. The NCAW system is inactive.

The NCAW Storage and Treatment System was spread among six process cells in the 221-B Building and includes 10 vessel systems (Chapter 2.0, Figure 2-9). The specifics of each vessel, its location, physical characteristics, and ancillary equipment are presented in Chapter 2.0, Tables 2-2 and 2-3. 


\section{l 3.3.2 Low-Level Waste Storage and Treatment System Process Summary}

2

The LLW Storage and Treatment System supported the general operations of the B Plant Complex. This was the only vessel system operated after the B Plant Complex became regulated as a TSD unit. The system consisted of a series of storage and treatment tanks. The system was used to collect and store process drainage from the B Plant Complex that would not be transferred to the DST System within 90 days. An example of process drainage included steam condensate contaminated with low-activity radionuclides. Similar liquids were collected from WESF. Before transfer to the DST System, the LLW was treated to meet the DST System waste acceptance criteria.

The LLW Storage and Treatment System was spread among six process cells in the 221-B Building and included eight vessel systems (Chapter 2.0, Figure 2-9). The specifics of each vessel, its location, physical characteristics, and ancillary equipment are presented in Chapter 2.0, Tables 2-2 and 2-3.

This system operated into the Transition Phase because the system supported WESF and the Transition Phase activities. The LLW Storage and Treatment System was deactivated in 1998.

\subsubsection{Low-Level Waste Concentrator Process Summary}

The LLW Concentrator was operated to concentrate the LLW in the LLW Storage and Treatment System. The LLW Concentrator last operated in 1987. Operations were completed before the B Plant Complex was regulated as a TSD unit. Following regulation, the primary process was waste storage in the vessels that comprise the LLW Concentrator.

The LLW Concentrator is located in one process cell and consisted of the three-component waste concentrator, a de-entrainer (that removed droplets of liquid from the vapor coming off the concentrator), a condenser, and two tanks. The three components of the waste concentrator were the concentrator and two tube bundles (a thermal-siphon reboiler and shell-and-tube heat exchanger). The vessels involved are identified in Chapter 2.0, Tables 2-2 and 2-3 and in Figure 2-9.

\subsubsection{Organic Mixed Waste Storage System Process Summary}

The Organic Mixed Waste Storage System was used to store the radiologically contaminated organic solvent left from the waste partitioning mission. Following regulation, the primary process was waste storage. From 1995 through 1997, the organic mixed waste was treated to reduce the concentration of radionuclides (Chapter 7.0, Section 7.1.3). This treatment activity was conducted per the Tri-Party Agreement Milestone M-32-07.

The Organic Mixed Waste Storage System originally consisted of 10 storage tanks (Chapter 2.0, Tables 2-2 and 2-3), eight in the 221-B Building process cells (Chapter 2.0, Figure 2-9) and two external tanks (Chapter 2.0, Figure 2-8) in the 276-BA Facility. One of the external tanks was removed as part of the Transition Phase activities, leaving only nine storage tanks in the Organic Mixed Waste Storage System. Chapter 7.0, Section 7.1.4 provides additional information on the removal of this tank.

\subsubsection{Miscellaneous Tank Storage System Process Summary}

The Miscellaneous Tank Storage System consisted of 21 tanks considered to have handled or contained dangerous waste after 1987. Twenty of these tanks were added to the B Plant Complex Part A, Permit 
1 Application, Form 3, in 1996. One of these tanks was added to the Part A, Form 3, in 1998. Following

2 regulation, the primary process conducted in the Miscellaneous Tank Storage System was waste storage.

3 The waste sources could include past operations (waste partitioning, pretreatment, WESF support) and

4 heels left after tank flushing. These tanks were not necessarily connected. These tanks are identified in

5 Chapter 2.0, Tables 2-2 and 2-3 and in Figures 2-5, 2-6, and 2-9.

6

\subsection{CELL 4 CONTAINER STORAGE}

9 The only process associated with the Cell 4 Container Storage is storage of solid waste. From 1987,

10 containers (e.g., 208-liter containers) of mixed waste have been stored in Cell 4 of the 221-B Building.

11 In addition to the mixed waste, radioactive waste also is stored in Cell 4. This waste was generated from

12 general maintenance-type operations in WESF. The level of radiation associated with these containers is

13 high enough to prevent the containers from being contact handled. The dangerous waste is lead that is

14 part of various types of spent light bulbs.

\section{3.5 CONTAINMENT BUTLDING}

18 The only process associated with the containment building is the storage of solid waste. Since 1987, discarded radioactively-contaminated process equipment was stored at various locations on the canyon deck and in some of the process cells. This discarded equipment is considered a mixed waste because the equipment contains lead in the form of weights, counter weights, or radiation shielding and/or has been contaminated with dangerous waste constituents associated with the pretreatment mission or with storing tank waste. Additional information on the dangerous waste concerns is presented in Chapter 4.0.

The mixed waste stored on the canyon deck could rest directly on the deck. The mixed waste stored in the process cells could rest directly on the floor of the cell. Separate storage containers were not used. Handling the mixed waste was performed remotely because of the high radiation levels associated with the radioactively-contaminated discarded process equipment. Remote handling was performed with two overhead, bridge-type maintenance cranes (41-tonne hoist maximum crane capacity). The cranes were used to remove equipment from the installed position and transport the equipment to the storage location. 
This page intentionally left blank. 


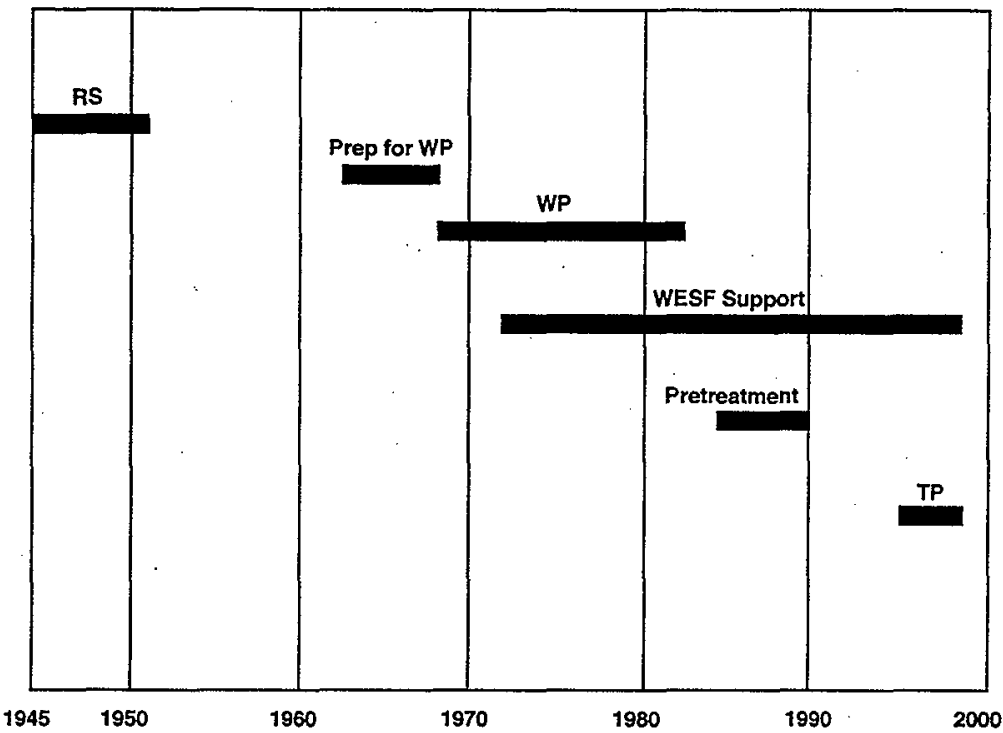

$\begin{array}{lll}\text { RS } & = & \text { Radiochemical Separations, } 1945 \text { to } 1952 \\ \text { Prep for WP } & = & \text { Preparation for the Waste Partitioning Mission, } 1963 \text { to } 1968 \\ \text { WP } & = & \text { Waste Partitioning Mission, 1963 to } 1983 \\ \text { WESF Support } & = & \text { Support of WESF Operations, 1972 to } 1998 \\ \text { Pretreatment } & = & \text { Tank Waste Remediation Pretreatment Project, } 1984 \text { to } 1990 \\ \text { TP } & =\quad \text { Transition Phase of Facility Decommissioning }\end{array}$

Figure 3-1. B Plant Complex Mission Summary through the Transition Phase. 
DOE/RL-98-12, Rev. 1

02/99

1

2

3

4

5

This page intentionally left blank. 
64.1 CHARACTERISTICS OF THE LIQUID MIXED WASTE

74.1 .1 Constituents of Concern: Metals ......................................................................................... 4-1

84.1 .2 Constituents of Concern: Listed Organics …................................................................. 4-1

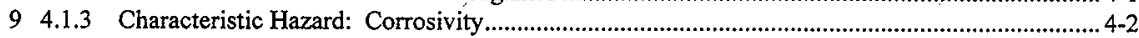

$10 \quad 4.1 .4$ Forms and Hazards of Liquid Mixed Waste: Waste Residues.................................................. 4-2

11 4.1.5 Forms and Hazards of the Liquid Mixed Waste: Tank Heels

\subsection{WASTE CHARACTERISTICS IN THE TREATMENT AND/OR STORAGE VESSEL} SYSTEMS

4.2.1 Listed Waste within the Treatment and/or Storage Vessel Systems

4.2.2 Neutralized Current Acid Waste Storage And Treatment System.......

4.2.3 Low-Level Waste Storage And Treatment System ................................................................ 4-4

4.2.4 Low-Level Waste Concentrator ................................................................................................4-4

4.2.5 Organic Mixed Waste Storage System.

4.3 CELL 4 CONTAINER STORAGE

244.4 CONTANNMENT BUILDING

4.4.1 Discarded Process Equipment in the Containment Building.

TABLES

32 Table 4-1. Tank Waste Constituents of Concern.

34 Table 4-3. Cell 4 Waste Inventory (lead solder on light bulb). 
DOE/RL-98-12, Rev. 1

This page intentionally left blank. 


\subsection{WASTE CHARACTERISTICS}

4 This chapter describes the characteristics of the waste within the B Plant Complex at the end of the

5 Transition Phase activities. There are three general waste types: liquid mixed waste handled by the

6 treatment and/or storage vessel systems, containerized mixed waste from WESF operations, and

7 discarded process equipment.

\section{4.1 CHARACTERISTICS OF THE LIQUID MIXED WASTE}

11 The liquid mixed waste handled in the treatment and/or storage vessel systems primarily came from the waste partitioning mission (Chapter 3.0, Section 3.1.2) and from the Tank Waste Remediation

Pretreatment Project (Chapter 3.0, Section 3.1.4). Both missions processed the high activity waste stored in Hanford Site waste tanks.

The liquid mixed waste consists of liquid and entrained solids with two types of dangerous waste constituents of concern: metals and listed organics. In addition, the liquid mixed waste could have a single characteristic hazard: corrosivity. Any liquid mixed waste remaining in the B Plant waste management systems could be in the form of residue or tank heels.

\subsubsection{Constituents of Concern: Metals}

The following are the eight metal constituents of concern in the liquid mixed waste: arsenic, barium, cadmium, chromium, lead, mercury, selenium, and silver. The primary source of these metals was the residue from the reprocessing of nuclear fuel for the recovery of plutonium. These constituents of concern and their corresponding dangerous waste numbers are presented in Table 4-1.

\subsubsection{Constituents of Concern: Listed Organics}

Before transfer to B Plant Complex, the liquid mixed waste contained various spent organic solvents. The constituents in these solvents resulted in the waste being determined to be listed waste with dangerous waste numbers F001, F002, F003, F004, and F005. Listed, spent solvents (F001, F002, and F004) also were generated at $B$ Plant during radiological decontamination of the canyon crane. The following are the seven listed organics associated with these dangerous waste numbers: acetone, o-cresol, p-cresol, methylene chloride, methyl ethyl ketone, methyl isobutyl ketone, and 1,1,1-trichloroethane.

These constituents of concern and their corresponding dangerous waste numbers are presented in Table 4-1. Within the B Plant Complex, none of these organic constituents of concern are expected to be found in concentrations above the analytical detection limits.

Three of the organic constituents of concern have synonyms that can cause confusion. A common synonym for methylene chloride is dichloromethane. A common synonym for methyl ethyl ketone is 2-butanone. Two common synonyms for methyl isobutyl ketone are hexone and 4-methyl-2-pentanone.

The organic constituents of concern can be classified into three categories based on chemical composition. Acetone, methyl ethyl ketone, and methyl isobutyl ketone are nonhalogenated volatile 
1 organics. Methylene chloride and 1,1,1-trichloroethane are halogenated volatile organics. The p-cresol

2 and o-cresol are phenols.

\section{4.1.3 Characteristic Hazard: Corrosivity}

6 The liquid mixed waste also could be dangerous waste due to the characteristic of corrosivity. This

7 characteristic resulted from adding sodium hydroxide to the waste to meet DST System acceptance

8 requirements before the original transfer of waste from the reprocessing plants. Also, the characteristic

9 of corrosivity can apply to the treatment by chemical addition (Chapter 3.0, Section 3.2.2) done in the

10 B Plant Complex before transferring waste to the DST System.

\subsubsection{Forms and Hazards of Liquid Mixed Waste: Waste Residues}

14 At the end of the Transition Phase activities, waste in the treatment and/or storage tanks could be in two

15 forms. One is waste residue in and on process equipment and structures (e.g., cell floors and tank walls).

16 The second form is tank heels (Section 4.1.5).

The waste residues could include coatings or deposits on various parts of the vessel systems or structures, sludge or solids in the bottoms of tanks or structures (e.g., sumps), and dried tank heels. The sources of the sludge and solids would be the solids carried in with the liquid mixed waste and the solids that precipitated out of the liquid solutions during past operations. Dried tank heels also could be sources of both the sludge and coatings or deposits. The mass and volume of coating and deposits are expected to be small relative to the mass and size of the equipment. The sludges and solids have a potential to be larger, but generally would be only a fraction of the volume of the tank heel.

The waste residues could contain the metal constituents of concern. It is also possible that the waste residue could exhibit the characteristic of corrosivity as a corrosive solid. Whether this characteristic is demonstrated would depend on the composition of the liquid mixed waste before becoming a residue. Analytical work (HNF-3208) conducted on the final tank samples as part of the transition phase activities

The original concentrations of the listed organic constituents of concem in the liquid mixed waste are believed to be below the analytical detection limits. Therefore, the listed organic constituents of concern in the waste residues are not expected to be found. Because of the regulatory requirements of the derived from and mixture rules [WAC 173-303-070(2)(a)(ii)(B)], the waste residue must carry the F001 through F005 dangerous waste numbers.

The condition of the specific treatment and/or storage vessel systems relative to waste residues is discussed in Sections 4.2 and 4.4.

\subsubsection{Forms and Hazards of the Liquid Mixed Waste: Tank Heels}

44 At the end of the Transition Phase activities, liquid mixed waste in the treatment and/or storage tanks

45 could be in two forms. One of these forms is tank heels. The other form is waste residue, discussed in

46 Section 4.1.4. The tank heels contain liquid and also could contain solids or sludges. The concentrations

47 of the constituents of concern in the liquid phase could differ from the concentrations in the solids or 
sludges. The tank heels could contain the metal constituents of concern. The tank heels also could demonstrate the characteristic of corrosivity, which depends on the composition of the tank heel.

The original concentrations of the listed organic constituents of concern in the liquid mixed waste are believed to be below the analytical detection limits. Therefore, the listed organic constituents of concern in the tank heels are not expected to be found. Because of the regulatory requirements of the derived from and mixture rules, the tank heeis must carry the F001 through F005 dangerous waste numbers.

The condition of the specific treatment and/or storage vessel systems relative to waste residues is discussed in Section 4.2.

There is potential for the liquid portion of the tank heels to evaporate during the S\&M Phase. It is not known how much or how fast the liquid would evaporate. It is possible for the tank heels to dry into a waste residue during the $S \& M$ Phase, leaving a waste residue having the form and hazards discussed in Section 4.1.4. Analytical work (HNNF-3208) conducted on the final tank samples as part of the transition phase activities confirmed that the waste is stable and would not react chemically as the tank heels dry and form waste residues.

\subsection{WASTE CHARACTERISTICS IN THE TREATMENT AND/OR STORAGE VESSEL SYSTEMS}

At the end of the Transition Phase, the waste remaining in the treatment and/or storage vessels systems was waste residues and tank heels.

The presence of waste residues and tank heels has been determined by several different methods. The presence of solids and sludges (i.e., waste residue) in the vessels or tanks has been determined by direct measurement using a dip rod. Some waste residues have been observed visually in various parts of the secondary containment. The presence of tank heels has been determined by measurements, both from the tank instrumentation and directly using a dip rod. Small amounts of waste residue in the form of coatings and deposits were suspected to exist but have not been confirmed visually.

\subsubsection{Listed Waste within the Treatment and/or Storage Vessel Systems}

All of the liquid mixed waste processed in the B Plant Complex has been determined to be listed waste subject to the land disposal restrictions ( 40 CFR 268). The applicable listed dangerous waste numbers are identified in Section 4.1.2. Because of the effects of the derived from and mixture rules, all of the treatment and/or storage vessel systems that handled liquid mixed waste are listed waste on disposal.

\subsubsection{Neutralized Current Acid Waste Storage And Treatment System}

The 10 vessels in the NCAW Storage and Treatment System could contain waste residue. The 10 vessels are identified in Chapter 2.0, Tables 2-2 and 2-3 and in Figure 2-9. All 10 vessels (TK-6-2, TK-7-1, TK-7-2, TK-8-1, TK-8-2, TK-13-1, TK-14-2, TK-29-3, TK-39-2, and TK-39-5) are empty and do not contain a tank heel. Additional information is given in Table 4-2. 


\section{4.2.3 Low-Level Waste Storage And Treatment System}

2 The eight vessels in the LLW Storage and Treatment System could contain waste residue. The eight

3 vessels are identified in Chapter 2.0, Tables 2-2 and 2-3 and in Figure 2-9. All eight treatment and/or

4 storage system vessels (TK-9-1, TK-9-2, TK-10-1, TK-24-1, TK-25-1, TK-25-2, TK-26-3, and TK-39-1)

5 are known to contain a tank heel. Additional information is given in Table 4-2.

\subsubsection{Low-Level Waste Concentratór}

The six vessels in the LLW Concentrator System could contain waste residue. The six vessels are identified in Chapter 2.0, Tables 2-2 and 2-3 and in Figure 2-9. Four vessels (TK-23-1, E-23-3, E-23-3-1, and E-23-3-2) are empty and do not contain a tank heel but are known to contain waste residue in the form of solids or a sludge in the bottom of the tanks. The other two vessels (E-23-4 and D-23-2) are empty and do not contain a tank heel. Additional information is given in Table 4-2.

\subsubsection{Organic Mixed Waste Storage System}

The 10 vessels in the Organic Mixed Waste Storage System could contain waste residue. The 10 vessels are identified in Chapter 2.0, Tables 2-2 and 2-3 and in Figures 2-8 and 2-9. Seven vessels (TK-26-1, TK-27-2, TK-27-3, TK-27-4, TK-28-3, TK-29-4, and TK-30-3) are known to contain a tank heel. Two vessels (TK-28-4 and ISO East) are empty and do not contain a tank heel. One vessel (ISO West) was never used to manage organic mixed waste. The ISO West tank was closed adminstratively and removed during Transition Phase activities. Additional information on the administrative closure of ISO west is presented in Section 7.1.4. Additional information for the Organic Mixed Waste Storage System vessels is given in Table 4-2.

\subsubsection{Miscellaneous Tank Storage}

The 21 vessels in the Miscellaneous Tank Storage could contain waste residue. These vessels are identified in Chapter 2.0, Tables 2-2 and 2-3 and in Figure 2-9. Seventeen vessels (E-5-2, T-18-2, TK-18-3, E-20-2, TK-21-1, TK-22-1, T-28-1, TK-29-2, T-30-1, TK-32-1, TK-34-2, TK-35-2, TK-100, BCP, BCS, 221-BF-A, and 221-BF-B) are known to contain a tank heel. One vessel (TK-33-1) is empty and does not contain a heel but is known to contain dry solids. The other three vessels (TK-17-1, TK-17-2, and TK-36-1) are empty and do not contain a tank heel. Additional information is given in Table 4-2.

\subsection{CELL 4 CONTAINER STORAGE}

The only dangerous waste constituent in the Cell 4 mixed waste containers is lead. The source of the lead is radiologically contaminated spent light bulbs from WESF. The total mass of lead waste is 0.0781 kilogram. No liquids are present. A total of seven 208-liter containers of mixed waste are stored. Table 4-3 lists the estimated inventory of waste for each mixed waste container. Additional containers of radioactive-only waste also are stored in Cell 4.

Interim storage in Cell 4 was chosen as the best stabilization method for this material because interim storage is environmentally sound, considered personnel safety, and was cost effective. The radiological hazard from these containers is much greater than the dangerous waste hazard as the radiological dose 
1 rates from these containers is in the rads per hour range. This is sufficiently high to preclude contact

2 handling of these containers. The waste in Cell 4 will remain in place through the S\&M phase.

\subsection{CONTAINMENT BUILDING}

6 Discarded process equipment, lead shielding, and lead counterweights are managed in the containment 7 building. Interim storage in the containment building was chosen as the best stabilization method for the

8 discarded equipment, lead shielding, and lead counterweights because interim storage was

9 environmentally sound, considered personnel safety, and was cost effective. The discarded equipment,

10 lead shielding, and lead counterweights will remain in the containment building through the S\&M phase.

11 This equipment will be dispositioned in conjunction with the rest of the process equipment during the

12 Disposition Phase of the Decommissioning Process.

13

14

\section{4.4.1 Discarded Process Equipment in the Containment Building.}

16 The specific discarded process equipment and their storage locations are identified in HNF-3208. Two 17 waste types associated with the discarded process equipment are waste residues (including listed 18 constituents) and elemental lead. The waste residues are from reprocessed tank waste. The applicable 19 listed dangerous waste numbers are identified in Section 4.1.5. Because of the effects of the 'derived 20. from' and 'mixture' rules, all the discarded process equipment (that had contacted DST liquid mixed 21 waste) stored in the containment building is listed waste. Elemental lead can be integral to the process 22 equipment in the form of weights, counterweights, and/or radiation shielding. However, the radiological hazard associated with this equipment and the associated lead is greater than the dangerous waste hazard.

\subsubsection{Lead in the Containment Building}

A total of $53,192.7$ kilograms of lead is being stored in the containment building. The lead is in the form of portable lead shielding (19.2 percent or 10,208.7 kilograms), lead shielding attached to the 221-B Building (1.2 percent or 613.9 kilograms), lead counterweights ( 7.6 percent or $4,046.1$ kilograms), and lead shielding integral to equipment (72.0 percent or 38,324.0 kilograms). Portable lead shielding consists of blankets and bricks. The lead shielding attached to the 221-B Building consists of lead sheets permanently attached to walls and lead shielding used for a pipe chase. The lead counterweights were used for balancing equipment and jumpers. The equipment with integral lead shielding includes a gilmont shield, a lead house, sample pits and pit covers, and a WESF waste drum cask. The specific inventory of lead shielding, lead counterweights, equipment containing lead, and their storage locations are identified in Table 4 of HNF-3208. The lead shielding, lead counterweights, and lead containing equipment either are potentially or known to be radiologically contaminated. 
1

2

3

4

5

This page intentionally left blank 
Table 4-1. Tank Waste Constituents of Concern.

\begin{tabular}{|l|l|l|}
\hline \multicolumn{1}{|c|}{$\begin{array}{c}\text { Dangerous waste } \\
\text { constituent of concern }\end{array}$} & \multicolumn{1}{|c|}{ CAS number } & \multicolumn{1}{c|}{$\begin{array}{c}\text { Dangerous waste } \\
\text { number }\end{array}$} \\
\hline Arsenic & $7440-38-2$ & D004 \\
\hline Barium & $7440-39-3$ & D005 \\
\hline Cadmium & $7440-43-9$ & D006 \\
\hline Chromium & $7440-47-3$ & D007 \\
\hline Lead & $7439-92-1$ & D008 \\
\hline Mercury & $7439-97-6$ & D009 \\
\hline Selenium & $7782-49-2$ & D010 \\
\hline Silver & $7440-22-4$ & D011 \\
\hline Methylene chloride & $75-09-2$ & F001, F002 \\
\hline 1,1,1-trichlorethane & $71-55-6$ & F001, F002 \\
\hline Acetone & $67-64-1$ & F003 \\
\hline Methyl isobutyl ketone & $108-10-1$ & F003 \\
\hline o-cresol & $95-48-7$ & F004 \\
\hline p-cresol & $106-44-5$ & F004 \\
\hline Methyl ethyl ketone & $71-36-3$ & F005 \\
\hline
\end{tabular}

$\mathrm{CAS}=$ Chemical Abstracts Service 
DOE/RL-98-12, Rev. 1

02/99

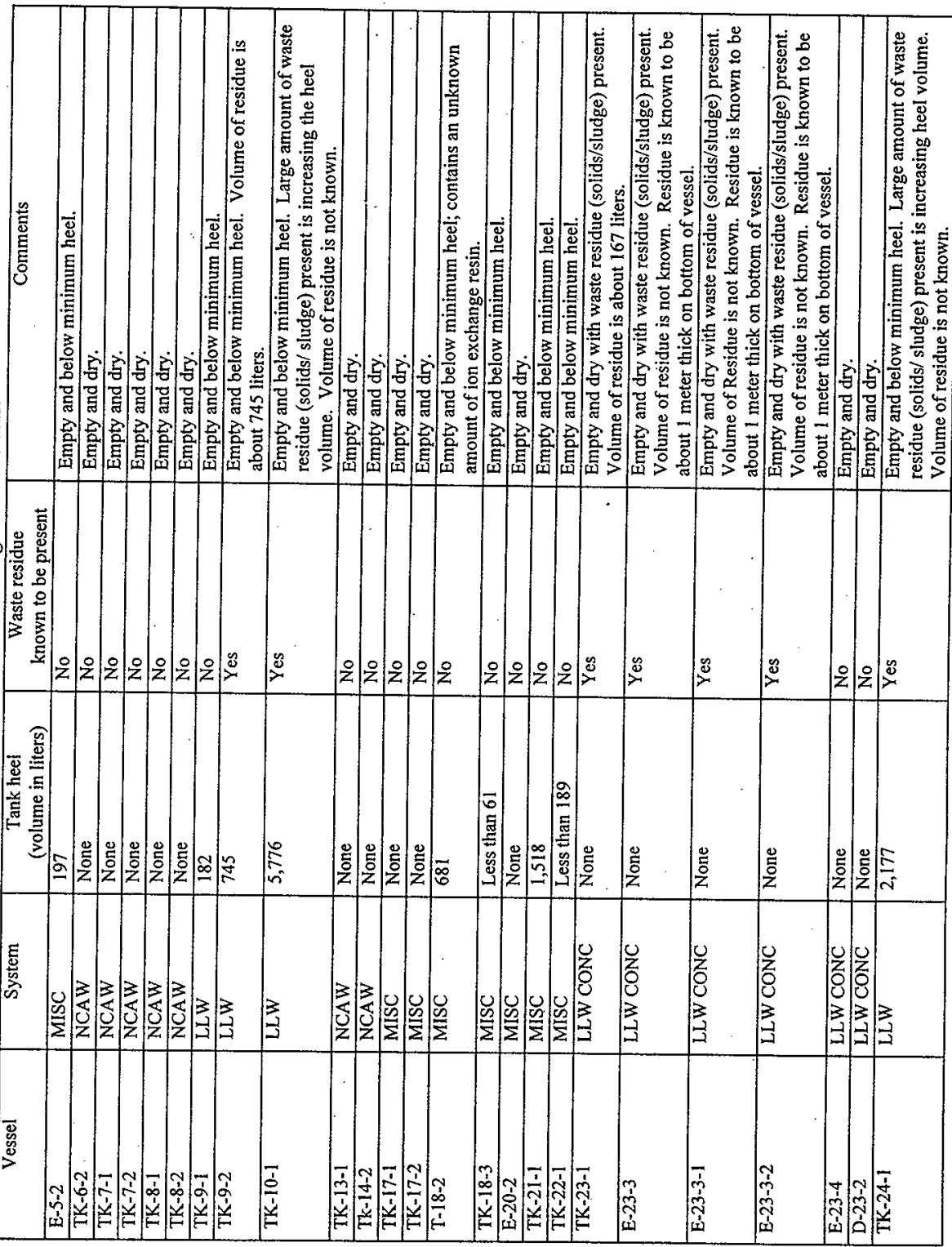


Table 4-2. Treatment and/or Storage Vessels Status.

\begin{tabular}{|c|c|c|c|c|}
\hline Vessel & System & $\begin{array}{c}\text { Tank heel } \\
\text { (volume in liters) }\end{array}$ & $\begin{array}{c}\text { Waste residue } \\
\text { known to be present }\end{array}$ & Comments \\
\hline TK-25-1 & LLW & None & No & Empty and dry. \\
\hline TK-25-2 & $\mathrm{LLW}$ & 7,972 & Yes & $\begin{array}{l}\text { Empty and below minimum heel. Large amount of waste } \\
\text { residue (solids/ sludge) present is increasing heel volume. } \\
\text { Volume of residue is not known. }\end{array}$ \\
\hline TK-26-1 & ORG & 833 & Yes & $\begin{array}{l}\text { Empty and below minimum heel. Large amount of waste } \\
\text { residue (solids/ sludge) present is increasing heel volume. } \\
\text { Volume of residue is not known. }\end{array}$ \\
\hline TK-26-3 & $\overline{\mathrm{LLW}}$ & 246 & Yes & $\begin{array}{l}\text { Empty and below minimum heel. Large amount of waste } \\
\text { residue (solids/ sludge) present is increasing heel volume. } \\
\text { Volume of residue is not known. }\end{array}$ \\
\hline TK-27-2 & ORG & 303 & Yes & $\begin{array}{l}\text { Empty and below minimum heel. Large amount of waste } \\
\text { residue (solids/ sludge) present is increasing heel volume. } \\
\text { Volume of residue is not known. }\end{array}$ \\
\hline TK-27-3 & ORG & 6814 & Yes & $\begin{array}{l}\text { Empty and below minimum heel. Large amount of waste } \\
\text { residue (solids/sludge) present is increasing heel volume. } \\
\text { Volume of residue is not known. }\end{array}$ \\
\hline TK-27-4 & $\mathrm{ORG}$ & 42 & No & Empty and below minimum heel. \\
\hline $\mathrm{T}-28-1$ & MISC & 151 & No & Empty and below minimum heel. \\
\hline TK-28-3 & ORG & 6,814 & Yes & $\begin{array}{l}\text { Empty and below minimum heel. Large amount of waste } \\
\text { residue (solids/sludge) present is increasing heel volume. } \\
\text { Volume of residue is not known. }\end{array}$ \\
\hline TK-28-4 & ORG & None & No & Empty and dry. \\
\hline TK-29-2 & MISC & Less than 189 & No & Empty and below minimum heel. \\
\hline TK-29-3 & $\mathrm{NCAW}$ & None & No & Empty and dry. \\
\hline TK-29-4 & ORG & 4 & No & Empty and below minimum heel. \\
\hline$T-30-1$ & MISC & 151 & No & Empty and below minimum heel. \\
\hline TK-30-3 & ORG & 435 & Yes & $\begin{array}{l}\text { Empty and below minimum heel. Large amount of waste } \\
\text { residue (solids/ sludge) present is increasing heel volume. } \\
\text { Volume of residue is not known. }\end{array}$ \\
\hline TK-32-1 & MISC & 379 & No & Empty and below minimum heel. \\
\hline TK-33-1 & MISC & None & Yes & $\begin{array}{l}\text { Empty and dry with waste residue (solids/sludge) present. } \\
\text { The solids layer is about } 150 \text { millimeters thick. The } \\
\text { volume of solids is estimated at about } 1,950 \text { liters. }\end{array}$ \\
\hline TK-34-2 & MISC & Less than 189 & No & Empty and below minimum heel. \\
\hline TK-35-2 & MISC & Less than 189 & No & Empty and below minimum heel. \\
\hline TK-36-1 & MISC & None & No & Empty and dry. \\
\hline TK-39-1 & LLW & 492 & Yes & $\begin{array}{l}\text { Empty and below minimum heel with waste residue } \\
\text { (solids/sludge) present. Volume of residue is not known. }\end{array}$ \\
\hline
\end{tabular}


DOE/RL-98-12, Rev. 1

02/99

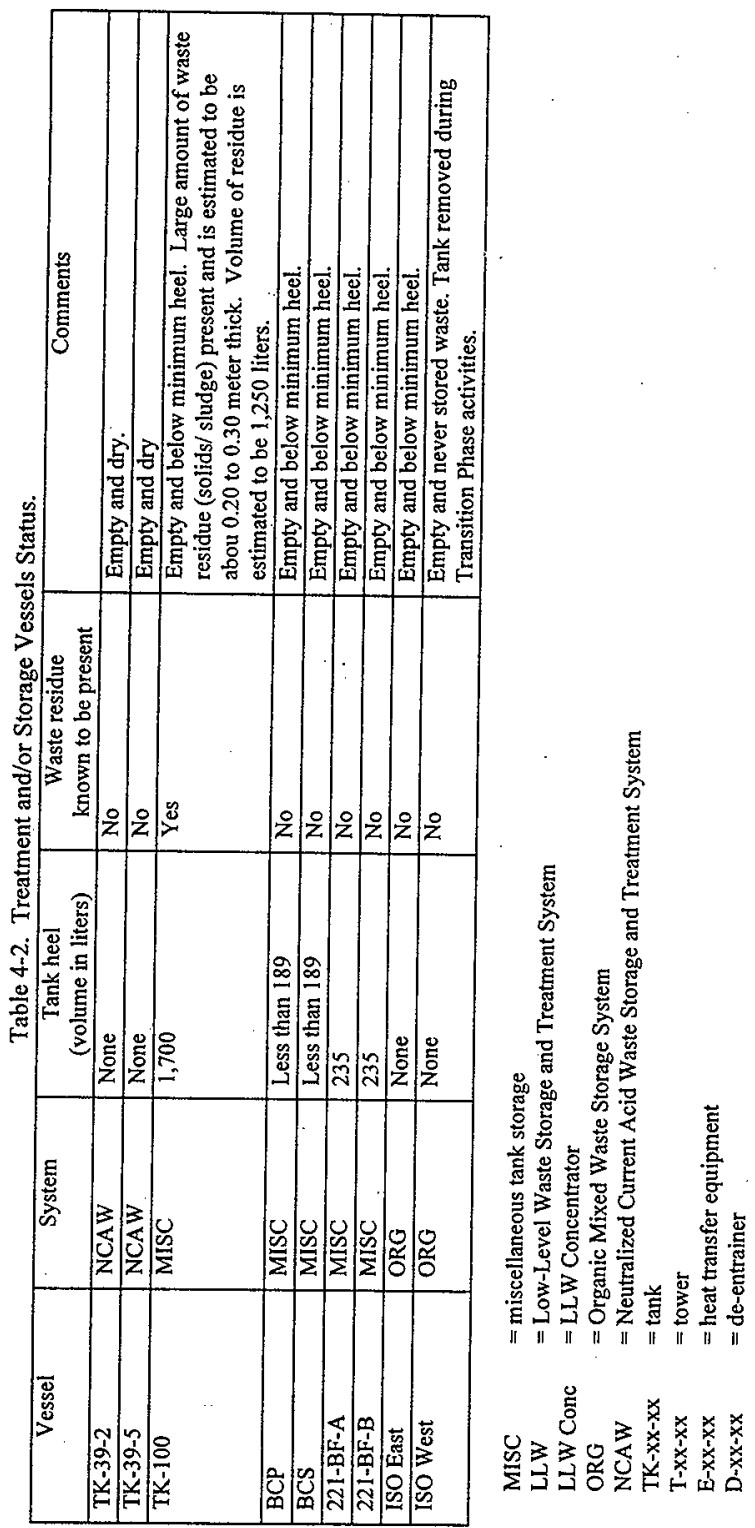


Table 4-3. Cell 4 Waste Inventory (lead solder on light bulb).

\begin{tabular}{|l|c|c|c|c|}
\hline $\begin{array}{c}\text { Container } \\
\text { number }\end{array}$ & $\begin{array}{c}\text { Total weight } \\
\text { (kilograms) }\end{array}$ & $\begin{array}{c}\text { Container } \\
\text { weight } \\
\text { (kilograms) }\end{array}$ & $\begin{array}{c}\text { Total waste } \\
\text { weight } \\
\text { (kilograms) }\end{array}$ & $\begin{array}{c}\text { Approximate weight of } \\
\text { regulated constituent } \\
\text { (kilogram) }\end{array}$ \\
\hline KT-984 & 80.3 & 34.9 & 45.4 & 0.0113 \\
\hline KT-993 & 75.3 & 34.9 & 40.4 & 0.0113 \\
\hline KT-A12 & 106.1 & 34.9 & 71.2 & 0.0113 \\
\hline KT-A15 & 75.7 & 34.9 & 40.8 & 0.0113 \\
\hline KT-983* & 90.7 & 34.9 & 55.8 & 0.0113 \\
\hline KT-A24 & 51.9 & 34.9 & 17.0 & 0.0113 \\
\hline KT-A16 & 45.0 & 34.9 & 17.0 & 0.0113 \\
\hline TOTALS & 525.0 & 244.3 & 280.7 & 0.0781 \\
\hline
\end{tabular}

* No inventory sheet was found for this container. All values are estimates. 
DOE/RL-98-12, Rev. 0

02/99

This page intentionaliy left blank. 


\section{CONTENTS}

3

45.0 GROUNDWATER. 5-1

5 
DOE/RL-98-12, Rev. 1

02/99

1

2

3

4

5

This page intentionally left blank. 


\subsection{GROUNDWATER}

4 As noted in Section 2.0, the secondary containment system for the 221-B Building has several potential

5 pathways for either RCRA dangerous waste and for Comprehensive Environmental Response,

6 Compensation, and Liability Act (CERCLA) of 1980 hazardous substances to have entered the soils

7 under the B Plant Complex. If released, the CERCLA hazardous substances would have originated from

8 B Plant Operations before August 1987 and the RCRA dangerous waste would have originated from

9 operations conducted after August 1987. It is not known how much or if any RCRA dangerous waste or

10 CERCLA hazardous substances might have entered the soil. It is not know to what degree, if any, that

11 the B Plant Complex has affected the groundwater in the 200 East Area. The final closure activities for

12 the B Plant TSD unit and the decontamination and decommissioning activities performed will need to

13 determine if any contamination occurred from a RCRA dangerous waste or a CERCLA hazardous

14 substance in the soil surrounding the 221-B Building.

15

16 In accordance with the Tri-Party Agreement (Ecology et al. 1996), groundwater in the 200 East Area will

17 be included in the 200-PO-1 operable unit and will be investigated under the CERCLA remedial

18 investigation/ feasibility study process. Therefore, groundwater investigation/remediation is not

19 addressed as part of this preclosure work plan. Work on the 200-PO-1 operable unit will be coordinated

20 with the final disposition process but will not occur until the final groundwater operable unit workplan

21 has been approved. Additional information on the 200-PO-I operable unit can be found in

22 DOE/RL-95-100, DOE/RL-96-59, and DOE/RL-96-66. 
DOE/RL-98-12, Rev. 1

$02 / 99$

1

2

3

4

5

This page intentionally left blank. 
CONTENTS

2

3

46.0 CLOSURE STRATEGY AND PERFORMANCE STANDARDS $6-1$ 5

6 6.1 OVERALL PROCESS TO REACH CLOSURE. $6-1$ 7

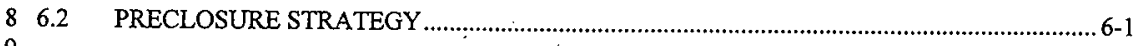

9

$10 \quad 6.3$ PRECLOSURE ACTIVITIES.. 6-1

12 6.4 CLOSURE OF THE TSD UNIT

13 6.4.1 Key Decisions for Developing the Closure Plan... 6-2

14 6.4.2 Closure Strategy and Closure Activities. 6-3 15

$16 \quad 6.5$ POSTCLOSURE. 17 
DOE/RL-98-12, Rev. 1

$02 / 99$

This page intentionally left blank. 
4 This chapter outlines the overall closure process. The preclosure strategies, preclosure activities, closure 5 strategies, closure performance standards, and closure activities are identified.

\section{6.1 OVERALL PROCESS TO REACH CLOSURE}

9 Closure will be reached as part of the three phases of the Facility Decommissioning process. Preliminary 10 closure strategies, closure performance standards, and possible closure activities were identified during

11 the Transition Phase and are documented in the following sections. The TSD unit will remain inactive

12 and stable through the S\&M Phase. The closure strategies, closure performance standards, and closure activities will be developed and documented within the closure plan during the Disposition Phase.

\subsection{PRECLOSURE STRATEGY}

17 The preclosure strategy is accomplished through the Facility Decommissioning process. The decommissioning process requires meeting end point criteria to:

- Bring the facility into a condition that is safe and environmentally secure

- Remove, reduce, or stabilize chemical hazards

- Allow for a long-term S\&M phase before final closure during the decommissioning phase

- Reduce or eliminate the potential for dangerous waste to enter the environment.

25 Meeting the criteria is achieved by meeting specific end points. The stable condition established is

26 maintained through the S\&M phase.

\subsection{PRECLOSURE ACTIVITIES}

30 The following specific preclosure activities for the B Plant TSD unit and the components in the TSD unit

31 were developed to meet the preclosure strategy.

32

33 - Document the physical characteristics and locations of the equipment and components (Section 2.0)

34 - Document the process information (Section 3.0)

35 - Document the waste characteristics and constituents of concern (Section 4.0)

36 - Isolate the tanks and vessels (Section 7.1.2)

37 - Remove and dispose of the organic mixed waste (Section 7.1.3)

38 - Remove the external storage tank that never managed waste (Section 7.1.4)

39 - Continue to manage the mixed waste in Cell 4 (Section 7.2)

40 - Continue to manage discarded process equipment and lead shielding materials in the containment

41 building (Section 7.3)

42 - Document the interim statius compliance measures at the end of the Transition Phase (Section 7.4)

43 - Develop a complete list of the hazardous substances and dangerous waste remaining in the TSD unit

44 and throughout the B Plant Complex (HNF-3208)

45 - Develop specific end-point criteria performance standards for the preclosure activities

46 (WHC-SD-WM-TPP-054). 


\subsection{CLOSURE OF THE TSD UNIT}

2 The closure plan will be developed during the Disposition Phase and will define how the TSD unit is to

3 be closed. The closure plan also will define how closure will be integrated with final decontamination

4 and decommissioning of the B Plant Complex. The closure plan includes a description of the TSD unit,

5 processing history, waste characteristics and waste types, the strategy for closure, the specific closure

6 activities, and postclosure requirements if any dangerous waste is left in place. The closure plan will

7 meet the regulatory requirements of WAC 173-303-610 and follow the Tri-Party Agreement

8 requirements in Chapters $6.0,8.0$, and 9.0. Other applicable regulations and guidance will be used as

9 appropriate. Other site actions, such as the Canyon Deactivation Initiative, also are expected to have an

10 affect on closure plan development.

\section{6.4.1 Key Decisions for Developing the Closure Plan}

14 Key decisions must be resolved before the closure plan can be finalized. Many of the key decisions overlap both decontamination and decommissioning and closure with some requiring the integration of

the CERCLA and RCRA requirements. Key decontamination and decommissioning decision points that affect the closure strategy and closure activities include, but are not limited to the following:

18

- Land use within and around the 200 East Area

- Overall strategy for cleanup of the 200 East Area

- Disposition of the canyon tanks, vessels, and equipment, including the failed process equipment

- Disposition of the canyon building

- Disposition of the various structures within the B Plant Complex

- Disposition of the process pipes and lines embedded within the B Plant canyon structure, (i.e., cellto-cell transfer lines)

- How the RCRA closure requirements are integrated into the CERCLA decontamination and decommissioning requirements

- Results of the Canyon Deactivation Initiative

- Disposition of the non-contact radioactive and mixed waste stored in Cell 4.

The key decisions for the TSD unit closure include, but are not limited to the following:

- Definition of the cleanup and dangerous waste decontamination methodologies

- Development of the specific cleanup criteria and performance standards (e.g., soil cleanup levels)

- Development of sampling and analysis information, either in the closure plan or as a separate document, needed to confirm that closure or clean-closure has been achieved, including, but not limited to the following:

- Constituents of concern for the sampling and analysis

40 - Appropriate analytical methods

41 - Use of field screening, if appropriate

42 - Sampling methodology for various media and locations

43 - Number of samples required

44 - Disposition of the TSD unit cleanup and decontamination residues from the closure activities. 


\section{6.4.2 Closure Strategy and Closure Activities}

2 The closure strategies and activities for the B Plant Complex TSD unit will be documented within the

3 closure plan. The strategies and activities will be integrated with the decontamination and

4 decommissioning activities for the B Plant Complex. Possible clean closure strategies and activities

5 include, but are not limited to the following:

6

7 - Removal of equipment, tanks, vessels, and structures with disposal as mixed waste

8 - Separation of lead counter-weights and shielding from tanks, vessels, and equipment, including the

9 failed process equipment in the containment building

10 - Decontamination of tanks, vessels, equipment, and structures to a 'clean debris surface' using the

11 approved technologies at the time of closure

12 - Item-specific decontamination method developed during the Disposition Phase

13 - Closure of the 276-BA secondary containment structure using the radioactive component of the

14 organic mixed waste as an indicatior of the presence or absence of mixed waste (i.e., not detecting

15 radiological contamination would indicate that no mixed waste contaminated the secondary

16 containment and the structure could be clean closed)

17 - Removal and demolition of structures (221-BB, 221-BF, and the 276-BA) associated with the TSD

18 unit

19 - Where possible, sample soil, concrete, and equipment to verify that concentrations of dangerous

20 waste are below cleanup performance standards.

22 Possible closure strategies and activities involving land disposal include, but are not limited to the

23 following:

25 - Use the 221-B canyon building as a structure for land disposal of radioactive waste

26 - Cover and cap the 221-B canyon building to avoid leaching of radioactive and dangerous

\section{6.5 POSTCLOSURE}

32 For a canyon facility such as B Plant, there is a possibility that some type of dangerous waste will remain in place after compietion of the Disposition Phase. This cannot be estimated until the decontamination and decommissioning and closure activities are defined during the Disposition Phase. The Tri-Party Agreement and the Hanford Facility RCRA Permit define how closure of the TSD unit can still be reached if not all the dangerous waste or dangerous waste residues can be removed during decontamination and decommissioning and closure. The postclosure care requirements are developed only if dangerous waste or dangerous waste residues are left in place after closure. Any postclosure care requirements will be defined within the closure plan. If required, postclosure care requirements could be integrated with the post-remediation groundwater monitoring requirements established for the 200-PO-1 
DOE/RL-98-12, Rev. 1

$02 / 99$

This page intentionally left blank. 
DISPOSITION OF TREATMENT AND/OR STORAGE VESSELS DURING THE

7 TRANSITION PHASE

8 7.1.1 Isolation of the Treatment and/or Storage Vessels.

Treatment and/or Storage Vessels Emptied Before October 5, 1995

Disposition of the 276-BA Facility External Organic Storage Vessel.

12 7.1.5 Disposition of Waste Encapsulation and Storage Facility TK-100

\section{APPENDIX}


DOE/RL-98-12, Rev. 1

02/99

1

2

3

4

5

This page intentionally left blank. 


\subsection{CLOSURE ACTIVITIES}

4 This chapter describes the closure activities implemented during the Transition Phase. The primary

5 objective of the Transition Phase activities was to place the B Plant Complex in a safe configuration with

6 respect to human health and the environment. A secondary objective was to close the TSD unit to the

7 greatest extent possible. Activities required to achieve final closure will be documented in a closure plan

8 implemented during the Disposition Phase and in conjunction with the overall facility disposition.

\subsection{DISPOSITION OF TREATMENT AND/OR STORAGE VESSELS DURING THE TRANSITION PHASE}

13 The closure activities and disposition of the treatment and/or storage vessels during the Transition Phase 14 are discussed in the following sections.

\subsubsection{Isolation of the Treatment and/or Storage Vessels}

18 The main Transition Phase closure activity associated with treatment and/or storage vessel systems was isolation. Isolation involved removing selected jumpers connecting each treatment and/or storage vessels to other vessels or liquid sources outside the B Plant canyon (e.g., DST System, chemical addition tanks, water lines, etc.) and installing blanks to prevent liquids from reaching the tanks. In addition, other jumpers (electrical, steam, water, chemical addition, and/or instruments) were removed, as necessary, to isolate the treatment and/or storage vessels.

\subsubsection{Treatment and/or Storage Vessels Emptied Before October 5, 1995}

27

Before the start of facility decommissioning on October 5, 1995, a total of 14 treatment and/or storage vessels in three systems had been emptied. These 14 vessels are as follows.

- NCAW Treatment and Storage System vessels: TK-6-2, TK-7-2, TK-8-2, TK-14-2, TK-39-2, TK-7-1, TK-8-1, TK-13-1, TK-29-3, and TK-39-5.

- Miscellaneous Storage Tanks: TK-17-1, TK-17-2, and TK-36-1.

- LLW Storage and Treatment System vessel: TK-25-1.

The emptied vessels comprise all 10 of the NCAW Treatment and Storage System vessels. In Miscellaneous Tank Storage, three of the 20 vessels were emptied. Emptying the NCAW and Miscellaneous Tank Storage vessels occurred in 1993 as part of the transfer of the tank waste back to the DST System. In the LLW Storage and Treatment System, one out of eight vessels was emptied.

\subsubsection{Disposition of the Organic Mixed Waste}


Actions" was established. M-32-07 included a target milestone M-32-07-T05 for treating the mixed

2 organic waste to support disposition of the waste for offsite disposal or onsite compliant interim storage.

3 The treatment method was to chemically wash the organic and filter the solids. This treatment activity

4 was conducted from 1995 to 1997 and successfully reduced the radionuclide concentration in the organic

5 mixed waste.

6

7 The completion of the treatment effort allowed for the transfer of the bulk of the organic waste from the

8 221-B Building canyon vessels to an external storage tank (ISO East) in the 276-BA Facility during

9 1997. This transfer allowed the canyon and the facility deactivation to proceed. In late 1997, this

10 organic mixed waste was shipped to Diversified Scientific Services, Inc., in Tennessee, for disposal by

11 incineration.

\subsubsection{Disposition of the 276-BA Facility External Organic Storage Vessel}

To support disposition of the organic mixed waste (Section 7.1.3), the 276-BA Facility and two storage tanks (ISO East and ISO West) were established for interim storage of the organic mixed waste until shipped offsite for disposal. Only one of the tanks (ISO East) was needed to store the organic mixed waste removed from the B Plant Canyon. The ISO West tank never stored or handled any organic mixed waste. An administrative closure process was initiated to allow the ISO West tank to be removed from the 276-BA Facility for reuse at WESF to manage liquid, nondangerous LLW.

To support the administrative closure, an administrative closure technical data synopsis (98-EAP-135) for the ISO West tank was prepared and submitted to Ecology on March 4, 1998 (Appendix B). The synopsis and the supporting documentation show that, during operations in the 276-BA Facility, the ISO West tank did not, at any time, manage, store, or contact dangerous or mixed waste. Closure was accepted by Ecology (Ecology 1998a).

The synopsis includes the following information:

- A description of the ISO West tank and the 276-BA Facility

- The operating history of the ISO West tank and the 276-BA Facility

- Identification of the documents used to support the administrative closure

- Certification by the owner/operator (DOE/RL) and by the co-operator (Fluor Daniel Hanford, Inc.) that the synopsis was "true, accurate, and complete".

After closure, the ISO West tank was slated for reuse at WESF to manage liquid LLW. With the administrative closure costing approximately $\$ 10,000$ and an equivalent tank costing approximately $\$ 50,000$, the B Plant Complex and WESF were able to avoid approximately $\$ 40,000$ in cost. To support the WESF de-coupling from the B Plant Complex, the ISO West tank needed to be transferred from the B Plant Complex during May 1998. After consultation with Ecology and at the owner/operator's and co-operator's risk of the need to address any public comments, the ISO West tank was relocated for reuse at WESF in May of 1998.

\subsubsection{Disposition of Waste Encapsulation and Storage Facility TK-100}


2 Although the TK-100 System had been managed as a LLW system not subject to the requirements of the 3 RCRA, it was determined in early 1998 that the system had been storing mixed waste. Therefore, the 4 TK-100 System was closed in accordance with the requirements in WAC 173-303-610. This included 5 preparing and submitting a closure plan for the TK-100 System (98-EAP-494). The closure plan was 6 subsequently approved by Ecology (Ecology 1998b) and the closure certifications submitted to Ecology 7 in November 1998 (98-EAP-588). The vault and the piping were clean closed and will continue to 8 support LLW management at WESF. Both the vault and the piping are integral to the 225-B Building.

9 The closure performance standard for TK-100 was to move the tank into the B Plant Complex.

10

11

The TK-100 was moved into the B Plant Canyon in August 1998 and placed on the canyon deck at Cell 34. The TK-100 contains listed mixed waste in the form of spent halogenated solvent (waste code F001) in the tank heel. Because TK-100 was used to support mixed waste operations at B Plant Complex and because the presence of a 1,700 liter heel (1,250 liters of solids/sludges and 450 liters of free-liquid), TK-100 is managed as part of the Miscellaneous Tank Storage System.

\subsection{CELL 4 ACTIVITIES DURING THE TRANSITION PHASE}

Cell 4 will continue storing highly radioactive waste and mixed waste through the S\&M Phase. The primary Transition Phase closure activities were the addition of two containers (KT-A16 and KT-A24) into Cell 4 and the documentation of the dangerous waste inventory in Cell 4 (Chapter 4.0, Section 4.3). No other closure activities occurred during the Transition Phase.

\subsection{CONTAINMENT BUILDING ACTIVITIES DURING THE TRANSITION PHASE}

The containment building will continue to store discarded process equipment through the S\&M Phase. The discarded process equipment was moved around within the containment building during the Transition Phase. The primary Transition Phase activities in the containment building were placing the discarded equipment in appropriate locations and documenting the hazards (Chapter 4.0, Section 4.4).

\subsection{INTERIM STATUS COMPLIANCE AT THE END OF THE TRANSITION PHASE}

During the S\&M Phase, some of the waste management units within B Plant Complex will not meet all of the requirements for interim status compliance invoked by WAC 173-303-400. The specific requirements of concern include secondary containment, container labeling, monitoring, inspections, and annual integrity testing of tank systems. The inability of the waste management systems to meet interim status requirements was a major driver for shutdown and decommissioning. For B Plant Complex to be in compliance with the interim status requirements during decommissioning would be impractical and expensive.

The Transition Phase closure activities were designed to addresses the regulatory and environmental concerns caused by not being able to meet the interim status requirements. Therefore, during the S\&M Phase, the waste management systems will be in an environmentally safe and stable condition that protects human health and the environment without meeting these interim status requirements. 


\section{7.4.1 Treatment and/or Storage Vessels}

2 For the hazards associated with each treatment and/or storage vessel, refer to Chapter 4.0, Section 4.2.

3 The regulatory requirements, treatment and/or storage vessels affected, noncompliance justification, and

4 compliance measures are described in the following sections:

5

6 7.4.1.1 Requirement: Daily visual inspections of aboveground tank systems

Vessels affected:

$\begin{array}{lllll}\text { E-5-2 } & \text { TK-6-2 } & \text { TK-7-1 } & \text { TK-7-2 } & \text { TK-8-1 } \\ \text { TK-8-2 } & \text { TK-9-1 } & \text { TK-9-2 } & \text { TK-10-1 } & \text { TK-13-1 } \\ \text { TK-14-2 } & \text { TK-17-1 } & \text { TK-17-2 } & \text { T-18-2 } & \text { TK-18-3 } \\ \text { E-20-2 } & \text { TK-21-1 } & \text { TK-22-1 } & \text { TK-23-1 } & \text { D-23-2 } \\ \text { E-23-3-1 } & \text { E-23-3-2 } & \text { E-23-3 } & \text { E-23-4 } & \text { TK-24-1 } \\ \text { TK-25-1 } & \text { TK-25-2 } & \text { TK-26-1 } & \text { TK-26-3 } & \text { TK-27-2 } \\ \text { TK-27-3 } & \text { TK-27-4 } & \text { T-28-1 } & \text { TK-28-3 } & \text { TK-28-4 } \\ \text { TK-29-2 } & \text { TK-29-3 } & \text { TK-29-4 } & \text { T-30-1 } & \text { TK-30-3 } \\ \text { TK-32-1 } & \text { TK-33-1 } & \text { TK-34-2 } & \text { TK-35-2 } & \text { TK-36-1 } \\ \text { TK-39-1 } & \text { TK-39-2 } & \text { TK-39-5 } & \text { TK-100 } & \text { BCP } \\ \text { BCS } & \text { 221-BF-A } & \text { 221-BF-B } & & \end{array}$

Noncompliance Justification: Inspection requirements will not be performed as the vessels are empty, inactive, and isolated. Also, these vessels are inaccessible to personnel during the S\&M phase.

Compliance measure: Surveillance of treatment and/or storage vessel systems will be in accordance with the S\&M plan.

\subsubsection{Requirement: Daily visual inspections of aboveground tank systems [(WAC 173-303-640(6)(b)].}

Vessel affected: ISO East.

Noncompliance Justification: Inspection is not needed as the tank is inactive, empty, and isolated.

Compliance measure: None required.

7.4.1.3 Requirement: Annual integrity test of tank systems without compliant secondary containment [(WAC 173-303-640(4)(i)].

Vessels affected:

$\begin{array}{lllll}\text { E-5-2 } & \text { TK-6-2 } & \text { TK-7-1 } & \text { TK-7-2 } & \text { TK-8-1 } \\ \text { TK-8-2 } & \text { TK-9-1 } & \text { TK-9-2 } & \text { TK-10-1 } & \text { TK-13-1 } \\ \text { TK-14-2 } & \text { TK-17-1 } & \text { TK-17-2 } & \text { T-18-2 } & \text { TK-18-3 } \\ \text { E-20-2 } & \text { TK-21-1 } & \text { TK-22-1 } & \text { TK-23-1 } & \text { D-23-2 } \\ \text { E-23-3-1 } & \text { E-23-3-2 } & \text { E-23-3 } & \text { E-23-4 } & \text { TK-24-1 } \\ \text { TK-25-1 } & \text { TK-25-2 } & \text { TK-26-1 } & \text { TK-26-3 } & \text { TK-27-2 } \\ \text { TK-27-3 } & \text { TK-27-4 } & \text { T-28-1 } & \text { TK-28-3 } & \text { TK-28-4 } \\ \text { TK-29-2 } & \text { TK-29-3 } & \text { TK-29-4 } & \text { T-30-1 } & \text { TK-30-3 }\end{array}$




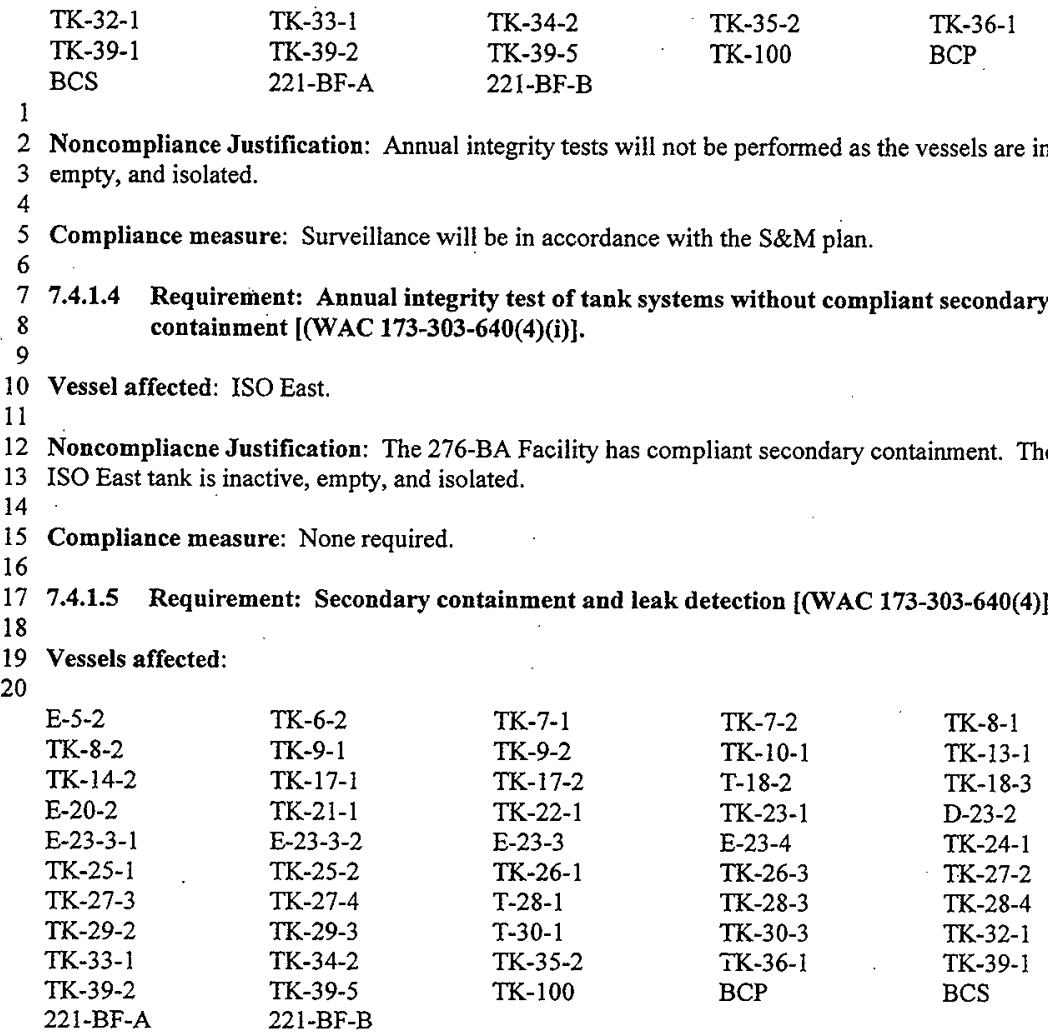

Noncompliance Justification: No upgrades to the secondary containment or leak detection equipment will be made as the vessels are inactive, empty, and isolated.

Compliance measure: $S \& M$ to meet leak detection requirements will be in accordance with the $S \& M$ Plan.

\subsubsection{Requirement: Secondary containment and leak detection [(WAC 173-303-640(4)].}

Vessel affected: ISO East.

Noncompliance Justification: No upgrades to the secondary containment or leak detection equipment will be performed. The ISO East tank is inactive, empty, and isolated. . 
1 7.4.1.7 Requirement: Major risk labeling of tank systems [(WAC 173-303-400(3)(a)(iii) and

$\begin{array}{lllll}\text { E-5-2 } & \text { TK-6-2 } & \text { TK-7-1 } & \text { TK-7-2 } & \text { TK-8-1 } \\ \text { TK-8-2 } & \text { TK-9-1 } & \text { TK-9-2 } & \text { TK-10-1 } & \text { TK-13-1 } \\ \text { TK-14-2 } & \text { TK-17-1 } & \text { TK-17-2 } & \text { T-18-2 } & \text { TK-18-3 } \\ \text { E-20-2 } & \text { TK-21-1 } & \text { TK-22-1 } & \text { TK-23-1 } & \text { D-23-2 } \\ \text { E-23-3-1 } & \text { E-23-3-2 } & \text { E-23-3 } & \text { E-23-4 } & \text { TK-24-1 } \\ \text { TK-25-1 } & \text { TK-25-2 } & \text { TK-26-1 } & \text { TK-26-3 } & \text { TK-27-2 } \\ \text { TK-27-3 } & \text { TK-27-4 } & \text { T-28-1 } & \text { TK-28-3 } & \text { TK-28-4 } \\ \text { TK-29-2 } & \text { TK-29-3 } & \text { TK-29-4 } & \text { T-30-1 } & \text { TK-30-3 } \\ \text { TK-32-1 } & \text { TK-33-1 } & \text { TK-34-2 } & \text { TK-35-2 } & \text { TK-36-1 } \\ \text { TK-39-1 } & \text { TK-39-2 } & \text { TK-39-5 } & & \end{array}$

WAC 173-303-640(5)(d)].

\section{Vessels affected (all canyon vessels):}

Noncompliance Justification: No labeling will be performed as the vessels in the canyon cells are inaccessible to personnel during the S\&M Phase.

Compliance measure: Major risks (i.e., hazards) for the canyon vessels are documented in Chapter 4.0, Section 4.2.

\subsubsection{Cell 4}

The interim status compliance concerns for the Cell 4 containers include labeling, monitoring, and inspections. The compliance measures have been developed and are in place and will be used during the S\&M Phase. For the hazards associated with the Cell 4 containers, refer to Chapter 4.0 , Section 4.3 . The regulatory requirements, noncompliance justification, and compliance measures are as follows.

\subsubsection{Requirement: Major risk labeling of containers systems [(WAC 173-303-640(3))].}

Noncompliance Justification: High radiation levels caused the labels to deteriorate and fall off. Relabeling during the Transition Phase was not performed because of as low as reasonably achievable (ALARA) concerns and cost. Retrieving containers for relabeling is not possible during the S\&M Phase because the canyon crane is not operable to remove the cell cover blocks. Also, radiation protection concerns for these containers are much greater than the dangerous waste concerns.

Compliance measure: Containers were properly labeled before being placed in Cell 4. A major risk label has been placed on the key cover block to the cell. The major risks (i.e., hazards) for the Cell 4 containers are documented in Chapter 4.0, Section 4.3.

\subsubsection{Requirement: Weekly inspection of containers [(WAC 173-303-320(2) and} WAC 173-303-630(6)].

Noncompliance Justification: Personnel entry into Cell 4 is not feasible because of high radiation levels. Opening the cell cover blocks is not possible during the $\mathrm{S} \& \mathrm{M}$ phase as the canyon crane is not operable. There are no liquids present in the containers. Also, radiation protection concerns for these containers are much greater than the dangerous waste concerns.

Compliance measure: Surveillance of Cell 4 will not be performed during the S\&M Phase. 


\section{7.4.3 Containment Building}

4 The containment building meets the interim status requirements in 40 CFR 265.1100 (Subpart DD), 5 invoked via WAC 173-303-400(3)(a). No additional compliance measures are required. 6 


\section{DOE/RL-98-12, Rev. 1}

$02 / 99$

1

2

3

4

This page intentionally left blank. 
DOE/RL-98-12, Rev. 1

$02 / 99$

1

CONTENTS

2

3

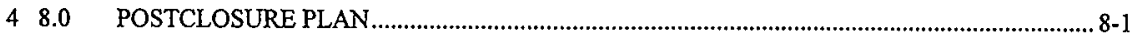

5 
DOE/RL-98-12, Rev. 1

02/99

1

2

3

4

5

This page intentionally left blank. 


\subsection{POSTCLOSURE PLAN}

4 If waste is left in place, a postclosure plan will be developed to address the disposition scenarios.

5 Groundwater contamination will be investigated and remediated through the operable units under the

6 CERCLA remedial investigation/feasibility study process as directed by the Tri-Party Agreement. 
DOE/RL-98-12, Rev. 1 02/99

1

2

3

4

5

This page intentionally left blank. 
DOE/RL-98-12, Rev. 1

02/99

1

CONTENTS

2

3

49.0

5 
DOE/RL-98-12, Rev. 1

02/99

1

2

3

4

This page intentionally left blank. 


\subsection{REFERENCES}

97-EAP-032, letter John D. Wagoner, RL, to Mary Riveland, Ecology, and Chuck Clarke, U.S. EPA. CHANGE REQUEST M-82-96-01: "ESTABLISH MILESTONES AND TARGET DATES FOR B PLANT FACILITY TRANSITION, MILESTONE SERIES M-82", dated October 25, 1996.

98-EAP-135, Letter, James E. Rasmussen, RL, to R. E. Skinnerland, Ecology, CERTIFIED ISO WEST INTERIM ORGANIC STORAGE TANK (ISO WEST TANK) ADMINISTRATTVE CLOSURE TECHNICAL DATA SYNOPSIS (TSD:TS-2-3), dated March 4, 1998.

98-EAP-494, Letter, James E. Rasmussen, RL to T. A. Wooley, Ecology, TRANSMTTTAL OF THE WASTE ENCAPSULATION AND STORAGE FACILITY (WESF) TANK 100 SYSTEM CLOSURE PLAN, dated September 3, 1998.

98-EAP-588, Letter, James E. Rasmussen, RL, and William D. Adair, FDH, to T. A. Wooley, Ecology, CLOSURE CERTIFICATION OF THE WASTE ENCAPSULATION AND STORAGE FACILITY (WESF) TANK 100 (TK-100) SYSTEM, dated November 3, 1998.

DOE/RL-88-21, Hanford Facility Dangerous Waste Part A Permit Application, U.S. Department of Energy, Richland Operations Office, Richland, Washington.

DOE/RL-90-39, Double-Shell Tank System Dangerous Waste Permit Application, U.S. Department of Energy, Richland Operations Office, Richland, Washington.

DOE/RL-95-100, RCRA Field Investigation Report for the 200 PO-1 Operable Unit, U.S. Department of Energy, Richland Operations Office, Richland, Washington.

DOE/RL-96-59, 200-PO-1 Operable Unit Permit Modification, U.S. Department of Energy, Richland Operations Office, Richland, Washington.

DOE/RL-96-66, Corrective Measures Study for the 200 Area PO-1 Operable Unit, U.S. Department of Energy, Richland Operations Office, Richland, Washington.

Ecology 1994, Guidance for Clean Closure of Dangerous Waste Facilities, Publication \#94-111, August 1994, Washington State Department of Ecology, Olympia, Washington

Ecology 1998a, Letter, Shir Mohan, Ecology, to James Rasmussen, RL, APPPROVAL OF THE PROCEDURAL CLOSURE OF THE B PLANT INTERNATIONAL STANDARDS ORGANIZATION (ISO) WEST TANK, dated October 20, 1998

Ecology 1998b, Letter, Ted A. Wooley, Ecology, to James Rasmussen, RL, APPPROVAL OF THE WASTE ENCAPSULATION AND STORAGE FACILITY (WESF) TANK 100 SYSTEM CLOSURE PLAN, dated September 15, 1998

Ecology, EPA, and DOE, 1996, Honford Federal Facility Agreement and Consent Order (Tri-Party Agreement), Washington State Department of Ecology, U.S. Environmental Protection Agency, U.S. Department of Energy, Olympia, Washington, as amended. 
1 ETS-W-96-524, Letter, G. R. Wagenblast, ICF Kaiser, to S. E. Killoy, Westinghouse Hanford Company, CERTIFICATION OF THE 221-B BUILDING AS A DANGEROUS WASTE CONTAINMENT BUILDING, dated January 5, 1996

HNF-3208, Documentation of Remaining Hazardous Substances/Dangerous Wastes in B Plant,

WHC-SD-HWV-TI-017, B Plant Secondary Containment System Analysis and Description, Revision 1, Westinghouse Hanford Company, Richland Washington.

11 WHC-SD-W024H-SA-001, B Plant Cell Drain Header Seismic Analysis, Revision 1, Westinghouse

WHC-SD-WM-ER-456, B Plant Low Level Waste Integrity Assessment Report, Revision 0, Hanford Company, Richland Washington.

WHC-SD-WM-TPP-054, B Plant End Points Document, Revision 1, B\&W Hanford Company, Richland, Washington.

WHC-SD-WM-WP-254, B Plant Low Level Waste Integrity Assessment Plan, Revision 1, Westinghouse Hanford Company, Richland Washington. 


\section{APPENDIX A}

3 
DOE/RL-98-12, Rev. 1

02/99

1

2

3

4

5

This page intentionally left blank. 
APPENDIX A

\section{B PLANT COMPLEX EQUTPMENT NOMENCLATURE}

7 The designation of equipment, including the treatment and/or storage vessels, in the B Plant Complex

8 follows several different conventions. These conventions can be inconsistent. The convention used can

9 depend on when the equipment was installed and on its original use.

11 B Plant canyon process cell equipment use a one or two letter equipment type designation, followed by a 12 number for the cell, followed by number for that specific piece of equipment. An additional number can 13 be included if a piece of equipment can be subdivided into two or more distinct components. The one or 14 two letter equipment type designation used shown on Table A1-1. Only the designations D, E, and TK are relevant to the treatment and/or storage systems.

An example of the process cell equipment is TK-17-2, the second vessel (tank) located in Cell 17. If e piece of equipment is present in a cell, then the numeral " 1 " is still used, e.g., TK-10-1 is the only equipment in Cell 10. Another example is E-23-3-1. This is one component of the waste concentrator located in Cell 23. Specifically, it is the theromsyphon reboiler on the low-level waste concentrator. Note that not all of the equipment used within the B Plant Complex is part of the treatment and/or storage systems.

Equipment outside the process cells uses a different system. The two vessels in the 221-BB Process Condensate and Steam Building are designated "BCP" and "BCS". While the designation was made with a specific purpose, BCP is not an acronym or an abbreviation and should be defined as such. The two vessels in the 221-BF Condensate Effluent Storage Facility use a location-based designation similar to

28 that used for the process cells, being designated 221-BF-A and 221-BF-B. The two vessels at the 276-

29 BA Interim Organic Storage Facility are designated based on their location. The vessels are ISO West 30 and ISO East. 
Table Al-1. Process Cell Equipment Designations Relative to the Treatment and/or Storage Vessels.

\begin{tabular}{|l|l|}
\hline $\begin{array}{l}\text { Letter } \\
\text { designation }\end{array}$ & Equipment description \\
\hline $\mathrm{D}$ & De-entrainer: separates droplets of liquid entrained in a stream of vapor \\
\hline $\mathrm{E}$ & $\begin{array}{l}\text { Heat transfer equipment: i.e., a heat exchanger to heat a liquid or a condenser to } \\
\text { cool and condense a vapor }\end{array}$ \\
\hline PG & Pulse generator: used to generate a pulse of liquid in the towers \\
\hline T & $\begin{array}{l}\text { Tower: vessel used for separations processes (i.e., solvent extraction or ion } \\
\text { exchange) }\end{array}$ \\
\hline TK & Tank. \\
\hline
\end{tabular}

2

3 


\section{APPENDIX B}

\section{CLOSURE TECHNICAL DATA SYNOPSIS}


DOE/RL-98-12, Rev. 1

02/99

This page intentionally left blank. 
98-EAP-136

\author{
Department of Energy \\ Richland Operations Office \\ P.O. Box 550 \\ Richland, Washington 99352
}

\title{
MAR 041998
}

Mr. R. E. Skinnarland

State of Washington

Department of Ecology

200 Area Section

1315 West Fourth Avenue

Kennewick, Washington 99336

Dear Mr. Skinnarland:

\section{CERTIFIED ISO WEST INTERIM ORGANTC STORAGE TANK (ISO WEST TANK) ADMINISTRATIVE CLOSURE TECHNICAL DATA SYNOPSIS (TSD:TS-2-3)}

The certified B Plant Complex ISO West Tank Administrative Closure Technical Data Synopsis (synopsis) is attached. Submittal of this synopsis to the State of Washington Department of Ecology (Ecology) is in accordance with the discussions beld at the B Plant Project Managers Meeting (PMM) on January 29, 1998.

The symopsis documents and provides certification that the ISO West Tank never contained dangerous waste. Acceptance of the synopsis by Ecology will allow the ISO West tank to be removed from regulation under the Washington Administrative Code Chapter 173-303, "Dangerous Waste" and allow the ISO West tank to be reused for other purposes. . 
Mr. R. E. Skinnarland

$-2-$

MAR 041998

98-EAP-136

- Should you have any questions, please contact Ellen M. Mattlin, U.S. Department of Energy, Richland Operations Office, on (509) 376-2385 or Fred A. Ruck , III, Fluor Daniel Fianford, Inc., on (509) 376-9876.

\section{EAP:EMM}

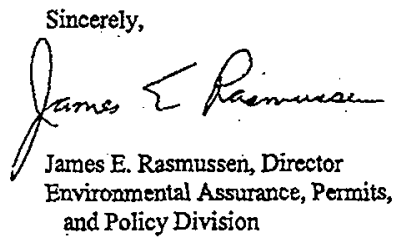

Attachment

cc w/attach:

Administrative Recond

Ecology Library, Lacey

S. D. Godfrey, BWHC

R. E. Heineman, BWHC

J. R.Wilkinson, CTUIR.

D. R. Sherwood, EPA

W.D. Adair, FDH

G. W. Reddick, FDH

F. A. Ruck III, FDH

D. Powaukee, NPT

J. Adler, WMH

R. Jim, YIN 


\section{Iso West Interim Organic Storage Tank Administrative Closure Technical Data Synopsis}

\subsection{INTRODUCTION \\ 1.1 Purpose}

The purpose of this synopsis is to support the request for administrative closure by the U.S. Department of Energy, Richland Operations office (RL), and Fluor Daniel Hanford, Inc. (FDH), of the Washington State Hazardous Waste Management Act (Chapter 70.105 Revjsed Code of Washington) Permitted ISO West Interim Organic Storage Tank (ISO West). The ISO West is one of two external storage tanks in the organic mixed waste storage system in the B Plant Complex's 276-8A Interim Organic Storage Facility (276-BA Facility). Information discussed below will denonstrate that the ISO West tank never stored dangerous waste or mixed waste. The administrative closure of the tank wiil modify the Hanford Facility Permit Application by eliminating the ISO West tank from the B Plant Complex Part A, Form 3.

\subsection{Previous Application Subrittal}

Revision 4 of the B Plant Complex Part A Permit Application, Form 3 was submitted to the State of Washingtor, Department of Ecology, by RL in May 1996. This revision added storage of organic mixed waste in two external tanks to the Part A, Form 3.

\subsection{FACILITY DESCRIPTION}

The ISO West tank is located within the 276-BA Facility. The 276-BA Facility is located north-east of the 22I-B Building (B Plant) within the B Plant Complex. The 276-BA Facility consists of a concrete secondary containment structure holding the ISO West and ISO East Interim Organic Storage Tanks (ISO East). The Iso West tank is a stainless steel tank originally designed as a 17,500 liter shipping container. The overall dimensions of the ISO West tank are 6.1 meters long by 3.0 meters high by 2.5 meters wide.

\section{0 . PROCESS INFORMATION}

3.1: Operations History

The Hanford Federal Facility Agreement and Consent Order (Tri-Party Agreement) established Mijestone M-82-03 "Complete Removal of Organic Solvent Waste from the B Plant Canyon." To meet this milestone, the 276-BA Facility was constructed and both the ISO West and ISO East tanks were installed during 1996. During March 1997, the organic mixed waste was transfered from the B Plant canyon tanks to the ISO East tank: The ISO West tank was left empty to be used as an emergency receiver tank if the need arose. The organic mixed waste was removed from the ISO East tank and shipped off-site for disposal during November 1997. During this time, the ISO West tank remained empty and never stored waste. 
ISO Hest Interim Organic Storage Tank -

Administrative Closure Technical Data Synopsis

\subsection{Data Gathering}

A records review was used to confirm that regulated waste storage did not occur in the ISO Kest tank. The approach used and the results of this data gathering effort is described in the following sections.

\subsubsection{Approach}

Several sources of information were used or examined to provide assurance to $\mathrm{FDH}$ and RL that the certification statement provided is true, accurate, and complete. These information sources included:

- DOE/RL-88-21, Hanford Facility Dangerous Haste Part A Pernit Application, B Plant Complex, Part A Permit Application, Form 3, Revision 4

- SD-WM-RRR-013 B Plant Organic Removal Readiness Checklist

- Letter, James E. Rasmussen, DOE-RL, to Jerry Leitch, EPA, "Notice of Construction (NOC) to Operate the B Plant Organic Solvent Transfer and Storage System," 96-EAP-324, dated September 4, 1996

- B Plant Plant Operating Procedure (POP) WP-B-97-005, Revision A, Modification 0, Transfer Organic to ISO Tank

- B-P7ant Organic Storage Tank Off-Loaḍing Critical Lift Procedure, Impact Level $S$, Revision 1

- B Plant POP 80-040-002, Revision G, Modification 0, Perform General Surveillance

- B Plant POP WP-B-097-015, Revision A, Modification 0, Transfer Organic fror Storage Tank to Tanker

\subsubsection{Data Gathering and Records Review}

The resuits of the data gathering supported the contention that no regulated activity took place in the Iso West tank. The results of the data gathering activity are summarized in the following sections.

The review of various documents (B Plant Organic Removal Readiness Checklist, NOC letter for air permitting, POP Transfer Organic to ISO Tank) cleariy indicated the intention was to use both the ISO East and ISO West tanks for storage of the organic mixed waste. For example, the POP Transfer Organic to ISO Tank contains the complete procedure for transferring organic mixed waste into both of the tanks. 
The plan for transferring the organic mixed waste was as follows:

1. Stage the empty tanks on a flat-bed trailer adjacent to the B Plant canyon building (221-B Building).

2. Transfer the organic mixed waste from the canyon tank(s) into the Iso tank(s) via a temporary transfer system.

3. After the transfer into the ISO $\operatorname{tank}(s)$, move the full tank(s) to the 276-BA Facility.

4. Lift the ISO tank(s) from the trailers into the 276-BA Facility and secure them in place.

A review of the completed POP, Transfer Organic to ISO Tank, showed that oniy. one of the tanks (ISO East) was used for storing organic mixed waste and the other tank (ISO Nest) was not used. The completed POP, Transfer Organic to Iso Tank, clearly identifies and documents that only 10,933 liters $(2,888,1$ gallons) of organic mixed waste was transferred into the ISO East tank (capacity 17,500 liters). The same procedure al so documents that oniy the ISO East tank was moved from the transfer location (adjacent to $B$ Plant) to the 276-BA Storage Facility. The completed POP inciudes signatures and initials from the operators and supervisory personnel involved. These sign-offs were done to document completion of hold-points and of specific activities. This provides a written, verifiable record of the activities performed.

The compieted Critical Lift Procedure also documents that one tank (ISO East) containing waste was moved from the transport truck into the 276-BA Facility secondary containment structure. The procedure includes signatures and initiais from the operators and supervisory personne? involved. These sign-offs were done to document completion of specific activities. This provides a written, verifiable record of the activities performed.

Additional documentation is provided in the completed POP, Perform General Surveillance. In this POP, only the ISO East tank was being checked for leakage or matertal in the secondary containment. None of the data sheets. show evidance of any leaks. These data sheets are signed and provide a written, verifiable record that there were no leaks. The iso Hest tank, since it did not contain waste, was not and did not need to be included in the procedure. The completed POP, Transfer Organic from Storage Tank to Tanker, continues in documenting that only one tank (ISO East) was involved when the organic mixed waste was transferred to a tanker trailer for shipment to of $f$-site disposal.

\subsection{SUMMARY}

The documents examined include verifiable, signed, and initialed documentation that the ISO West tank was never used for the storage of dangerous waste. Also, the documents clearly identify that dangerous waste was placed into and. managed only in the ISO East tank. Therefore, RL and Project Hanford Management Contract personne] request that the ISO West tank at B Plant's 276-BA Facility be administratively closed. 
ISO Kest Interim Organic Storage Tank Administrative Closure Technica? Data Synopsis

\subsection{ISO WEST INTERIM ORGANIC STORAGE TANK ADMINISTRATIVE CLOSURE TECHNICAL} DATA SYNOPSIS CERTIFICATION

-I certify under penalty of law that this document was prepared under my direction or supervision in accordance with a system designed to assure that qualified personnel properly gather and evaluate the information subnitted. Based on my inquiry of the persons directiy responsible for gathering the information, the information submitted is, to the best of my knowiedge and belief, true, accurate, and complete. I am aware that there are significant penalties for submitting false information, including the possibility of fine and imprisonment for knowing violations."

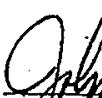
ownor roperator Johh 0. Hagoner, Mhager 6.6. Department of Energy Richland Operations office

\section{co-operator}
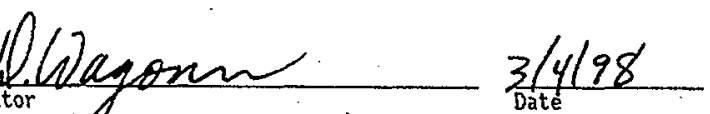

H. J. Hatch

President and

Chief Executive officer

Flour Daniel Hanford, Inc. 


\section{DISTRIBUTION}

MSIN

Shir Mohan

Washington State Department of Ecology

B5-18

T. A. Wooley

Washington State Department of Ecology

J. R. Wilkinson

Department of Natural Resources

Confederated Tribes of the Umatilla Indian Reservation

P.O. Box 638

Pendleton, OR 97801

Russell Jim, Manager

Environmental Restoration/Waste Management

Confederated Tribes and Bands of the Yakama Nation

P.O. Box 151

Toppenish, WA 98948

Donna Powaukee

Nez Perce Tribe

P.O. Box 305

Lapwai, ID 80540

\section{U.S. Department of Engergy, Richland Operations Office}

D. T. Evans

R3-79

E. M. Mattlin

A5- 15

L. E. Rogers

R3-79

Reading Room (2)

$\mathrm{H} 2-53$

B\&W Hanford Company

R. W. Bailey

S4-49

S. G. Godfrey

S4-59

K. A. Hadiley

G. J. LeBaron (2)

R3-56

B. H. Lueck Jr.

S6-15

S6-70

Bechtel Hanford Company

R. P. Henckel

S3-21

G. M. MacFarlan 


\section{DISTRIBUTION}

MSIN

Fluor Daniel Hanford. Inc.

A. M. Hopkins

L $5-65$

L. J. Olguin

N1-26

J. K. Perry

H6-23

G. W. Reddick Jr

N1-26

F. A. Ruck III

H6-23

B. D. Williamson

B3-15

Pacific Northwest National Laboratory

Hanford Technical Library

P8-55

Waste Management Federal Services of Hanford, Inc.

J. G. Adler

H6-24

D. B. Jensen (RCRA File)

H6-24

Lockheed Martin Services

Central Files

B1-07

DPC

H6-08

EDMC (2)

H6-08 
99-EAP-165

\section{Department of Energy}

Richland Operations Office

P.O. Box 550

Richland, Washington 99352

\section{FEB 241999}

Mr. Michael A. Wilson, Program Director

Nuclear Waste Program

State of Washington

Department of Ecology

P. O. Box 47600

Olympia, Washington 98504

Dear Mr. Wilson:

B PLANT PRECLOSURE WORK PLAN REVISION 1 (TSD: TS-2-3)

Enclosed is DOE/RL-98-12, "B Plant Preclosure Work Plan," Revision 1. This revision of the plan incorporates comments from the State of Washington Department of Ecology (Ecology) and updates of activities completed or finalized since the issue of Revision 0 in February 1998.

The plan is a critical document supporting the decommissioning of the B Plant Complex. The transmittal of the plan meets commitments made to Ecology at various B Plant Complex Project Manager Meetings.

If you have any questions regarding the plan, please contact Ellen Mattlin, U.S. Department of Energy, Richland Operations Office, on (509) 376-2385, Fred Ruck III, Fluor Daniel Hanford, Inc., on (509) 376-9876, or Greg LeBaron, of B\&W Hanford Company on (509) $373-1792$.

EAP:EMM Sincerely,

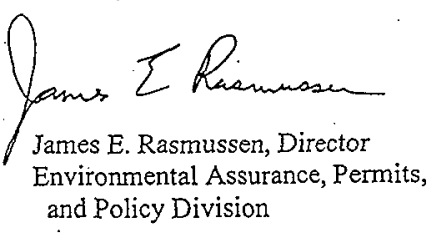

Enclosure .

cc: (See next page) 
Mr. Michael A. Wilson

99-EAP-165

cc w/encl:

T. A. Wooley, Ecology

W. D. Adair, FDH

J. R. Wilkinson, CTUIR

D. Powaukee, NPT

R. Jim, YIN

EDMC, H6-08

cc w/o encl:

G. J. LeBaron, BWHC

S. M. Price, FDH

J. G. Adler, WMH

J. A. Winterhalder, WMH 